\title{
Petrophysical Analysis and Sequence Stratigraphy of the Middle Ordovician Point Pleasant from a Cored Interval in Morgan County, Ohio
}

Erica Schubert

Follow this and additional works at: https://researchrepository.wvu.edu/etd

\section{Recommended Citation \\ Schubert, Erica, "Petrophysical Analysis and Sequence Stratigraphy of the Middle Ordovician Point Pleasant from a Cored Interval in Morgan County, Ohio" (2016). Graduate Theses, Dissertations, and Problem Reports. 6589.}

https://researchrepository.wvu.edu/etd/6589

This Thesis is protected by copyright and/or related rights. It has been brought to you by the The Research Repository @ WVU with permission from the rights-holder(s). You are free to use this Thesis in any way that is permitted by the copyright and related rights legislation that applies to your use. For other uses you must obtain permission from the rights-holder(s) directly, unless additional rights are indicated by a Creative Commons license in the record and/ or on the work itself. This Thesis has been accepted for inclusion in WVU Graduate Theses, Dissertations, and Problem Reports collection by an authorized administrator of The Research Repository @ WVU. For more information, please contact researchrepository@mail.wvu.edu. 


\title{
Petrophysical Analysis and Sequence Stratigraphy of the Middle Ordovician Point Pleasant from a Cored Interval in Morgan County, Ohio
}

\author{
Erica Schubert \\ Thesis submitted \\ to the Eberly College of Arts and Sciences \\ at West Virginia University \\ in partial fulfillment of the requirements for the degree of \\ Master of Science in \\ Geology
}

\author{
Timothy R. Carr, Ph.D., Chair \\ Amy Weislogel, Ph.D. \\ Joseph Smith, PDC Energy, Inc. \\ Department of Geology and Geography
}

Morgantown, West Virginia

2016

Keywords: Utica Shale, Point Pleasant, Sequence Stratigraphy, Petrophysics, Appalachian Basin, Ordovician

Copyright 2016 Erica Schubert 


\section{ABSTRACT \\ Petrophysical Analysis and Sequence Stratigraphy of the Middle Ordovician Point Pleasant from a Cored Interval in Morgan County, Ohio, USA}

\section{Erica Schubert}

The Middle Ordovician Point Pleasant Formation has become a major focus in the United States for unconventional, horizontal drilling. It stretches throughout Ohio, Pennsylvania, New York, Kentucky, and West Virginia and is estimated to contain upwards of 38 trillion cubic feet of natural gas and 940 million barrels of oil. Due to its low porosity, low permeability, and great burial depth, the Point Pleasant was not considered an economically feasible option until recent advancements in horizontal drilling and hydraulic fracturing techniques. In order to increase production and drill more profitable wells, the geology of the Point Pleasant Formation needs to be studied in greater detail. To do this, mineralogy, porosity, total organic content (TOC), geochemistry, and geomechanical properties are studied further as they directly relate to the sequence stratigraphy and depositional environment.

PDC Energy's Palmer 44-20 well was used to evaluate factors impacting production. The units of the Trenton Limestone to the Utica Shale represent three, third order sequences based on transgressive-regressive sequences. Approximately 1,711 wells and the Palmer's core were used to evaluate geological parameters affecting production. The 184 foot (56.08 meters) long Palmer core was described in detail and was accompanied by X-Ray Diffraction (XRD) results, Scanning Electron Microscope (SEM) images, thin section photographs and advanced mineralogical logs. TOC-rich intervals were identified using the Passey $\Delta$ LogR method, the Schmoker bulk density method, and a regression fit between bulk density and TOC. The results of each of these tests were compared to TOC data taken from the core. Geomechanical properties were calculated using Poisson's Ratio, Young's Modulus, and mineralogy. Collectively, the results provide insights into the depositional environment and productive zones of the Point Pleasant in eastern Ohio. 


\section{Table of Contents}

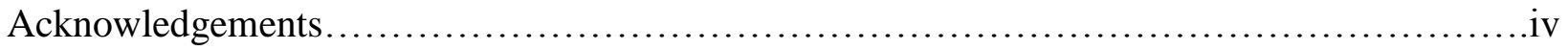

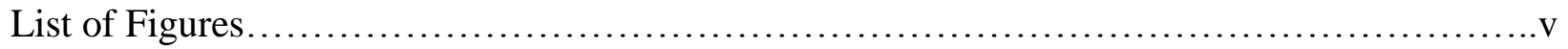

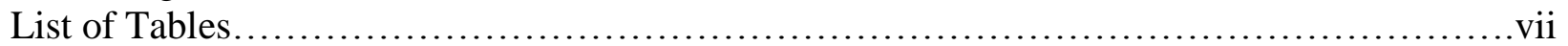

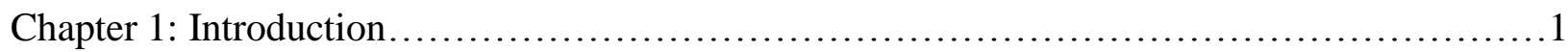

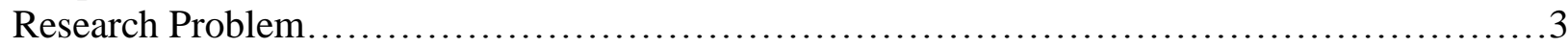

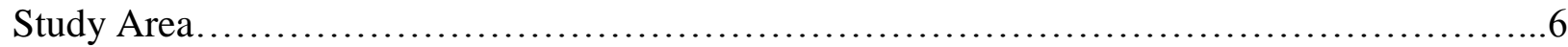

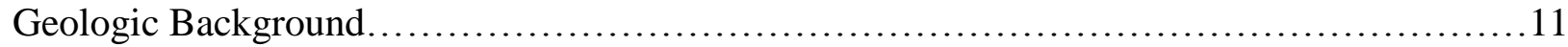

Chapter 2: Sequence Stratigraphy and Depositional Environment........................... 14

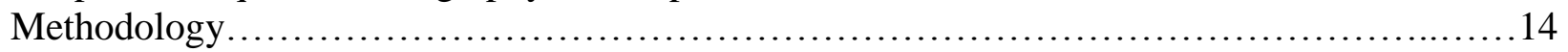

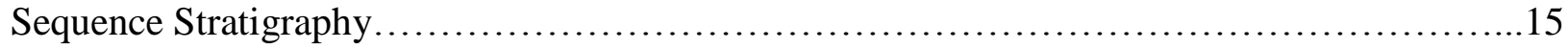

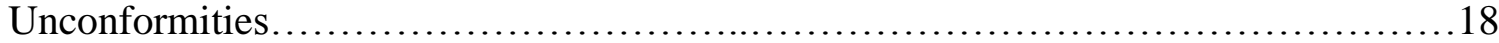

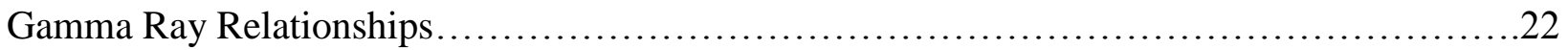

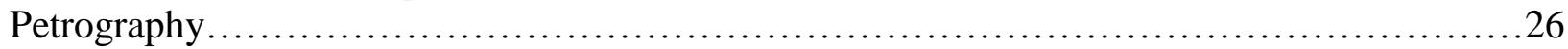

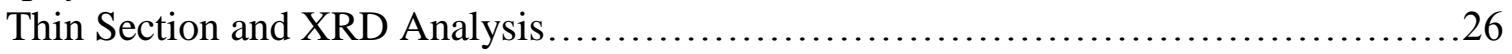

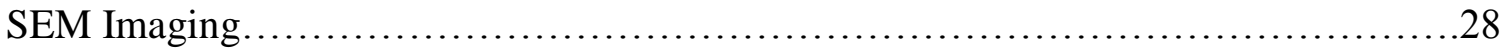

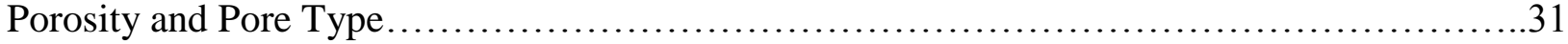

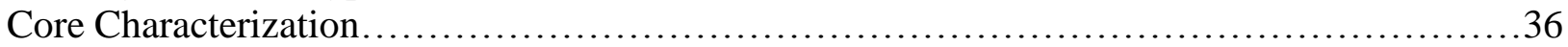

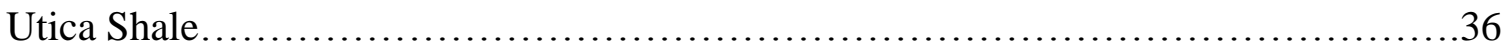

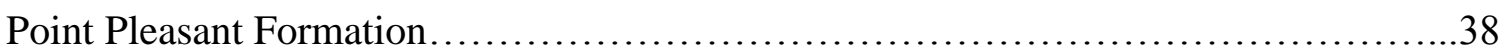

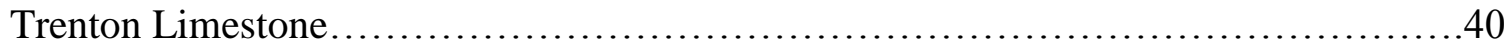

Lithofacies Correlation..........................................................

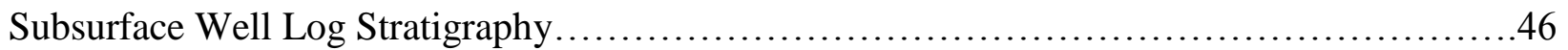

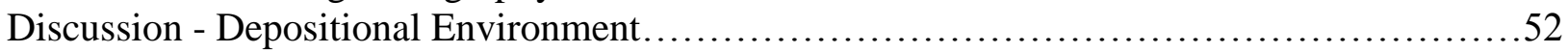

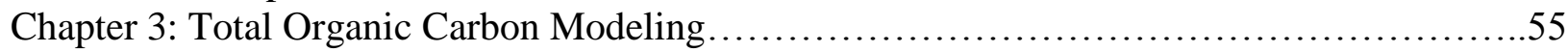

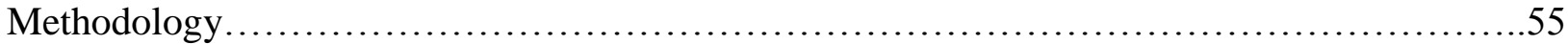

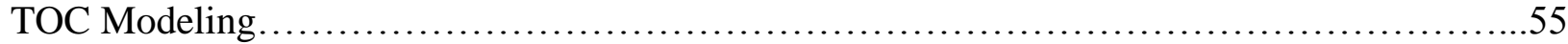

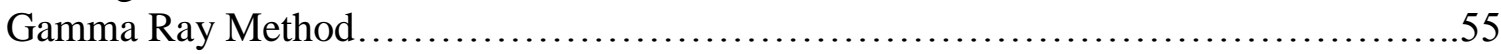

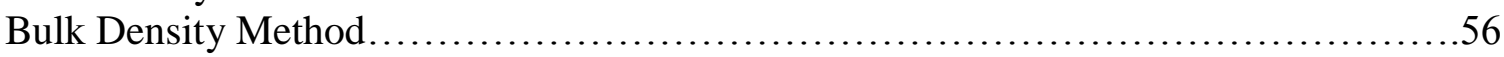

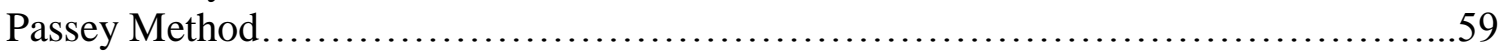

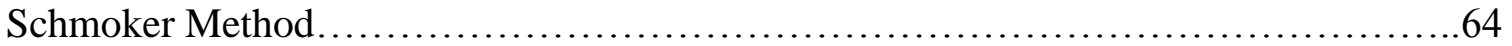

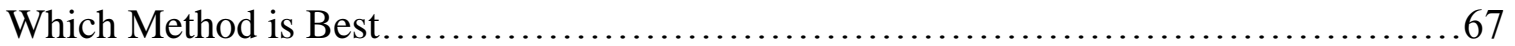

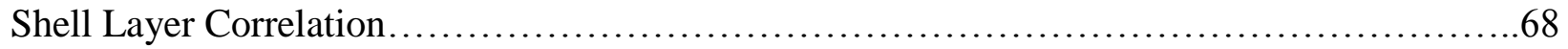

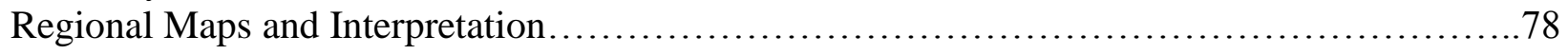

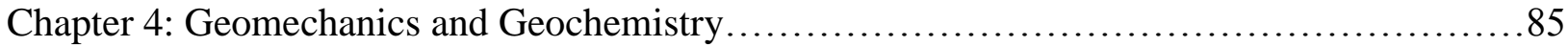

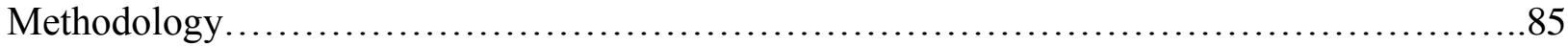

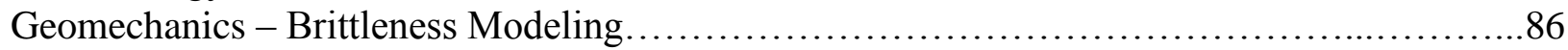

Young's Modulus and Poisson's Ratio Method......................................... 86

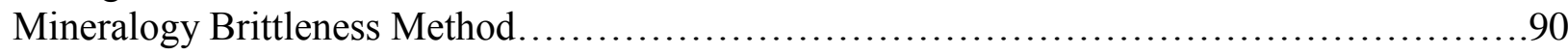

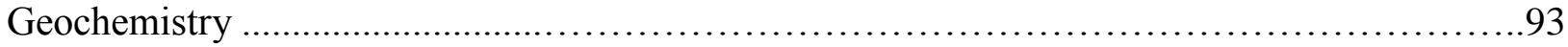

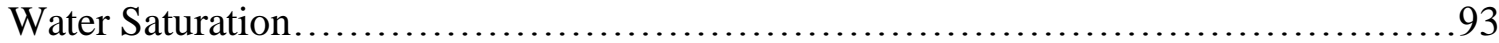

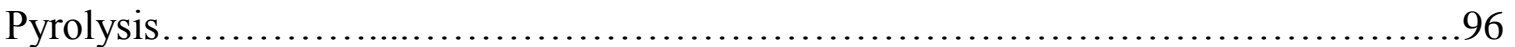

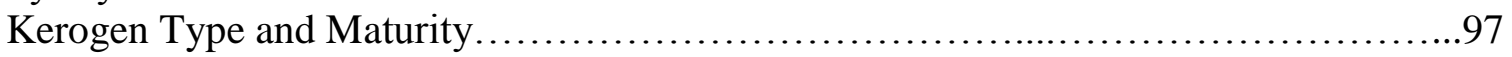

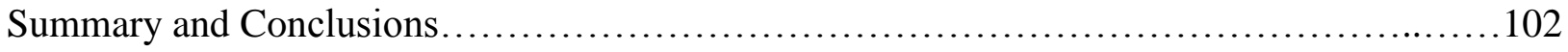




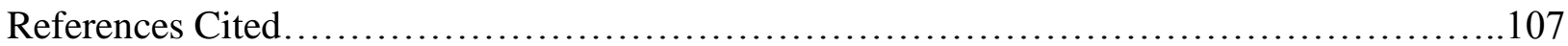

Appendix A: Palmer 44-20 Stratigraphic Column.................................111 


\section{Acknowledgements}

I would like to begin by acknowledgements by thanking my mother, Kerry, my father, Mark, my brother, Justin, and my fiancé, Nick for all of their encouragement and support throughout my graduate school career.

I would also like to thank my advisor, Dr. Timothy Carr, for all of his support, guidance, and assistance throughout this thesis and his willingness to accept me as a graduate student and Graduate Research Assistant. This thesis is also benefitted from the feedback of my other committee members, Dr. Amy Weislogel and Joseph Smith.

I would like to thank PDC Energy for access to the Palmer 44-20 dataset. A special thanks goes to PDC Energy and Core Laboratories for providing access to the Palmer core and shipping it to West Virginia University for observations.

Thank you also to the Ohio Department of Natural Resources, the West Virginia Geological and Economical Survey, and the Appalachian Oil and Natural Gas Consortium at West Virginia University for the publication of Utica-Point Pleasant well completion reports and additional well logs used in this study.

Finally, thank you to the many companies that contributed to the wells observed in this study and ultimately this research. 


\section{List of Figures}

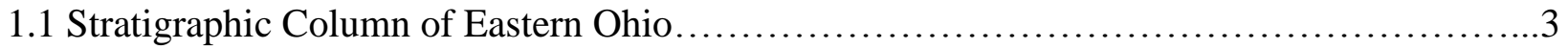

1.2 ODNR Estimated TOC Content within Ohio...........................................

1.3 Current Producing Ohio Utica-Point Pleasant Wells ................................... 5

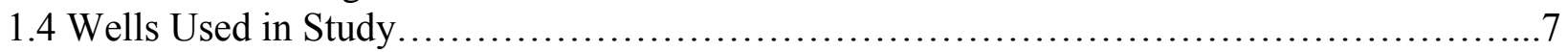

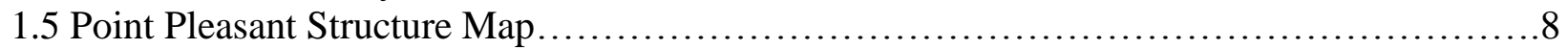

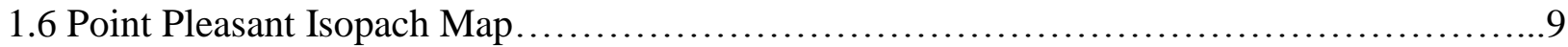

1.7 Location of PDC Energy's Palmer 44-20........................................... 10

1.8 Late Ordovician Paleogeographic map of eastern North America..........................12

1.9 Late Ordovician Paleogeographic map of Ohio.......................................... 13

2.1 Sequence Stratigraphic Boundaries for Trenton-Utica Interval............................17

2.2 Unconformities within Well Logs........................................................ 19

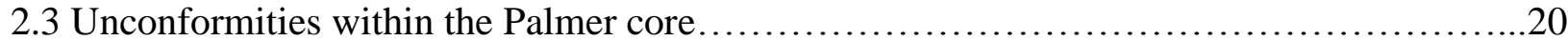

2.4 Mineralogy Logs Compared to Sequence Stratigraphic Boundaries.........................21

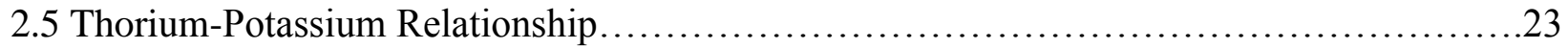

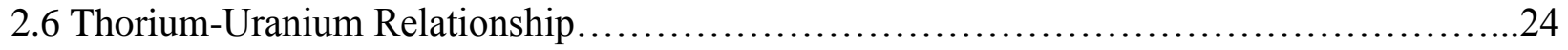

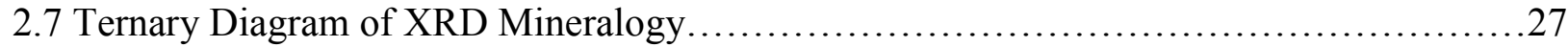

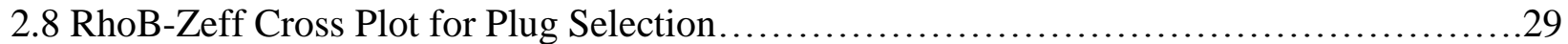

2.9 Example Mineralogy Results from Ingrain Analysis.................................... 30

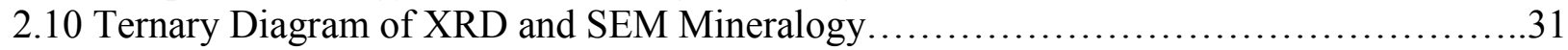

2.11 Organic Matter- Density Cross Plot Results from Plugs...................................33

2.12 Porosity and Permeability Plug Results.....................................................

2.13 Pore Types Found Within Palmer's Point Pleasant Formation.............................34

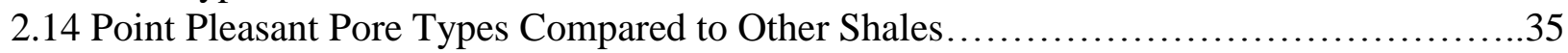

2.15 Scour Marks within Utica Shale from Core .......................................... 36

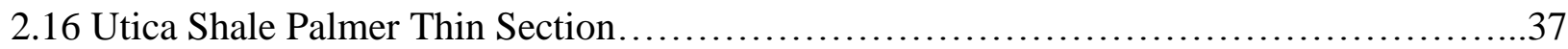

2.17 Scours and Burrows within Point Pleasant from Core.......................................38

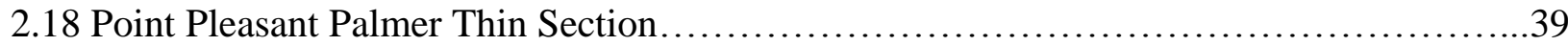

2.19 Mudclasts, Scours, and Burrows within Trenton Limestone from Core.....................41

2.20 Argillaceous Limestone Portion of Trenton Limestone Thin Section.......................42

2.21 Calcite Dominated Portion of Trenton Limestone Thin Section...........................43

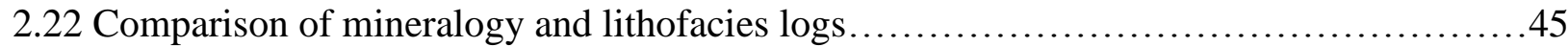

2.23 Cross Section Index Lines.......................................................... 47

2.24 A Regional Cross Section A-A' ................................................... 48

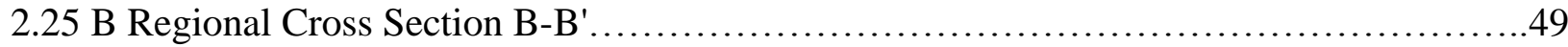

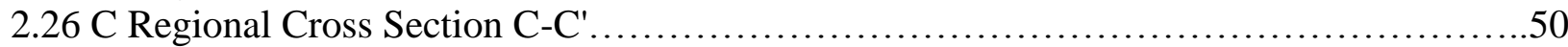

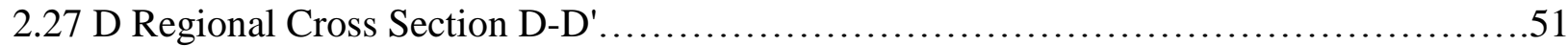

2.28 Point Pleasant Depositional Environment.............................................5

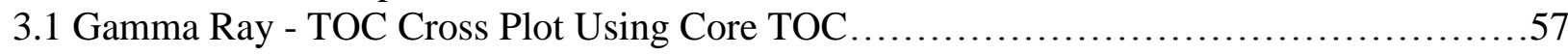

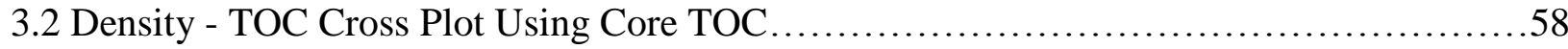

3.3 Well Log Showing Passey Method TOC Overlay..........................................60

3.4 Level of Maturity Cross Plots..............................................................61

3.5 Well Log Showing Level of Maturity Values for Passey Method...........................62

3.6 Well Log Showing Passey Curve and Core TOC Overlay.................................63 
3.7 Schmoker Method - TOC Cross Plot Using Core TOC..................................65

3.8 Well Log Showing Schmoker Method and Core TOC Overlay.............................66

3.9 Well Log Showing Shell and Calcite Overlay .......................................... 70

3.10 Well Log Showing Calcite and Resistivity Overlay....................................74

3.11 Well Log Showing Calcite and Core TOC Overlay..................................... 75

3.12 Well Log Showing Calcite and Total Porosity Overlay.....................................76

3.13 Well Log Showing Calcite and Volume of Hydrocarbons Overlay .........................77

3.14 M6 Density Contour Map......................................................... 80

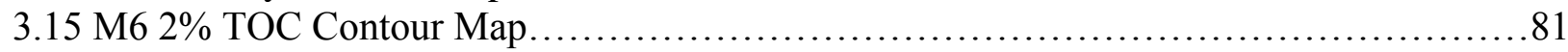

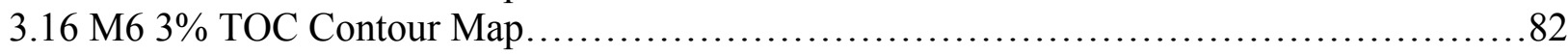

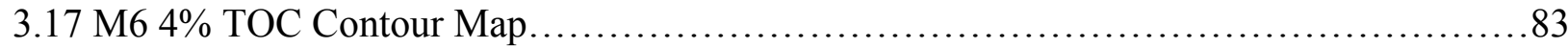

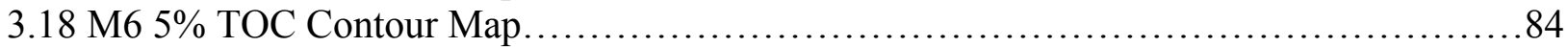

4.1 Young's Modulus and Poisson's Ratio - Brittleness Cross Plot.............................88

4.2 Well Log Showing Poisson's Ratio and Young's Modulus................................89

4.3 Well Log Showing Brittleness Based on Mineralogy ...................................... 91

4.4 Well Log Showing Brittleness Based on Schubert Mineralogy............................99

4.5 Pickett Plot for Water Saturation.......................................................

4.6 Well Log Showing Water and Hydrocarbon Saturation..................................99

4.7 Hydrogen Index vs Tmax - Kerogen Type Graph........................................ 99

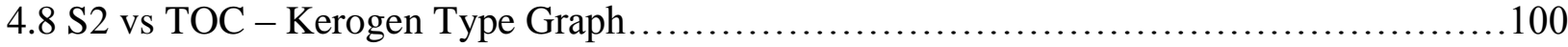

4.9 PI vs Tmax - Kerogen Maturity Graph..............................................101 


\section{List of Tables}

2.1 Gamma Ray Correlation Results................................................25

2.5 Ingrain Organic Matter and Porosity Plug Analysis Results ............................32

3.1 TOC Methods Compared to Core TOC ..............................................67

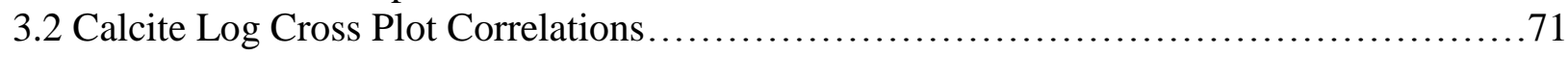




\section{Chapter 1: Introduction}

In 1814, Silas Thorla and Robert McKee drilled a 475 foot deep salt well in Macksburg, Ohio. Instead of salt, the duo happened upon the first recorded crude oil well in the United States. At the time, salt was a commodity to settlers for food preservation, while crude oil was viewed as a nuisance to salt production. Until the mid-1860's, whale oil was still the predominate burning fluid of choice in the United States. Around 1850, Samuel Kier took the advice of Philadelphia chemist, J.C. Booth, and began distilling crude oil in order to create kerosene, discovering a new form of energy. Subsequently, commercial drilling in Ohio began to take off around 1884, and by the end of the nineteenth century, 76 out of Ohio's 88 counties were drilling. In some areas, as many as 500 wells were drilled within a single year and at their peak, they could produce 3,500 barrels of oil per day (Spencer and Camp, 2008).

Over 100 years later, Ohio has a new petroleum potential with the Point Pleasant Formation, an Ordovician aged, organic-rich, siliciclastic black shale and skeletal limestone found throughout the Appalachian basin. Informally referred to collectively as the Utica Shale, the Point Pleasant Formation is found lying above the Trenton Limestone and beneath the true Utica Shale (Figure 1.1).

The Point Pleasant has become a source of interest in unconventional horizontal drilling due to its hydrocarbon potential, high total organic content (TOC), and high initial pressure brought on by increased burial depth (Figure 1.2). Interest in the Point Pleasant has increased in recent years due to the enhanced technologies of hydraulic fracturing combined with horizontal drilling. In the past, it was not thought to be an economically viable option for drilling due to its low permeability. Hydraulic fracturing is a technique employed during the completion stage. Through this process, a mixture commonly composed of water, proppant, and chemicals is 
hydraulically injected into the formation until the rock fractures. The proppant holds open the fractures, leading to increased permeability and flow rates (Gluyas and Swarbrick, 2004). The United States Geological Survey (USGS) estimated the recoverable resources of the Point Pleasant to contain nearly 38 trillion cubic feet of natural gas, 940 million barrels of oil, and 208 million barrels of natural gas liquids (USGS, 2012). However, based on a recent study organized by West Virginia University, the Point Pleasant may contain nearly 20 times more than the USGS's estimate three years ago (Hickman et al., 2015). With increased drilling activity in West Virginia and Pennsylvania, estimates now may be as high as 782 trillion cubic feet of natural gas and almost 2 billion barrels of oil (Hickman et al., 2015).

Back in early 2011, there wasn't much activity in the Point Pleasant of eastern Ohio, even with the proven technologies of hydraulic fracturing in the Marcellus Shale. Despite this, Chesapeake Energy was actively seeking leases in eastern Ohio as early as 2010 (Baker, 2011). By August 2011, a leasing frenzy had erupted in the region. An acre of land in 2010 would have been leased for as low as $\$ 15$, but by 2011 an acre had increased to as much as $\$ 3,800$, as residents looked to make a profit from royalties and signing bonuses (Baker, 2011).

As of July 11, 2015, the Ohio Department of Natural Resources (ODNR) reported that there were 1,974 permits, 1,531 wells drilled, and 922 producing Point Pleasant wells within eastern Ohio. Carroll County remains the primary target county with over 360 producing wells (ODNR, 2015) (Figure 1.3). The current trend in drilling resembles the structure within the subsurface. The wells trend north to south in Ohio, swinging northeast to southwest in the upper northeast corner of Ohio and the northwest corner of Pennsylvania (Figure 1.3 and 1.4). 
The goal of this paper is to determine the parameters affecting production within the Point Pleasant Formation of eastern Ohio. To accomplish this, a detailed core and well log analysis is performed. These analyses look to better understand the sequence stratigraphy, petrography, porosity, lithology, TOC, geomechanics, and geochemistry of the study area. Together, the results lead to an interpretation of the Point Pleasant's depositional environment, as well as determining the occurrences of organic-rich facies that respond best to hydraulic fracturing.

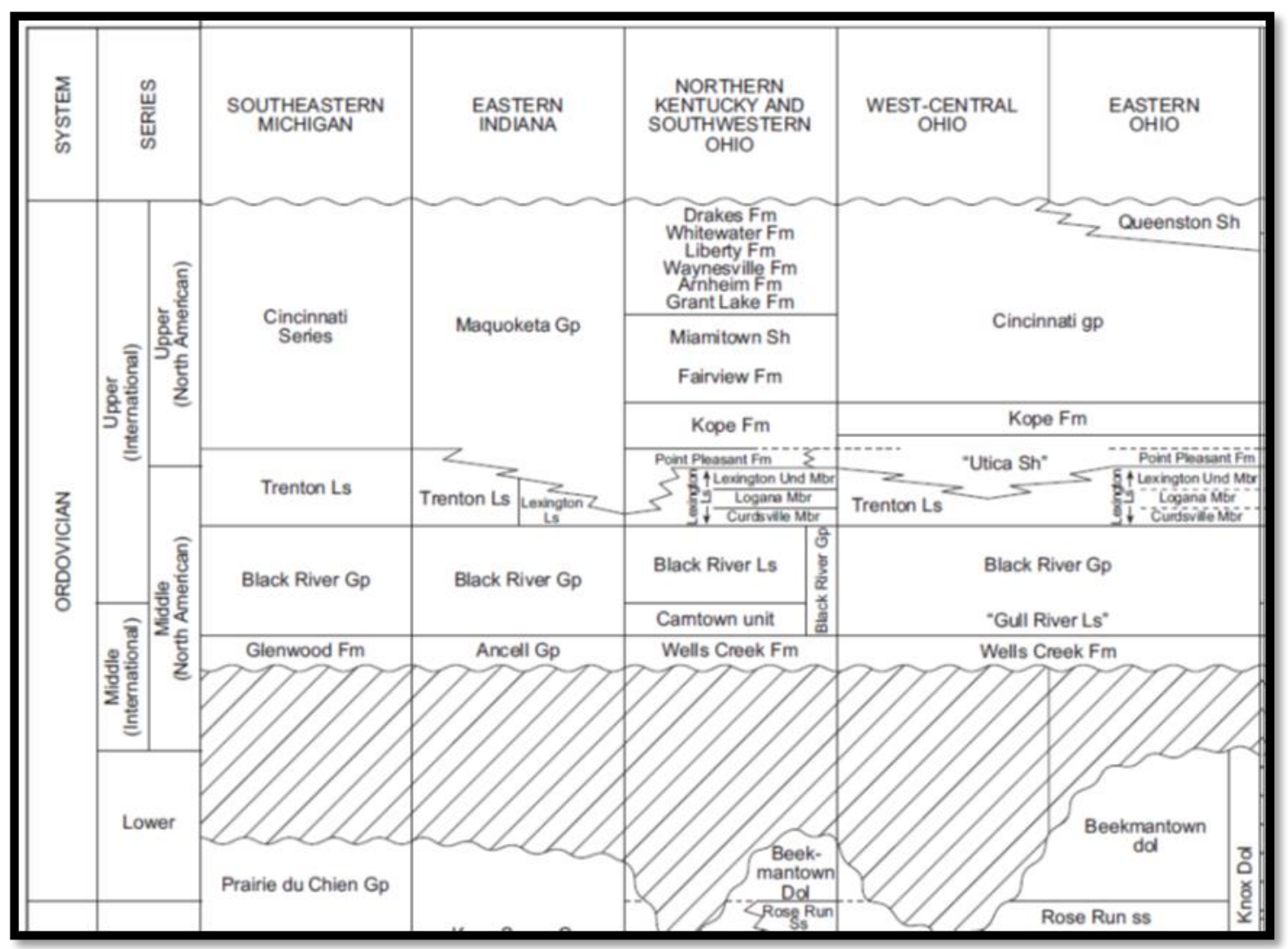

Figure 1.1: Stratigraphic column of the Ordovician for eastern Ohio, modified from Patchen et al. (2006). The Point Pleasant Formation can be found beneath the Utica Shale and above the Trenton Limestone. 
Maximum TOC Value per Well of the Upper Ordovician Shale Interval* in Ohio

("Incl. "Utica," Point Pleasant, Lexington, and Logana)

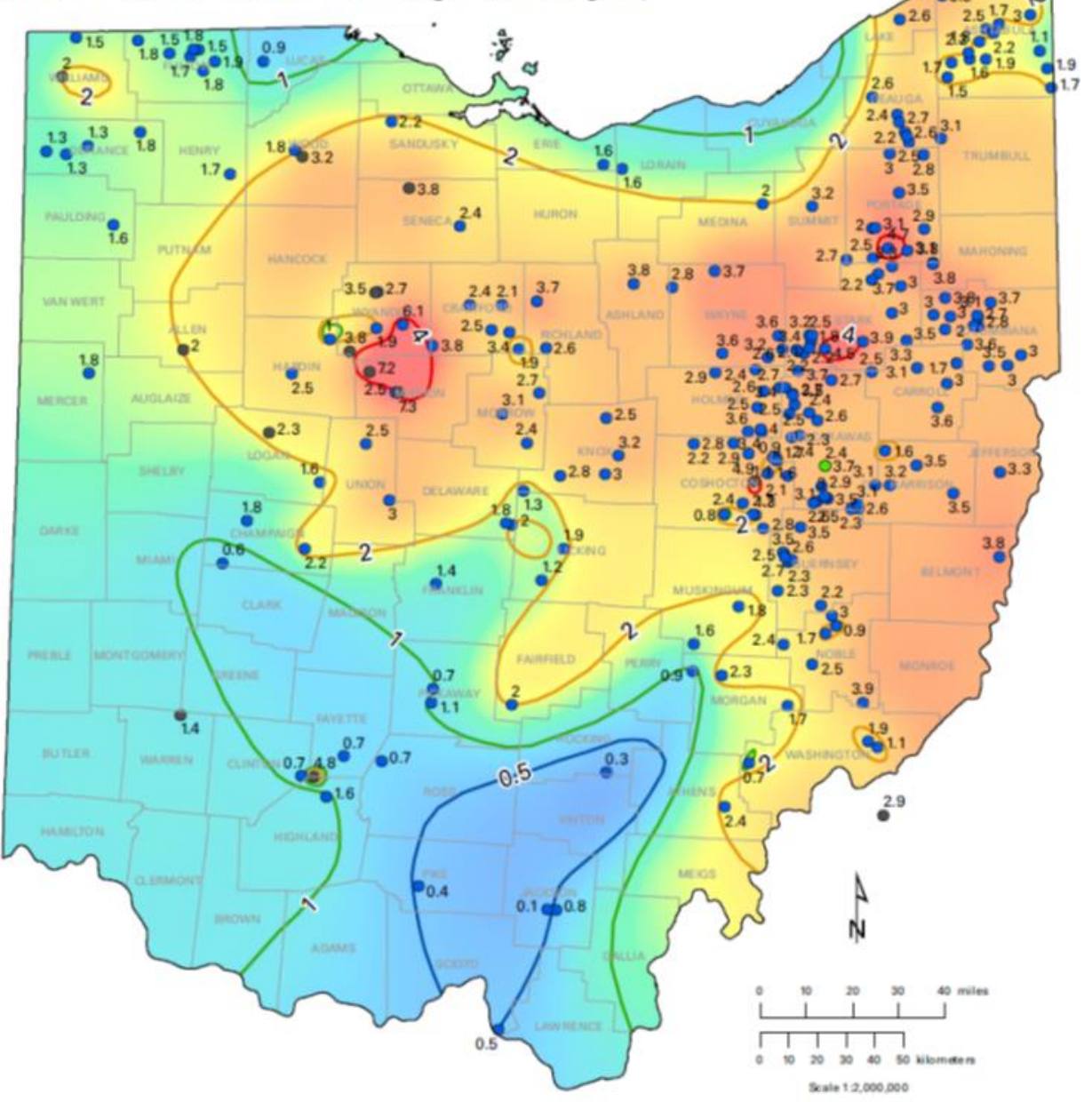

EXPLANATION

TOC data source

- Core

- Cuttings

- Sidewall core/cuttings

TOC contours - weight $\%$

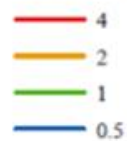

TOC maximum - weight \%

Excellent $>4$ Very Good 2-4 Good 1-2

Fair $\quad 0.5-1$

Poor $\quad 0-0.5$

\section{DISCLAIMER}

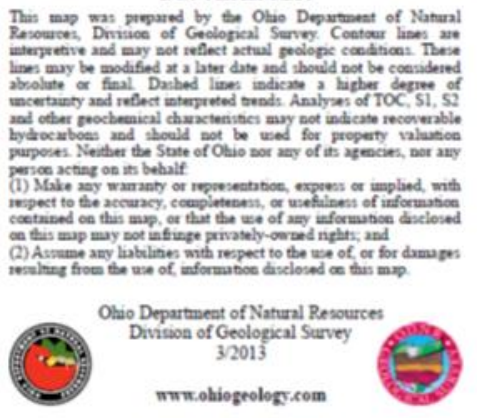

Figure 1.2: Estimated maximum TOC values for the state of Ohio per well within the UticaPoint Pleasant. The study well is labeled by a small red star. Image from the Ohio Department of Natural Resources (ODNR, 2013). 


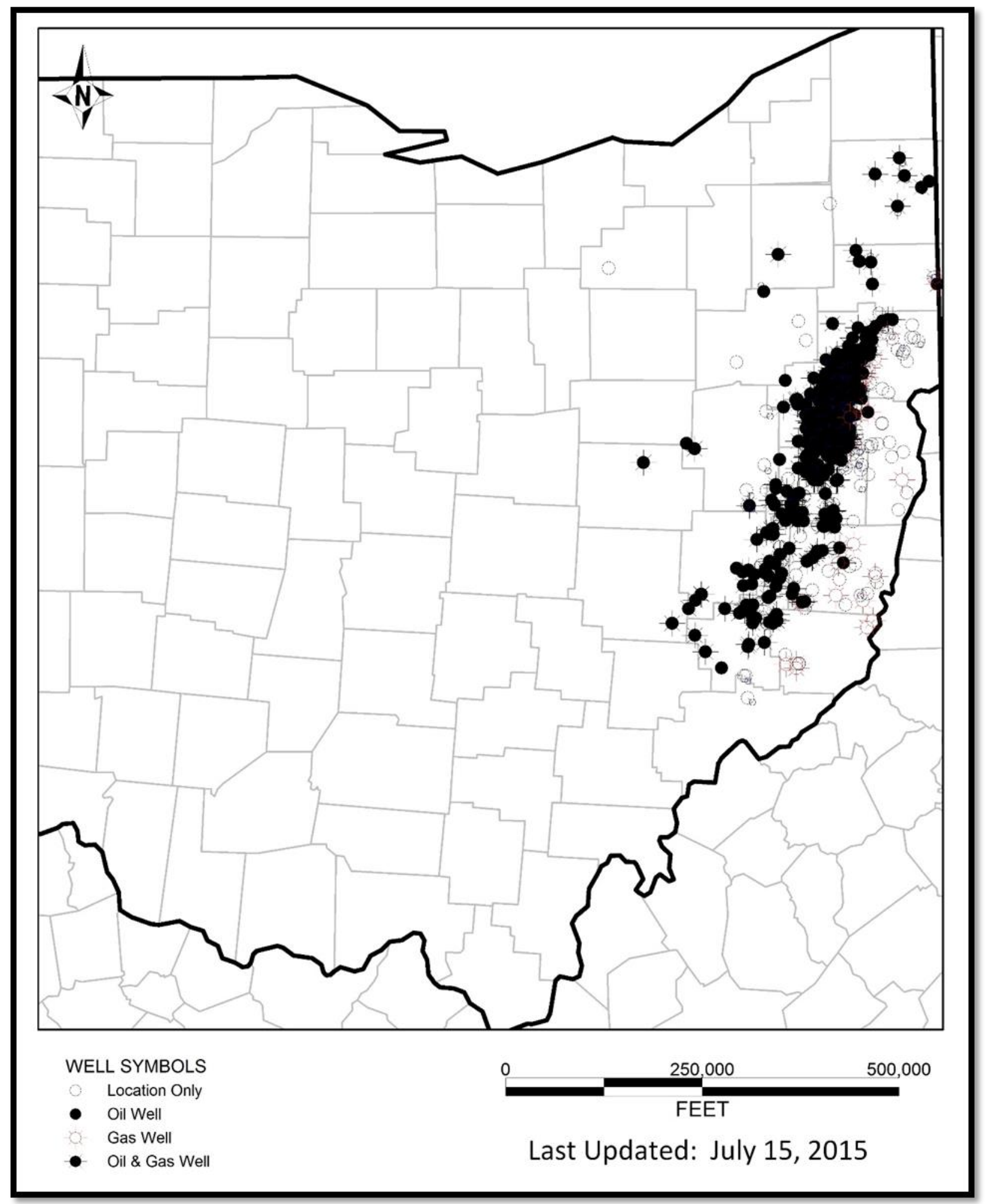

Figure 1.3. Map location for all Utica-Point Pleasant wells in eastern Ohio as of July 11, 2015 (922 total wells). Drilling activity has been concentrated mostly in Carroll County (364 producing wells). 
Although the Point Pleasant can be found throughout Ohio, Pennsylvania, West Virginia, New York, and Kentucky, the study area is focused on eastern Ohio due to data availability and the interest of industry expressed by the number of Point Pleasant well permits and drilled wells (Figure 1.4). From north to south, the potential for the Point Pleasant stretches from Ashtabula County to Meigs County and as far west as Franklin and Delaware Counties (Figure 1.5). Its extent throughout Ohio tends to thicken from west to east in Ohio, as the Point Pleasant subbasin allowed for more accommodation space for sediment to accumulate. The average thickness in eastern Ohio is approximately 60 to 130 feet (18.29-39.62 meters) thick with some areas displaying thicknesses over 200 feet (60.96 meters) (Figure 1.6). 


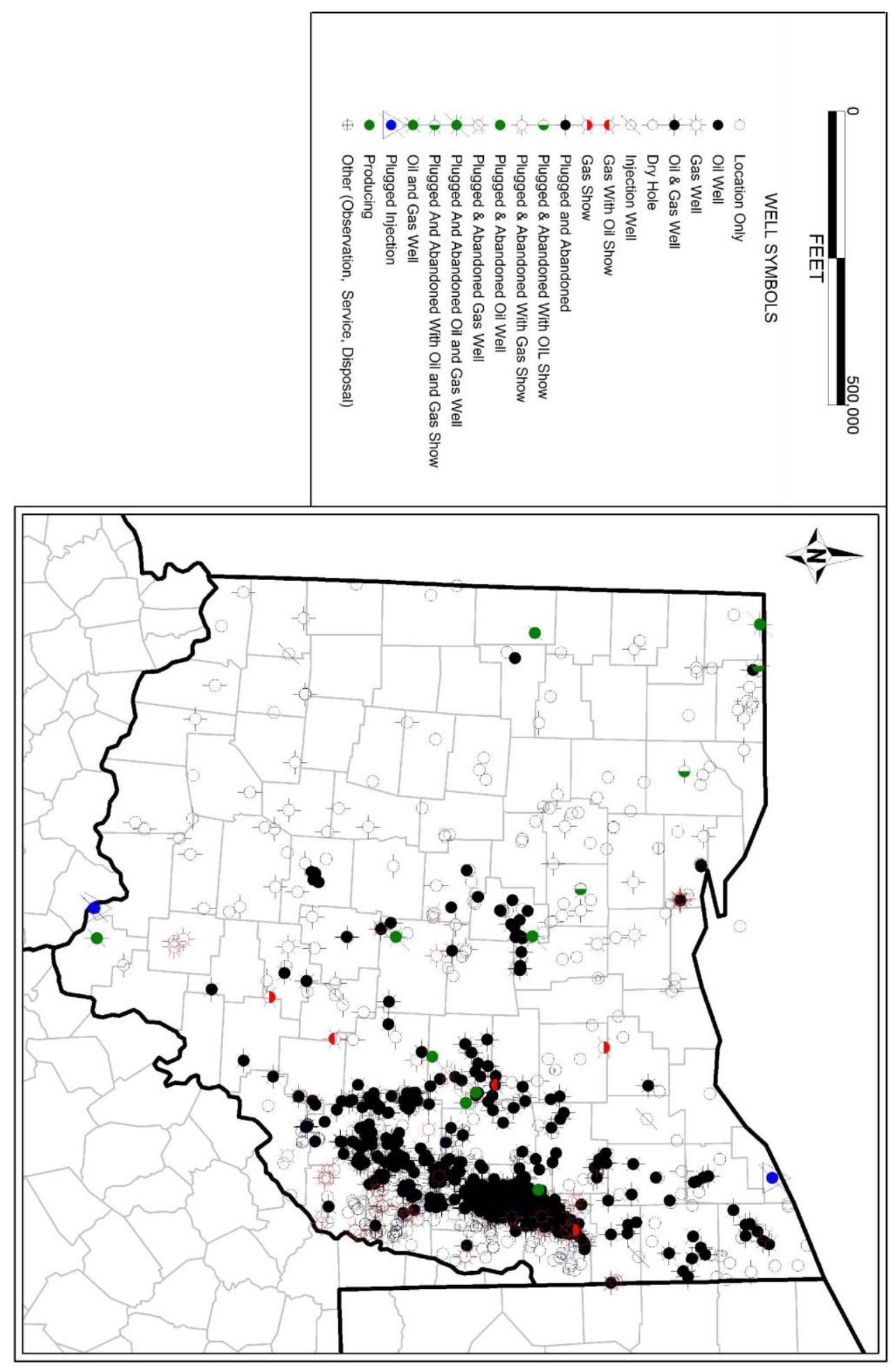

Figure 1.4. 1,711 Ohio wells were used in this study, of which 335 had well logs available. 


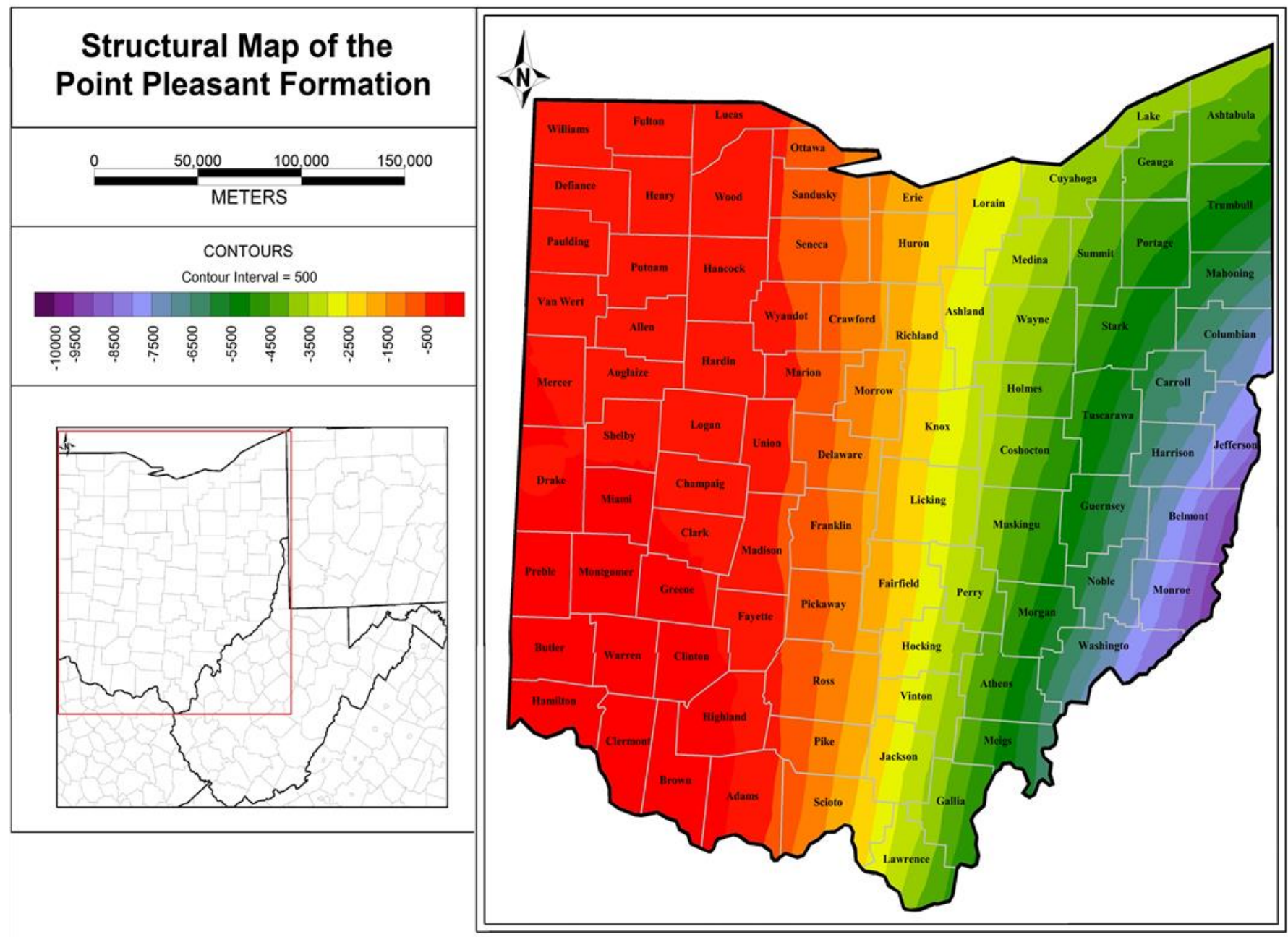

Figure 1.5. Structural map of the Point Pleasant Formation based on subsea total vertical depth (SSTVD). The Point Pleasant Formation is present in the subsurface from Ashtabula to Meigs County and as far west as Delaware and Franklin Counties. 


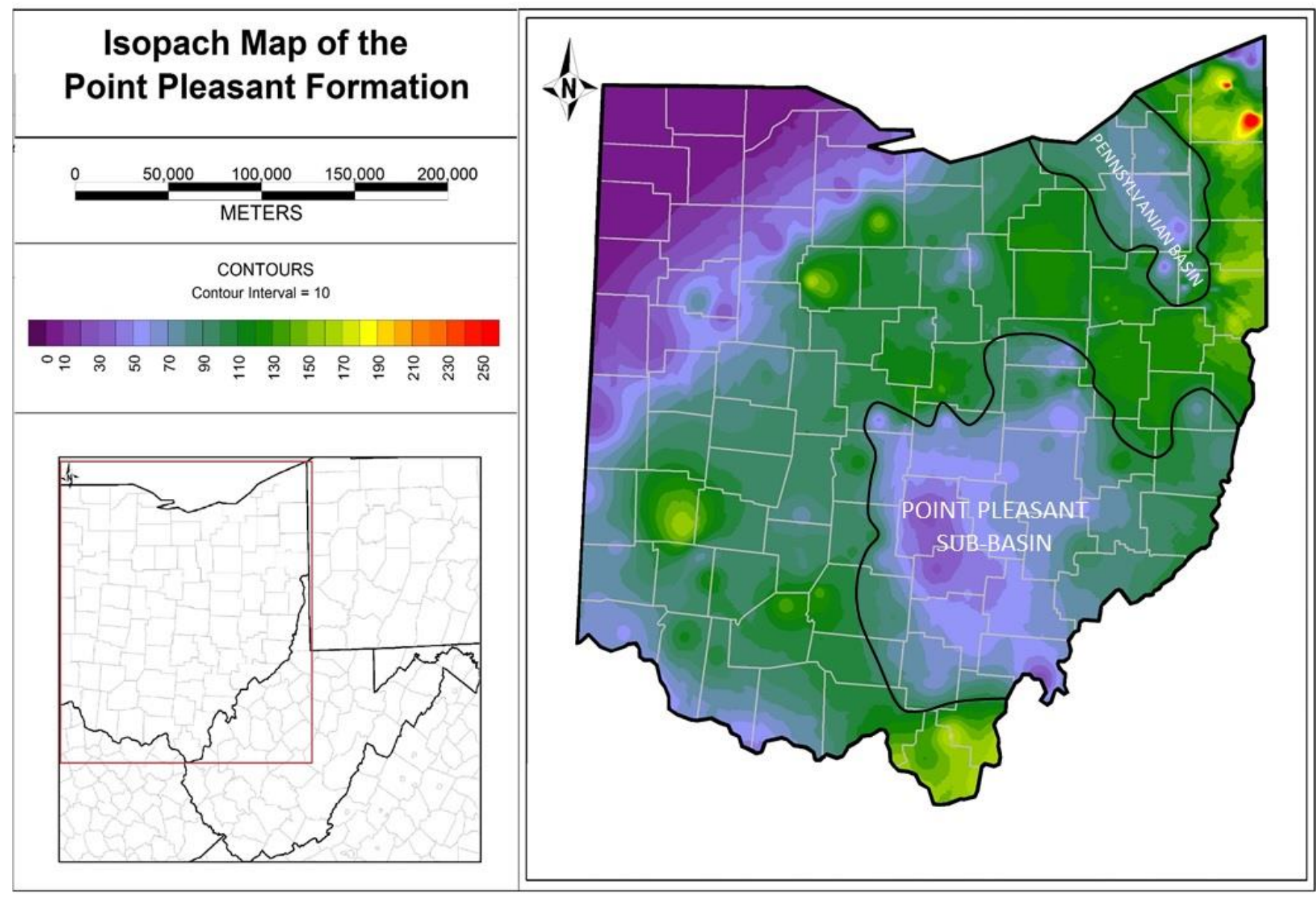

Figure 1.6. Isopach thickness map for the Point Pleasant Formation. Thickness is displayed in feet with a 10 foot contour interval.

The case well for this study is PDC Energy's Palmer 44-20, located three miles west of Beverly in Morgan County, Ohio (Figure 1.7). Drilling began on May 12, 2012 and was finished on June 8, 2012. The Dallas Morris Rig \#7 used nine bits to drill the vertical bore a total depth (TD) of 7,100 feet in 183.5 hours on an air/soap potassium-chloride brine mud. The goal of this venture was to drill down and to produce from the Point Pleasant. While drilling, a 184 foot long core was taken, which extends from the lower Utica to the upper Trenton.

A digital gas detector and chromatograph were interfaced with a Pason electric data system to record the total air gas in the core. Samples cut from the core were examined wet 
under a binocular microscope using plain (broad spectrum) light. Measurements were given in units, where 100 units represent $1 \%$ methane equivalent in the air.

Mud log analysis by Sunburst Consulting noted the penetration of the Utica at 6,600 feet measured depth (MD). Gas shows within the Utica increased with drilling depth as values ranged from 11-19 units in the upper Utica, to 21-63 units in the lower Utica. The highest values were reached closest to the Point Pleasant boundary. The Point Pleasant was reached at a depth of 6,762 feet MD. Gas values were far greater here than they had been in the preceding Utica, ranging from 63-438 units. When drillers reached the Point Pleasant-Trenton boundary, gas shows had significantly decreased, but maintained levels of 37-85 units.

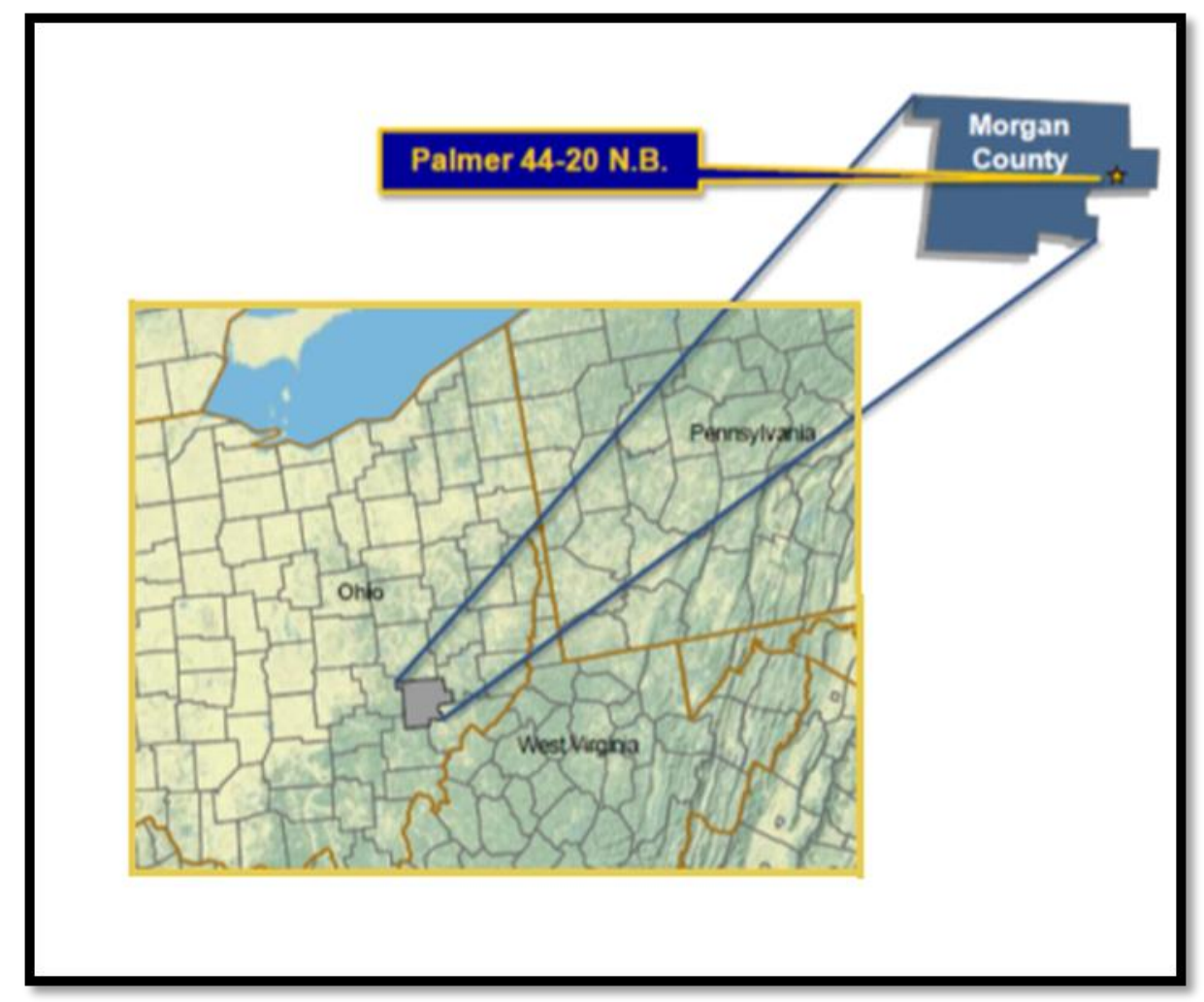

Figure 1.7: Map of Ohio outlining the location study area of Morgan County and the PDC well Palmer 44-20. 


\section{Geologic Background}

The Appalachian basin is a foreland basin containing Paleozoic rocks from early Cambrian to early Permian and stretches from New York to northeastern Alabama. The Appalachian basin also contains some of the United States' largest deposits of oil and natural gas, predominately throughout Ohio, Pennsylvania, West Virginia, and New York.

The creation of the Appalachian basin was largely influenced by three major orogenies: the Ordovician Taconic (500-440 million years ago), the Devonian Acadian (416-359 million years ago), and the Pennsylvanian-Permian Alleghenian (325-260 million years ago). This paper will focus on the first wave of tectonic mountain building affecting the formation of the Appalachians: the Taconic.

The Taconic orogeny initiated in the Cambrian when the Iapetus ocean began to close. The closing of the Iapetus ocean was caused by the continued convergent plate movement and subsequent subduction of the Iapetian oceanic continent beneath the North American continental plate (Faill, 1997). The subduction created a chain of island arcs east of the present day Appalachian basin, known as the Taconic island arc (Hansen, 1997). Continued convergence caused the Taconic island arc to be accreted onto the eastern edge of the U.S., creating the Taconic mountains. This over-thrusting of the Taconic island arc onto the North American craton led to the drowning of the carbonate bank through the development of the Taconic foreland basin (Rowley and Kidd, 1981).

While the Taconic mountains and the Taconic foreland basin were forming throughout the Ordovician, North America was situated at 20-25 degree south latitude (Witzke, 1990). This location along with the continued closing of the Iapetus allowed for the majority of Ohio to be covered by tropical inter-continental seas (Figure 1.8). These warm waters resulted in the widespread deposition of shallow-water carbonate beds (Cornell, 2008). 
The Point Pleasant Formation was deposited during the middle Ordovician (465-455 million years ago). These rocks were formed from terrigenous sediment eroded from the Taconic mountains to the east. The sediments were then transported and deposited west of the mountains into the Taconic foreland basin, which created a complex delta system, known as the Queenston delta (Figure 1.9). This delta provided the mud and other fine sediments that would be deposited into the inter-continental seas and later become the Point Pleasant (Hansen, 1997).

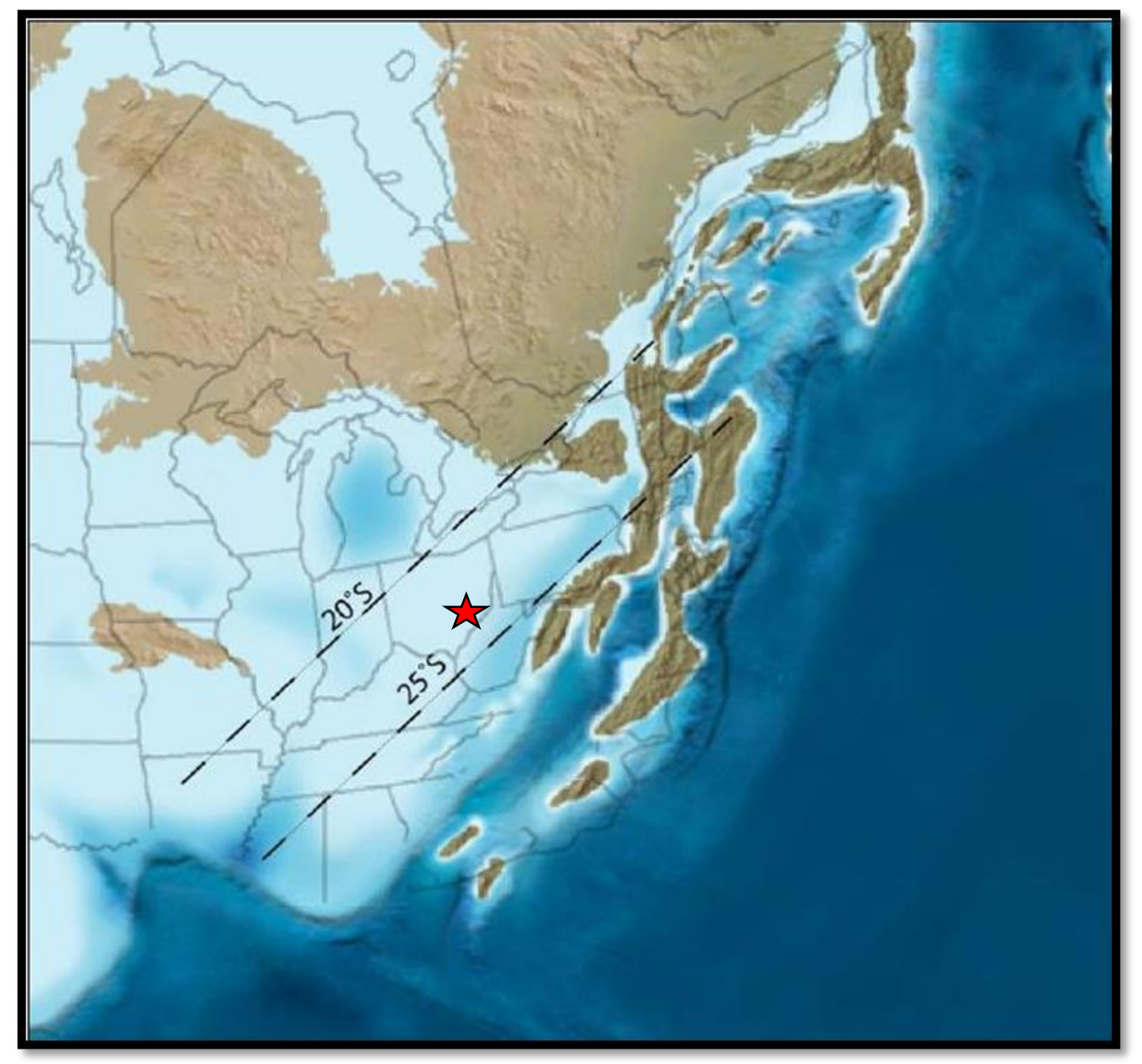

Figure 1.8: Paleogeographic map of the United States at the time of deposition of the Point Pleasant during the middle Ordovician. The current United States is outlined. During the Ordovician the Ohio was located at 20-25 degrees south latitude in warm tropical intercontinental seas. The study area is marked by a small red star. Modified from Blakey, (2011); paleolatitudes from Witzke, (1990). 


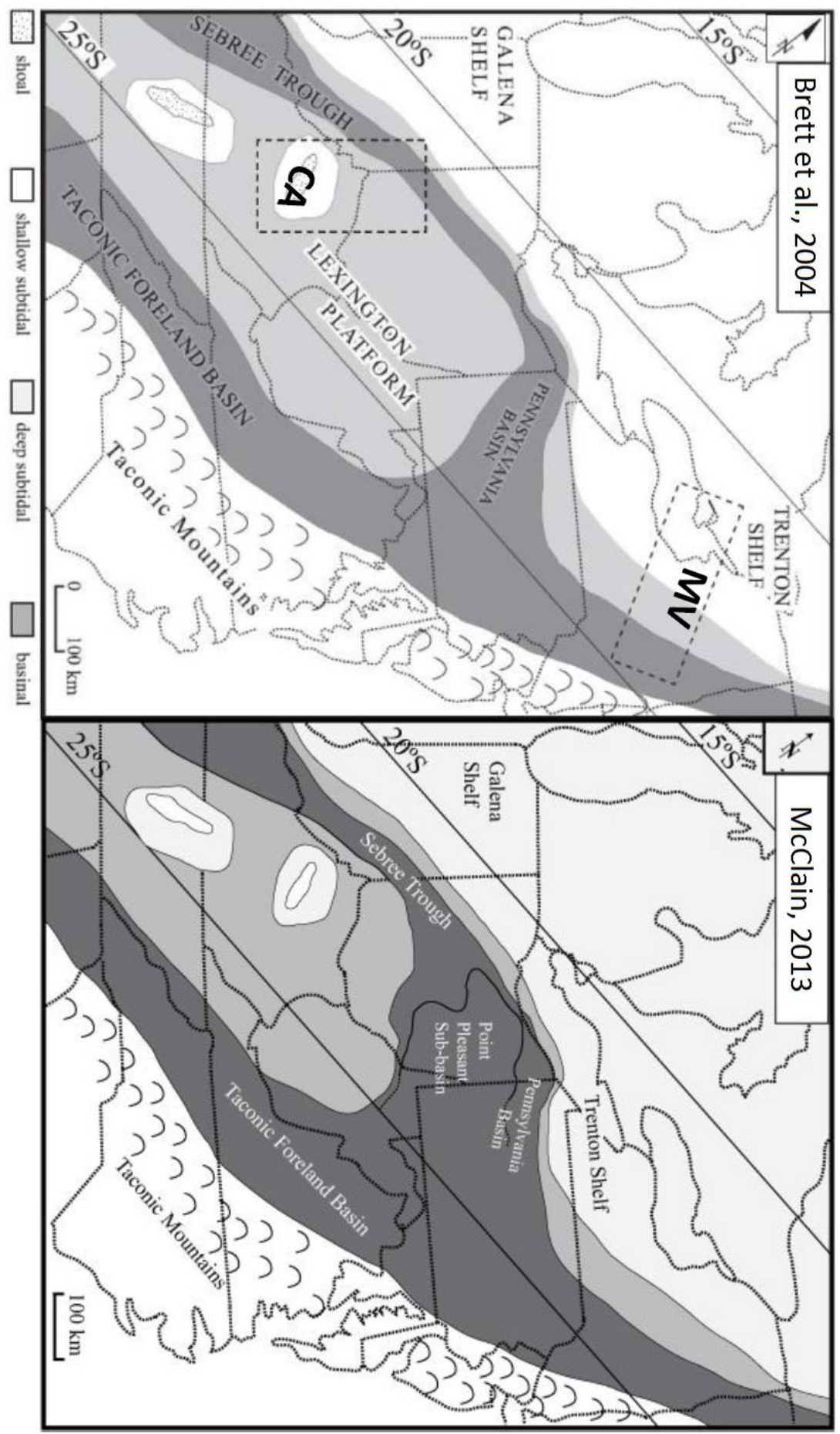

Figure 1.9. Paleogeographic map of the Appalachian basin during the Ordovician showing subbasin provinces and major depositional features after Brett et al., 2004 (left) and McClain, 2013 (right). Dotted areas indicate locations of outcrop stratigraphic studies, of Brett et al., 2004. CA Cincinnati Arch outcrop belt, MV - Mohawk Valley outcrop belt. 


\section{Chapter 2: Sequence Stratigraphy \& Depositional Environment}

The focus of this chapter is to identify the sequence stratigraphy and depositional environment of the middle Ordovician strata of eastern Ohio. The study interval includes the Utica Shale, Point Pleasant Formation, and the Trenton Limestone. The Trenton and Lexington limestones are formal names for the same interval of rock. In this study, the formation beneath the Point Pleasant will be referred to as the Trenton. The Trenton is further divided into the Lexington, Logana, and Curdsville members. In this study, the Curdsville Member will be referred to as the Trenton, keeping with the nomenclature used by drilling companies in eastern Ohio.

\section{Methodology and Dataset}

In order to interpret the sequence stratigraphy and depositional environment of the Point Pleasant, a detailed core analysis was performed in order to document and describe lithofacies for the study interval. The Palmer core is a 184 foot (56.08 meters) long core, spanning the lower Utica to upper Trenton. The core was slabbed and cut into three foot long sections, and was preserved in plastic bags and cardboard boxes.

In addition to the core, high resolution scanning electron microscope (SEM) images, thin section photographs, and X-Ray CT scanning videos of the core were utilized in order to qualitatively and quantitatively assess the mineralogy and sedimentary structural components of the core (Appendix A).

Finally, once lithologies had been identified in the core, they were tied to the logs of 1,711 wells that were imported into Petra in order to correlate lithofacies to petrofacies. All the 
well logs used in this study contained the Point Pleasant or deeper formations. The purpose of identifying the petrofacies was to create several basin-wide cross sections used to interpret stratigraphy and facies changes across the Point Pleasant sub-basin.

\section{Sequence Stratigraphy}

According to Vail et al. (1997, pg. 53), a sequence is a "stratigraphic unit composed of genetically related strata bounded at their top and bottom by unconformities or their correlative conformities." However, Embry (1995) noticed difficulties is accurately identifying and correlating these correlative conformities and proposed a different type of sequence identification, referred to as a Transgressive-Regressive Sequence, or a T-R Sequence. In a T-R Sequence, the sequence boundary (SB) is placed at the subaerial unconformity and the correlative transgressive surface (TS) in the absence of the SB, or where the TS and SB merge (McClain, 2013). The T-R Sequence is divided into an underlying transgressive system tract (TST), identified as a deepening upward sequence (decreasing carbonate and increasing shale content), and an overlying regressive system tract (RST), identified as a shallowing upward sequence (increasing carbonate and decreasing shale content). The boundary between these two sequences is referred to as the maximum flooding surface (MFS).

This type of sequence identification has been proven useful in Ordovician strata due to the fact that the transgressive surface and sequence boundary separates a distinct lithology change and is identifiable in both shelf and slope environments. Additionally, these Ordovician strata represent transgression within second-order sequences and lack noticeable lowstand deposits in third-order sequences (McClain, 2013). T-R sequence stratigraphy is only a reliable method of correlation in deposits lacking lowstand deposits (Holland and Patzkowsky, 1997). 
This study will utilize the nomenclature of Holland and Patzkowsky (1996, 1997, 1998) and McClain (2013), where M5, M6, and C1 refer to third order sequences within the Trenton Limestone, Point Pleasant Formation, and Utica Shale respectively (Figure 2.1). The M5 sequence falls within the lower Mohawkian Series, containing the Curdsville Member of the Trenton Limestone. The M6 sequence is an upper Mohawkian Series sequence. The transgressive system tract contains the Lexington and Logana submembers of the Trenton Limestone and part of the lower Point Pleasant Formation, while the regressive system tract is entirely composed of the Point Pleasant. The $\mathrm{C} 1$ sequence falls within the lower Cincinnatian Series and contains the entire Utica Shale. The Utica is divided into transgressive and regressive system tracts based on two distinct gamma ray signals, creating an upper and lower Utica in eastern Ohio.

Further correlation of the Point Pleasant sub-basin will be done through the use of bentonite ash beds. These ash beds allow for the correlation of chronostratigraphic surfaces across large distances in the study area. These bentonite beds contain radioactive potassium, thorium, and uranium. When observed by the gamma ray log, they appear as sharp spikes due to increased radioactive content. However, when observed by the density log, these ash beds have very low densities which are easily seen deviating from the average density of the Trenton-Utica interval. The first bed is the Millbrig-Deicke bentonite ash bed, located just below the top of the Black River Limestone. The second bentonite horizon important to this study is identified just below the Point Pleasant sequence boundary (Figure 2.1). 


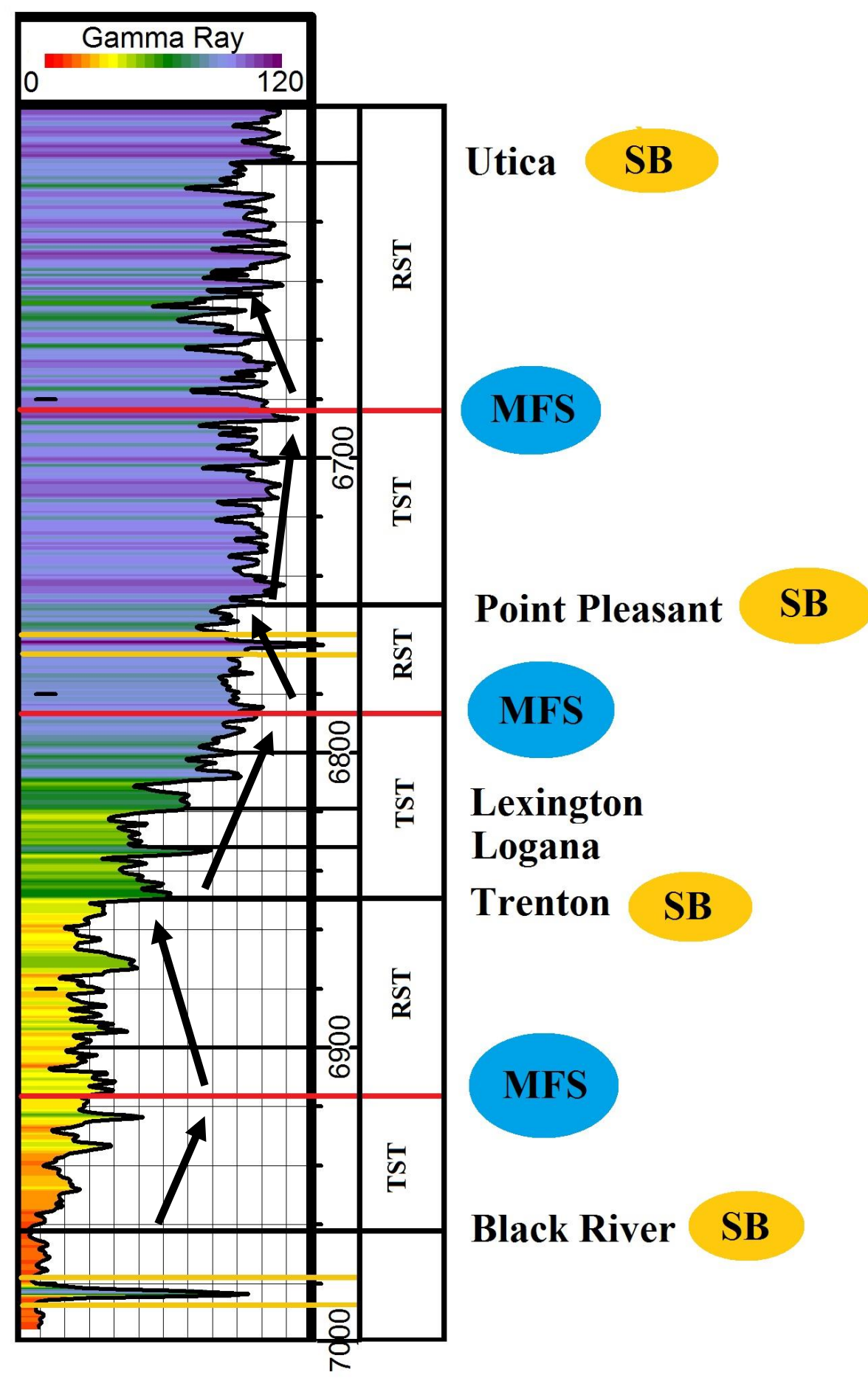

Figure 2.1. The Utica-Trenton interval for the Palmer $44-20$ was subdivided based on the gamma ray signal into surface boundaries (SB), transgressive system tracts (TST), regressive system tracts (RST), and maximum flooding surfaces (MFS) where the transgressive and regressive tracts meet. Gold lines indicate key bentonite ash beds which are widely traceable throughout the Appalachian basin and serve as a strong time correlation marker. 


\section{Unconformities}

Because Vail et al. (1997) described sequence stratigraphy as identifying stratigraphic units that are bounded at their top and base by unconformities, it is important to identify potential unconformities within the Palmer core. Four potential unconformities were identified within the Trenton-Utica interval. These unconformities are apparent in well log cross sections and are represented by abrupt changes in gamma ray, density, porosity, and other logs (Figure 2.2). When observed in the core, these unconformities lack any discernable change in character (Figure 2.3). The core shows no change in color or fossil abundance at these boundaries which may mark a change in lithology, sedimentation rate, or depositional environment. Additionally, there are no core shifts at these boundaries, indicating a change in coring technique. However, if mineralogy is overserved in the logs, distinct mineralogy changes can be seen at the boundaries for these unconformities (Figure 2.4). The most notable changes are shifts between clay dominated and carbonate dominated environments. 


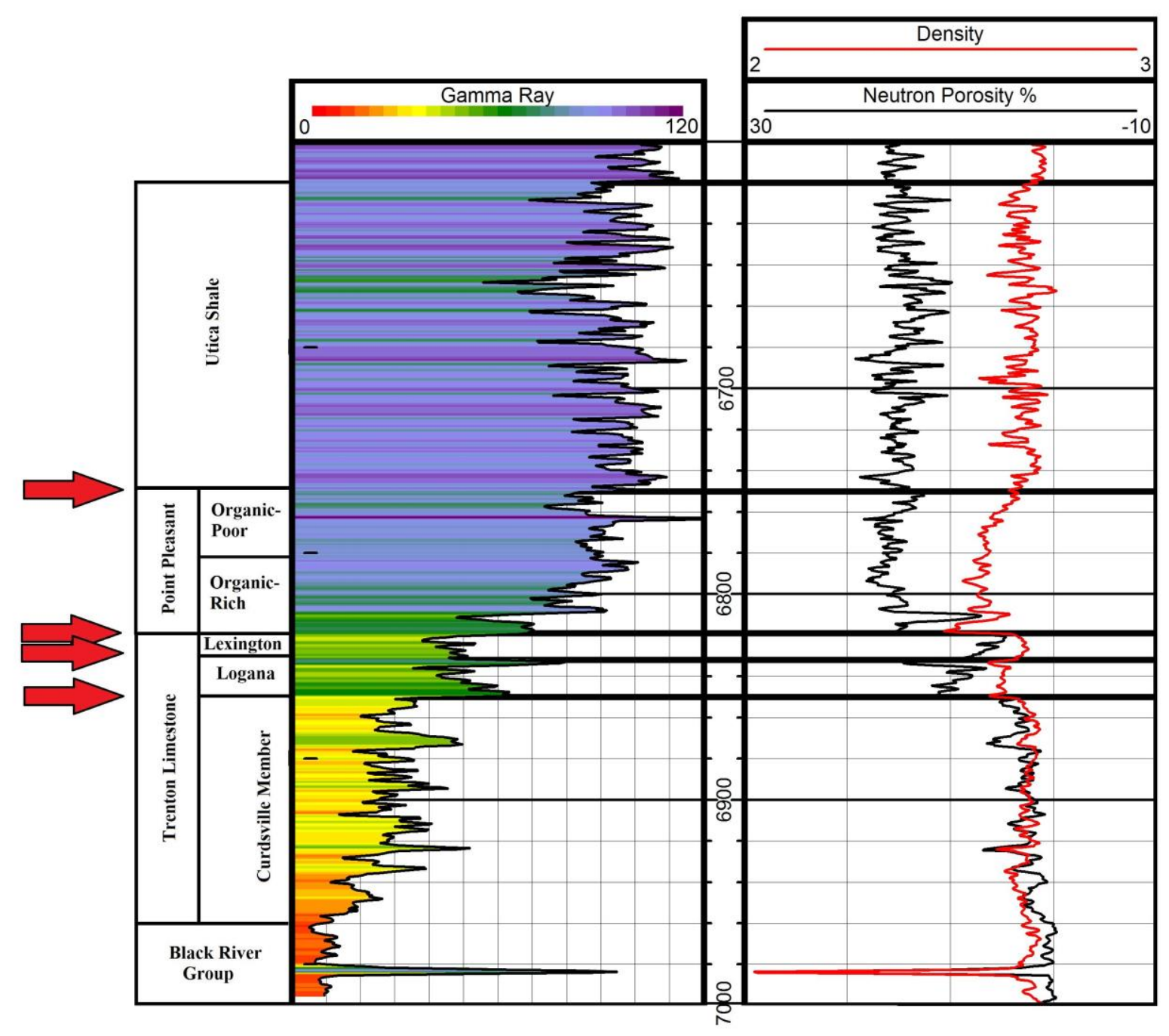

Figure 2.2. Three potential unconformities are apparent in well log cross sections. These appear at the top of the Curdsville, at the top of the Lexington, and at the top of the Point Pleasant. These potential unconformities are represented by a red arrow. 


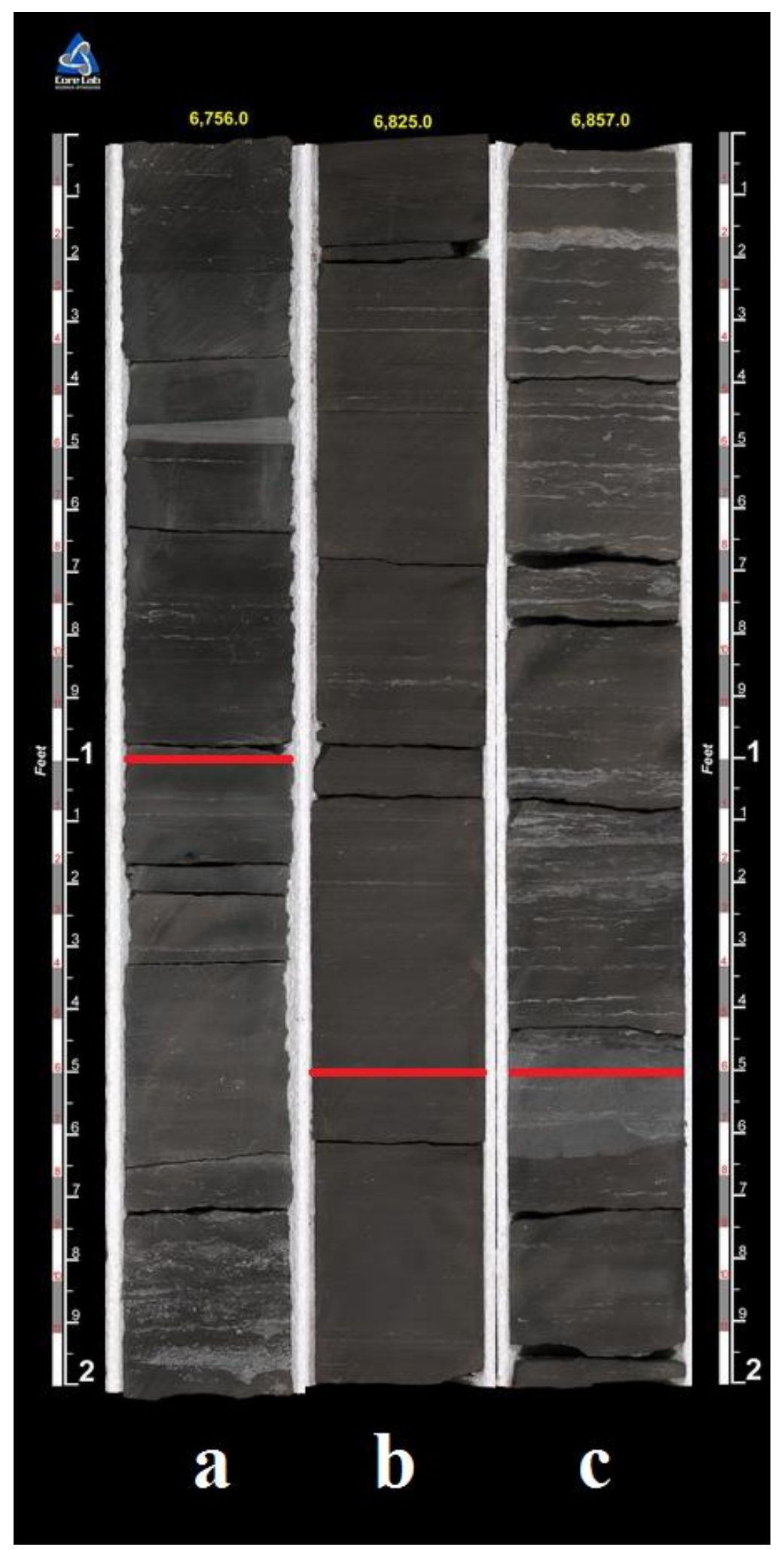

Figure 2.3. Photographs of the Palmer core. Based on core analysis, no noticeable changes were seen at the top of the Point Pleasant (a), at the top of the Lexington (b), or at the top of the Trenton (c) that may represent unconformities. The unconformity at the top of the Logana is missing and thus cannot be observed for unconformities. 


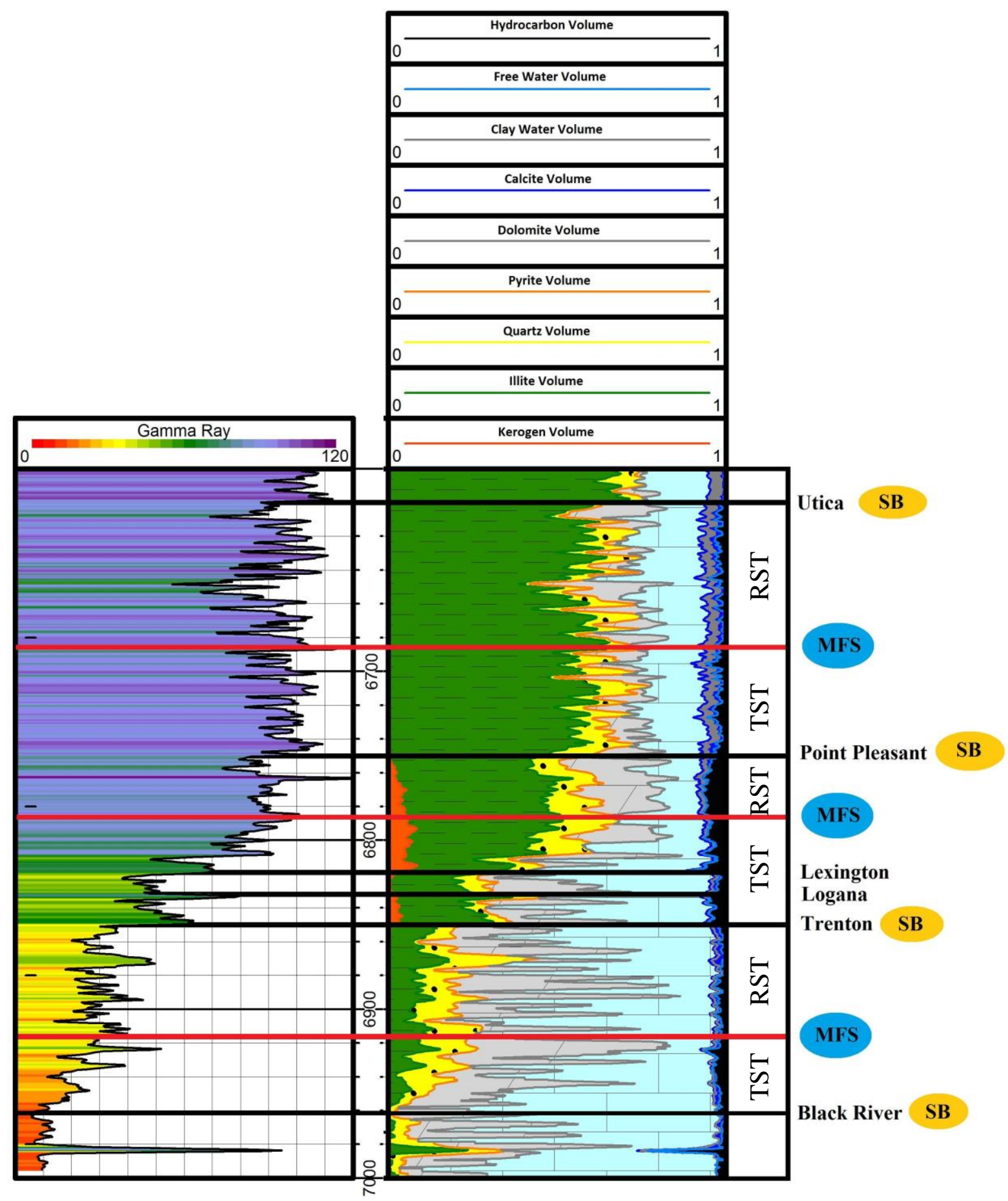

Figure 2.4. When mineralogical logs are observed for the Trenton-Utica interval, abrupt changes in mineralogy at the top of the Point Pleasant, Lexington, Logana, and Trenton (Curdsville) can be seen. These abrupt changes may reflect unconformities as the depositional environment shift between clay dominated and carbonate dominated environments. 


\section{Gamma Ray Relationships}

The gamma ray log is a logging tool which measures the natural radioactivity of rock in American Petroleum Institute (API) units. The majority of radioactivity found in the earth is emitted from potassium 40, uranium 238, and thorium 232. The average concentration of potassium, uranium, and thorium in the earth's crust is $2.6 \%, 3 \mathrm{ppm}$, and $12 \mathrm{ppm}$, respectively (Doveton, 2010). Although the overall radioactivity of rock formations can be used to help identify shale dominated from sand dominated lithologies, the proportion of the individual radioactive elements can be used to identify clay type and to differentiate between reducing and oxidizing environments.

A potassium-thorium cross plot is useful for the identification of clay minerals. In this method, the proportion of potassium is measured against the proportion of thorium. Illite has a higher amount of potassium than mixed-layer clays or smectite, while kaolinite has little to no potassium (Quirein et al., 1982) (Figure 2.5). In this method, the results indicate that the TrentonUtica interval of the Palmer well is dominated by a mixture of clay minerals, with a potassiumthorium ratio of above 3.5 .

Then, the relative proportion of thorium and uranium has been useful in indicating the redox-potential of depositional environments (Adams and Weaver, 1958). Uranium occurs in an insoluble tetravalent state that is fixed under reducing conditions, but becomes soluble and may be mobilized into solution under oxidizing conditions, where the uranium is transformed to a hexavalent state. On the other hand, thorium occurs solely in an insoluble tetravalent state in both oxidizing and reducing conditions. Based on a series of laboratory analyses, Adams and Weaver (1958) concluded that a thorium-uranium ratio of less than two (uranium rich) represents a reducing environment, while a ratio of greater than seven (uranium poor), represents an oxidizing environment (Figure 2.6). The ratio between thorium and uranium was then calculated 
in Petra and plotted as a log curve. When observed in this fashion, periods of decreasing oxygen and periods of increasing oxygen can be identified. Similarly, the reducing conditions seen within the lower Point Pleasant correspond with increasing TOC values, as the decreasing oxygen content during this time period may have allowed for better preservation of organic material.

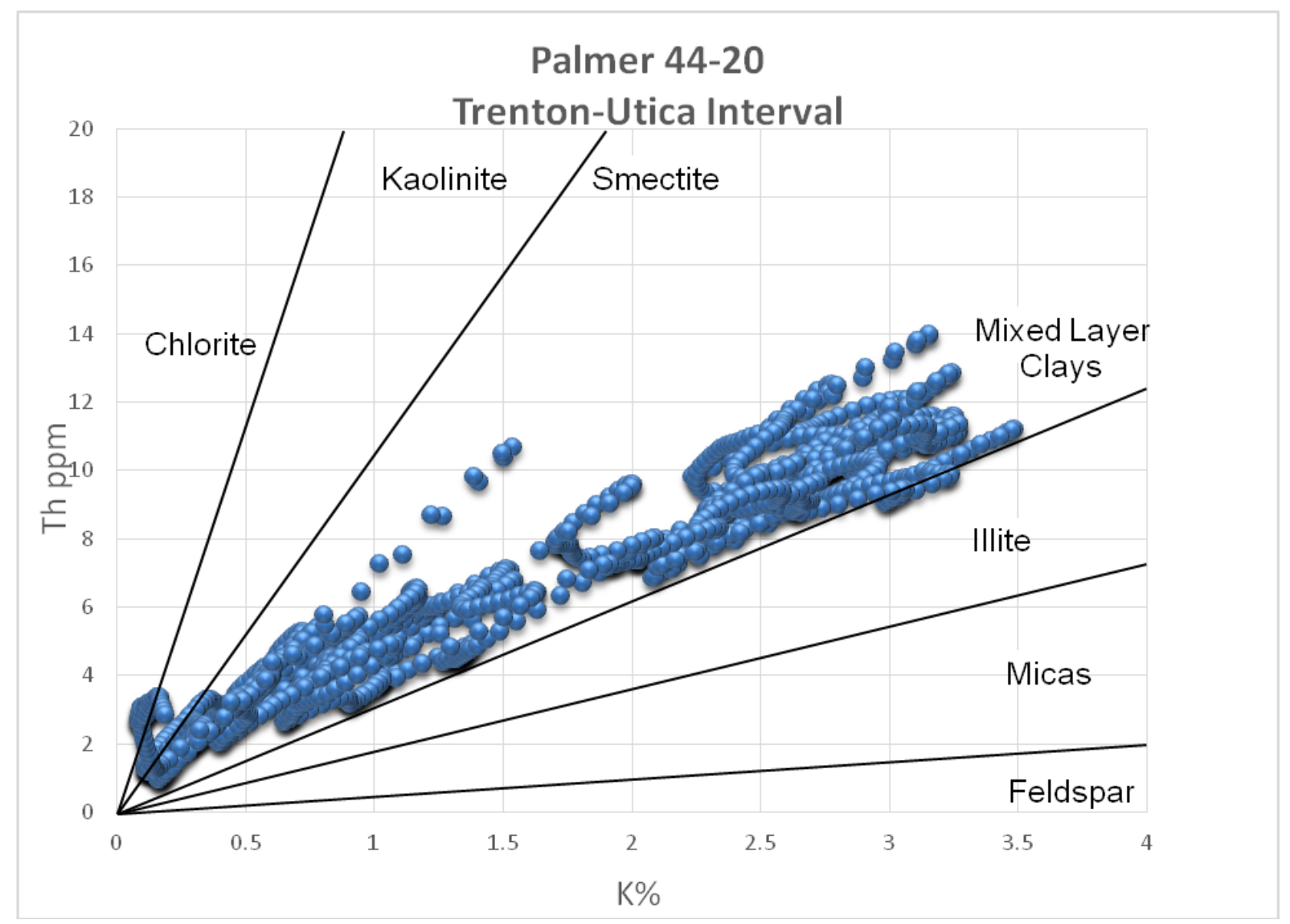

Figure 2.5. Thorium and potassium cross plot for the Palmer's Trenton-Utica interval. The results of this plot can be used to determine the type of clay minerals in a shale formation. The results show that the Palmer contains mixed clays. 


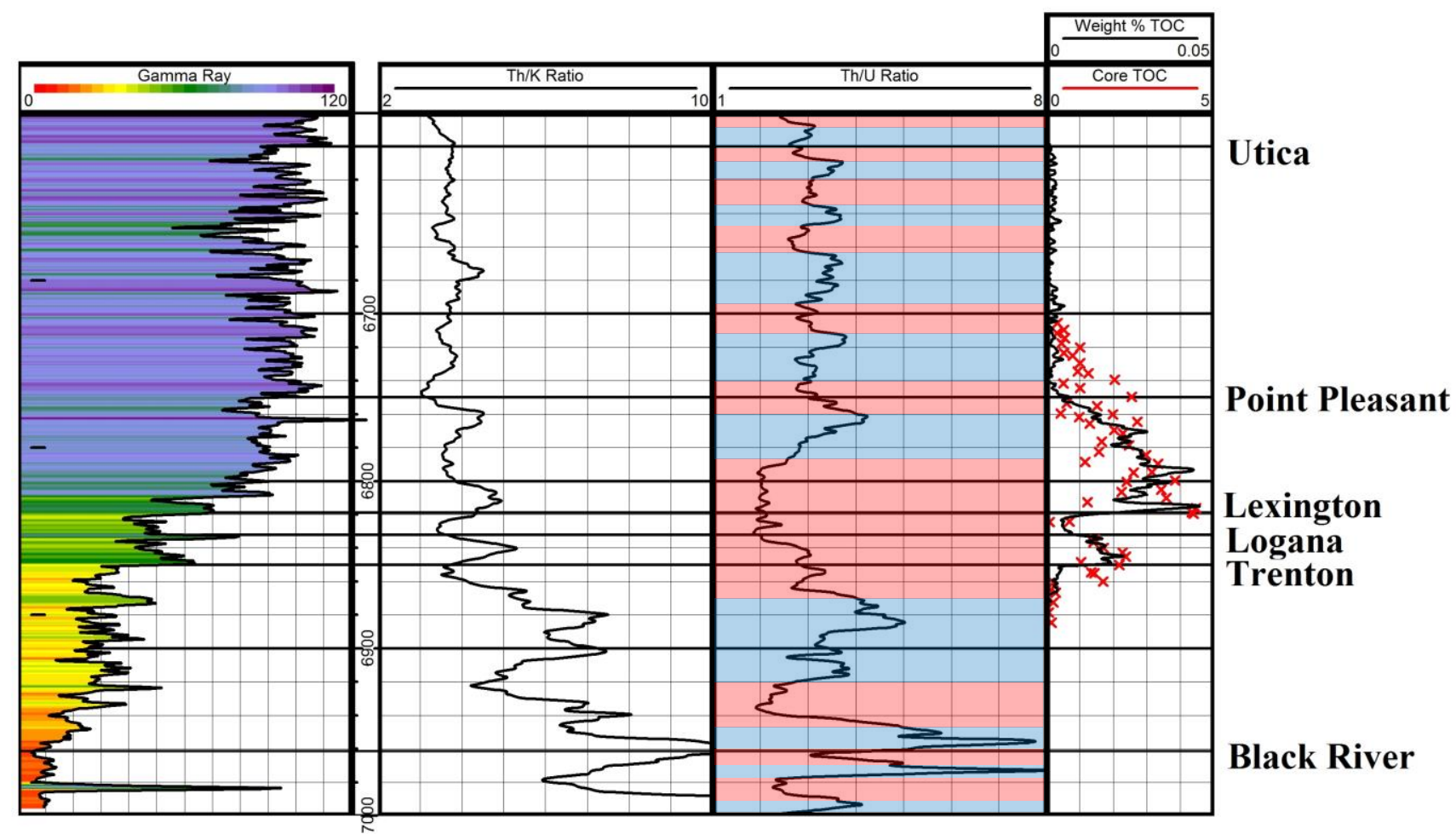

Figure 2.6. Gamma ray log and the computed ratio of thorium and uranium for the Palmer well's Trenton-Utica interval used to predict reducing and oxidizing environments, based on Adams and Weaver (1958). When used, the thorium-uranium plot indicates fluctuating periods of decreasing oxygen (shaded red areas) and periods of increasing oxygen (shaded blue areas).

Additionally, several gamma ray cross plots were created for the Palmer well in order to determine what elements or minerals most likely affect the gamma ray signal of the TrentonUtica interval and how these correlations changed across formations (Table 2.1). These X-Y cross plots were then fitted with a line of best fit and refer to a correlation coefficient (CORR). The following guidelines were used in order to characterize relationships:

$$
\begin{gathered}
\text { +/- 1.0-0.8 Very Strong Relationship } \\
\text { +/- 0.6-0.8 Strong Relationship } \\
\text { +/- 0.4-0.6 Moderate Relationship } \\
\text { +/- 0.2-0.4 Weak Relationship } \\
\text { +/- 0.0-0.2 No Relationship }
\end{gathered}
$$




\begin{tabular}{|l|l|l|l|l|l|l|l|l|}
\hline Formation & $\begin{array}{l}\text { GR vs. } \\
\text { Potassium }\end{array}$ & $\begin{array}{l}\text { GR vs. } \\
\text { Uranium }\end{array}$ & $\begin{array}{l}\text { GR vs. } \\
\text { Thorium }\end{array}$ & $\begin{array}{l}\text { GR vs. } \\
\text { Quartz }\end{array}$ & $\begin{array}{l}\text { GR vs. } \\
\text { Carbonate }\end{array}$ & $\begin{array}{l}\text { GR } \\
\text { vs. } \\
\text { Illite }\end{array}$ & $\begin{array}{l}\text { GR vs. } \\
\text { Chlorite }\end{array}$ & $\begin{array}{l}\text { GR vs. } \\
\text { TOC }\end{array}$ \\
\hline $\begin{array}{l}\text { Trenton- } \\
\text { Utica }\end{array}$ & 0.956 & 0.857 & 0.953 & 0.009 & -0.963 & 0.945 & 0.001 & -0.046 \\
\hline Utica & 0.879 & 0.680 & 0.807 & 0.335 & -0.828 & 0.828 & -0.071 & -0.046 \\
\hline $\begin{array}{l}\text { Point } \\
\text { Pleasant }\end{array}$ & 0.868 & 0.156 & 0.825 & 0.118 & -0.809 & 0.928 & -0.134 & 0.236 \\
\hline Trenton & 0.798 & 0.872 & 0.841 & -0.295 & -0.845 & 0.831 & 0.00 & -0.033 \\
\hline
\end{tabular}

Table 2.1 Gamma ray correlation results for the Palmer well. Very strong correlations were seen for potassium, uranium, thorium, carbonate, and illite. No correlation was seen with quartz, chlorite, or TOC. Correlation graphs can be found in Appendix B.

When the entire Trenton-Utica interval was analyzed, very strong relationships were seen for all of the radioactive elements tested, with the strongest correlation occurring between gamma ray and potassium (0.956).

The results also indicate a very strong relationship between gamma ray and carbonate (0.963), and gamma ray and illite (0.945). High gamma ray signals are generally connected to higher shale content due to its natural radioactivity from potassium, uranium, and thorium. Due to this, as clay content increases, the gamma ray signal should strongly increase, while as carbonate content increases, the gamma ray signal should strongly decrease. Meanwhile, no relationship was noted between gamma ray and quartz (0.009), magnesium chlorite (0.001), or TOC (-0.046), further indicating the lack of influence these substances have on gamma ray signal.

\section{Petrography}

In order to determine lithologies in the core, it is important to understand the mineralogy distribution throughout the entire interval. This was performed through the use of mineralogy well logs, thin sections, XRD analysis results, and SEM images. 


\section{Thin Sections \& XRD Analysis}

To begin with, thin section photographs from the Palmer were prepared by Core Labs. Photographs were taken every five feet, were stained with Alizeran Red-S staining, and were each photographed with plane and epifluorescent light. This particular staining was chosen because anything found in the thin section composed of calcium carbonate will be stained pink or red. This allows for a visual representation of the amount of carbonate in a sample. Epifluorescent light allows for the identification of pores and organic matter, including hydrocarbons within sedimentary rocks. Each thin section was described quantitatively by providing the mineralogical volume percent at each depth that were determined through XRD analysis.

$\mathrm{XRD}$ is a non-destructive tool for identifying and quantifying the mineralogy of crystalline compounds in rocks, soils, and particulates. Every mineral has a characteristic X-ray diffraction pattern. This has been found to be particularly beneficial for fine grained compounds, such as clays, where mineralogy cannot be easily identified by the human eye. The results for the Palmer well were plotted in a ternary plot and shaded by the volume percent of kerogen (Figure 2.7). The highest kerogen values were found in lithologies that contained large proportions of both carbonate and clay minerals, with little siliciclastic influence. 


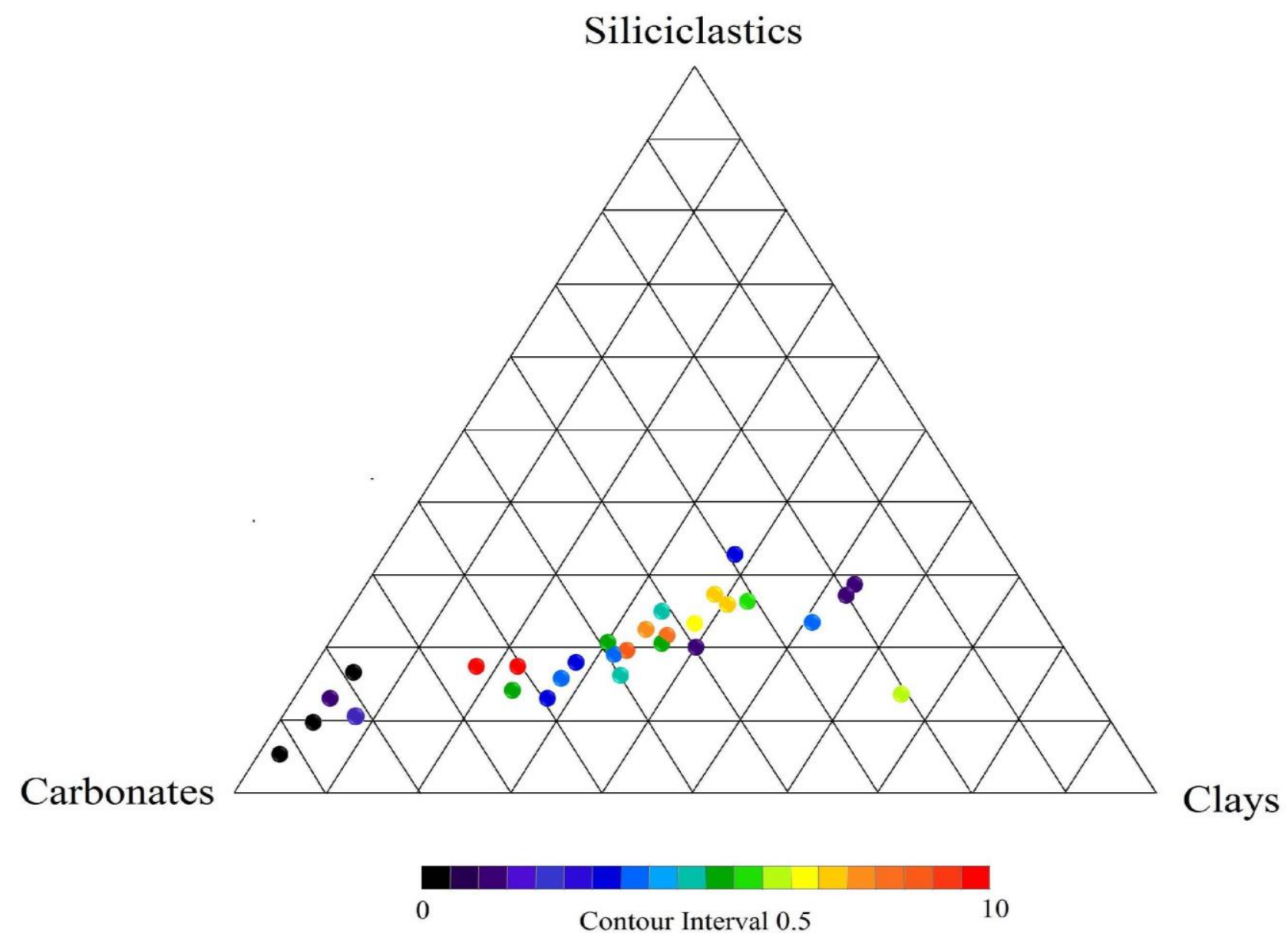

Figure 2.7. XRD results for the Palmer core were plotted within a ternary diagram and shaded by the volume percent of kerogen. Highest kerogen values were found in lithologies containing nearly equal proportions of carbonate and clay content, with little siliciclastic influence. 


\section{SEM Imaging}

SEM imaging was also utilized to identify mineralogy throughout the use of plug sample analysis. Ingrain extracted four plugs from the Palmer core, which were identified as having low bulk density (RhoB) and a lower effective atomic number (zeff). Zeff is related to the photoelectric log (PE) and can be calculated using the following equation:

$$
Z e f f=10 * P E^{1 / 3.6}
$$

All four samples fell within the Point Pleasant Formation between 6,773- 6,825 feet. RhoB-Zeff cross plots were used to qualitatively define four quadrants. Each quadrant corresponds to a specific rock facies and is assigned a color; green, red, blue, or black (Figure 2.8). The four plugs were then scanned with an X-ray CT system to characterize the samples at a resolution of approximately 30 microns per voxel.

One area from each of the four samples was polished and then analyzed with Ingrain's SEM system to produce sets of 2D images for each sample at a resolution of approximately 10 nanometers per pixel. Initially 12-15 images were attained for a given depth, from which 10 were then used to calculate the average porosity, organic matter, and high density material.

Of the four plugs provided to Ingrain for analysis, all except sample 3HA were subjected to mineralogy analysis (Figure 2.9). Despite differing numerical values, the results for SEM mineralogy appeared consistent with those from XRD analysis, showing the main constituents of the Point Pleasant are clay, calcite, and very little quartz and feldspar (Figure 2.10). 


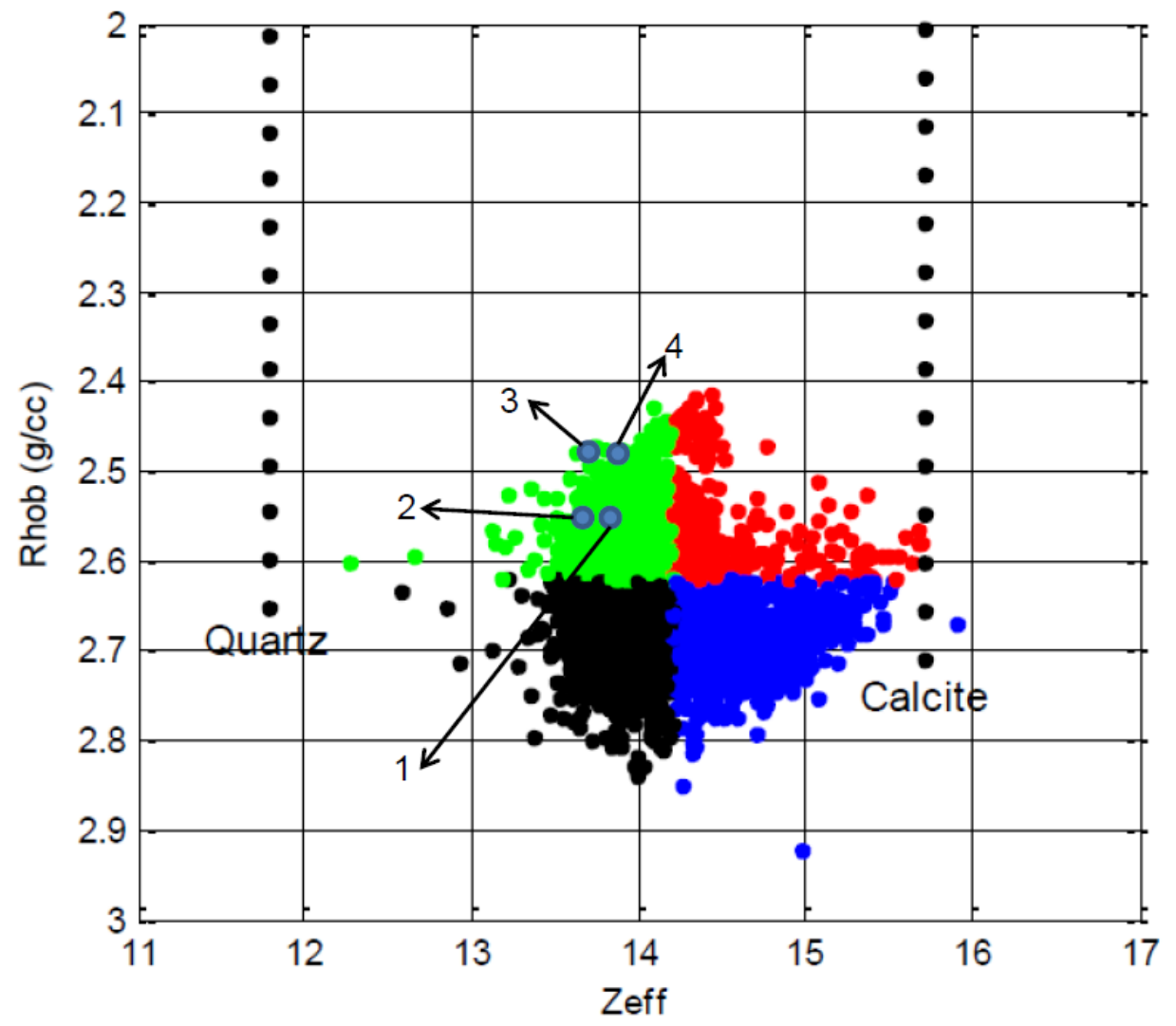

Green $=$ Higher porosity and/or om

Red = Higher phi or om; more calcite

Blue = Lower phi or om, more calcite

Black $=$ Lower phi or om, less calcite

Figure 2.8. Cross plot of the CoreHD log data Color-Coded by CoreHD facies. Ingrain was provided with four plugs from the PDC Energy. All four samples are from the Palmer's Point Pleasant formation and represents facies with lower bulk density (RhoB) and lower effective atomic number (zeff), represented by the color green. 


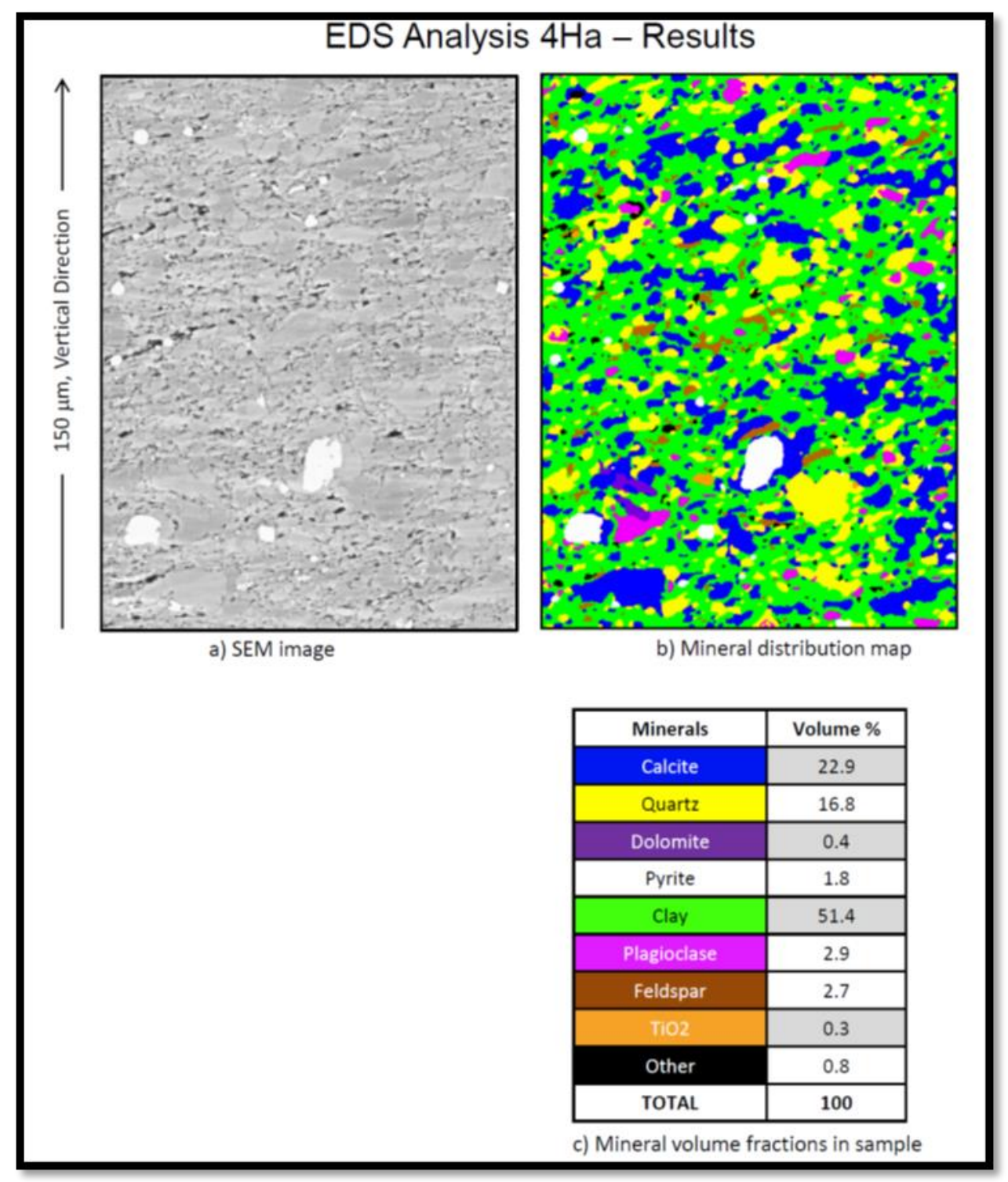

Figure 2.9. Example of Ingrain's mineralogy analysis for plug 4HA. The SEM images were color coordinated to represent the various minerals present in the samples. 


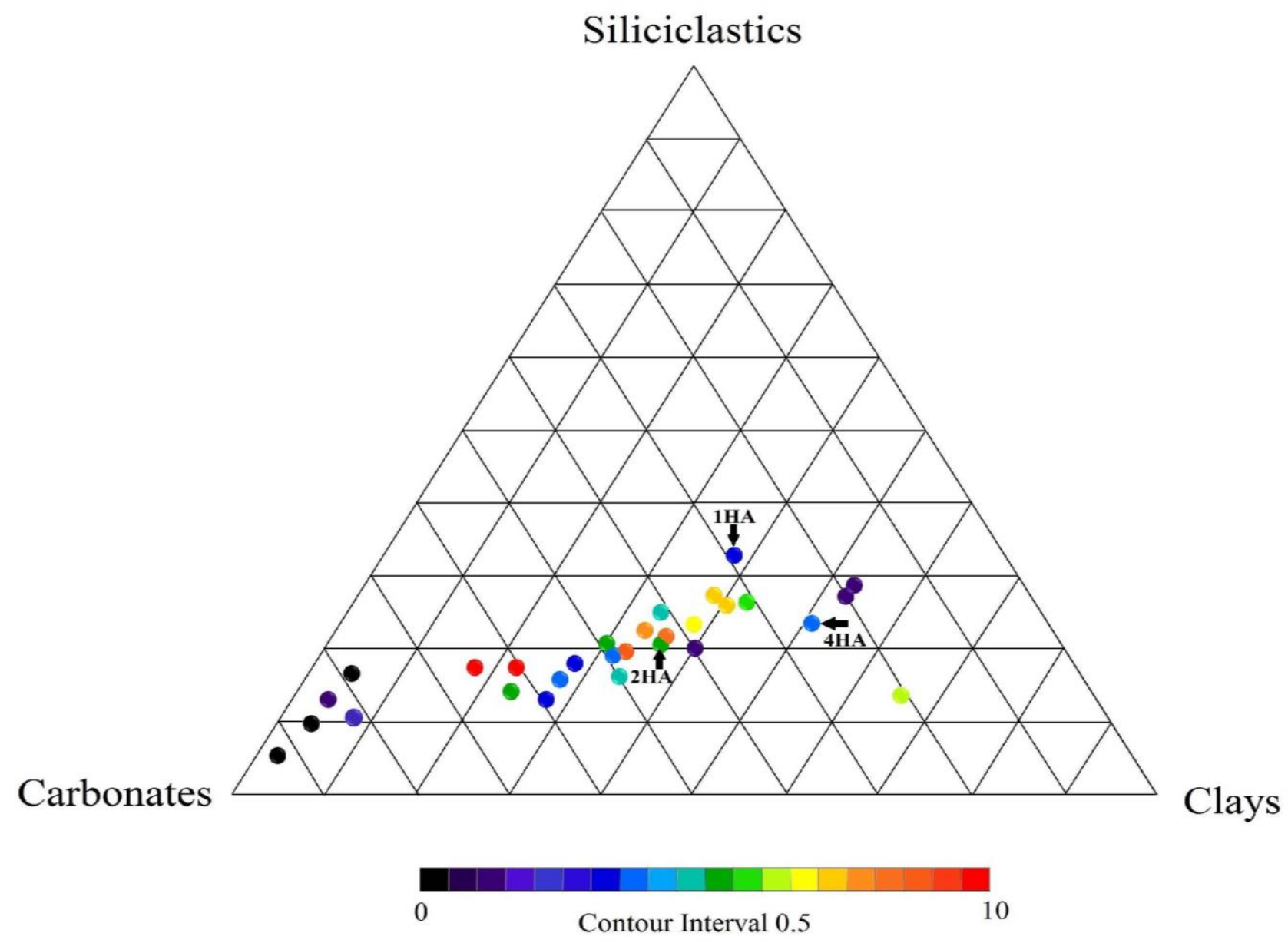

Figure 2.10. Results for Ingrain's mineralogy analysis were plotted alongside XRD mineralogy data within a ternary diagram. The three plugs chosen used are labeled above and show results consistent to those from XRD.

\section{Porosity and Pore Type}

Through thin section observations, no visible pores were identified. Due to this, SEM images were utilized. Through these observations, it was determined that the pore space within the Point Pleasant is dominated by intergranular porosity and organic matter porosity.

Based on the plug analysis results, the Point Pleasant varies in porosity from 1.6-2.6\%, with an average organic content of $0.4-6.7 \%$ (Table 2.5). Plug sample data shows that while porosity values across the four plugs remains relatively consistent, there are differences in the organic matter content (Figure 2.11). Samples 3 and 4 have higher organic content than samples 
1 and 2. Through the examination of samples 2 and 3, it was also determined that pore size distribution and permeability appear to be related, as greater porosity was related to greater permeability (Figure 2.12). According to Ingrain, these results are consistent with other samples of the Point Pleasant.

Plug sample data shows that samples 1 and 2 contain mostly intergranular clay-associated porosity, while samples 3 and 4 contain mostly organic matter porosity (Figures 2.13 and 2.14). As a result, samples 3 and 4 represent the lower, organic-rich Point Pleasant and indicate that organic matter porosity may result in higher permeability.

The lack of visible pore space may suggest there is no matrix porosity in the limestone portions of the Point Pleasant. Any indication of the porosity on the logs therefore is coming from the organic matter, which exhibits lower density, lower velocity, and looks like porosity on the neutron $\log$ (Hickman et al., 2015). This suggests that within the targeted lower Point Pleasant, the only pores contributing to hydrocarbon flow are coming from organic matter pores that formed during maturation.

\begin{tabular}{|c|c|c|c|c|}
\hline Sample & Depth (ft) & $\begin{array}{c}\text { Average Porosity } \\
(\%)\end{array}$ & $\begin{array}{c}\text { Average Organic } \\
\text { Matter } \\
(\%)\end{array}$ & $\begin{array}{c}\text { Average } \\
\text { High Density } \\
\text { Material } \\
(\%)\end{array}$ \\
\hline $1 \mathrm{HA}$ & 6773.45 & 1.6 & 0.4 & 0.7 \\
\hline $2 \mathrm{HA}$ & 6791.75 & 2.6 & 1.6 & 0.7 \\
\hline $3 \mathrm{HA}$ & 6806.75 & 1.7 & 6.3 & 1.3 \\
\hline $4 \mathrm{HA}$ & 6824.90 & 1.6 & 6.7 & 2.8 \\
\hline
\end{tabular}

Table 2.2. The four Palmer plugs were analyzed for average porosity, organic matter, and high density material. Higher amounts of organic matter and high density material were seen in the lower Point Pleasant (3HA and 4HA). 


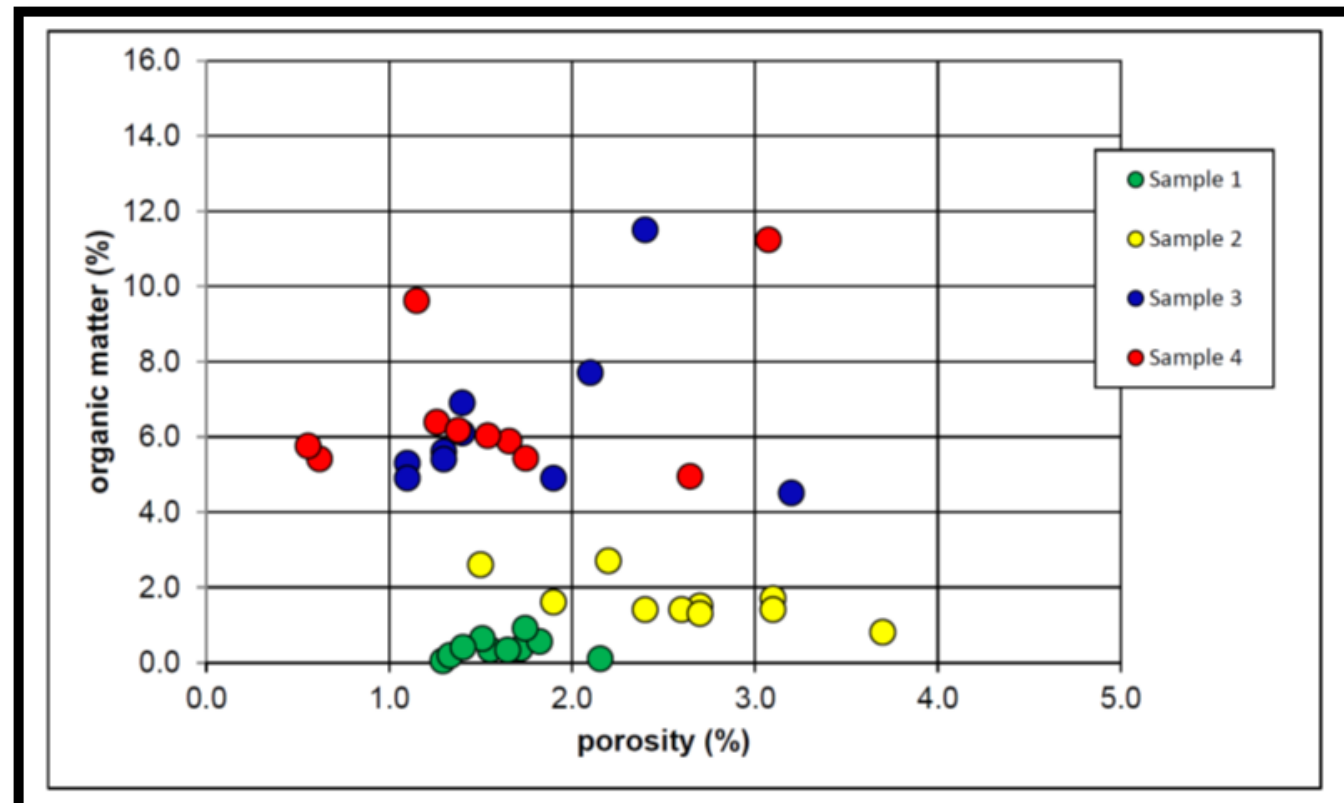

Figure 2.11. Ingrain compared weight percent of organic matter to porosity through the four Palmer plugs. Although porosity remained relatively consistent across the Point Pleasant Formation, higher organic matter was seen in the lower Point Pleasant (Samples 3 and 4).

\section{Palmer 44-20 Permeability}

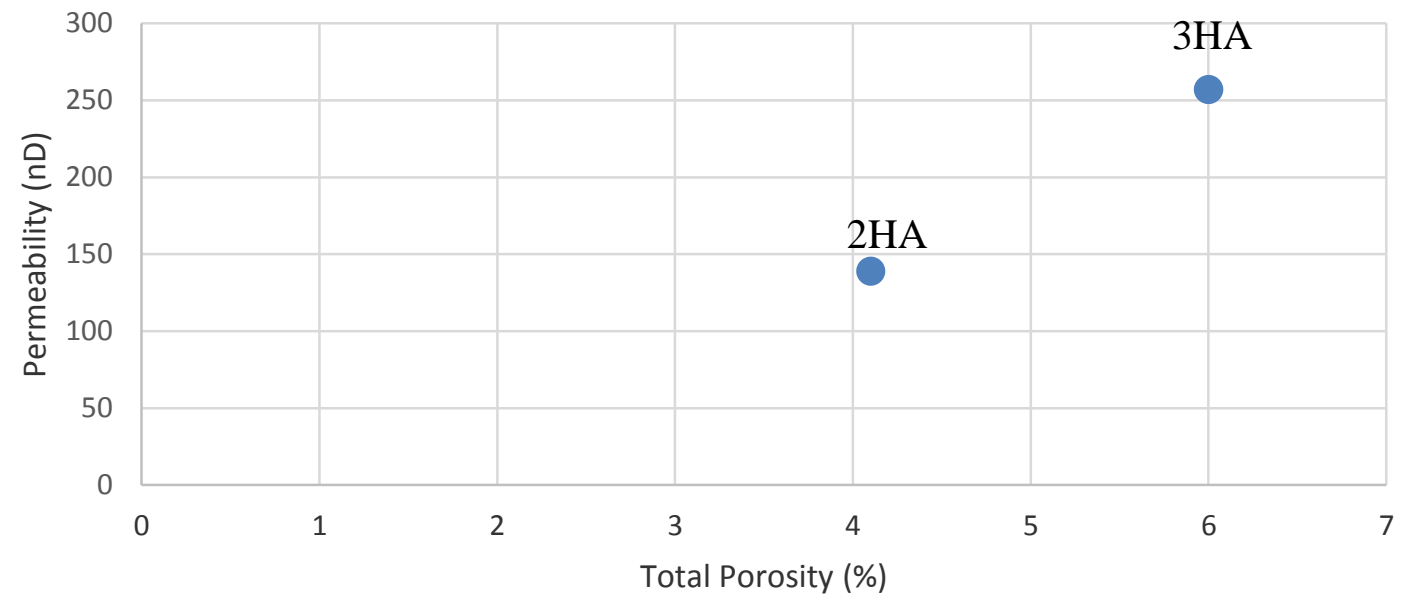

Sample 2: Porosity: $4.1 \%$

K_horizon: $139 \mathrm{nD}$

Sample 3: Porosity $6.0 \%$

K_horizon: $257 \mathrm{nD}$

Figure 2.12. Porosity and permeability were compared for plug samples $2 \mathrm{HA}$ and $3 \mathrm{HA}$. The graph indicates that as porosity increases, so does permeability. 
Comparison of Pore Types: Samples 2 (interparticle) and 3 (organic matter)
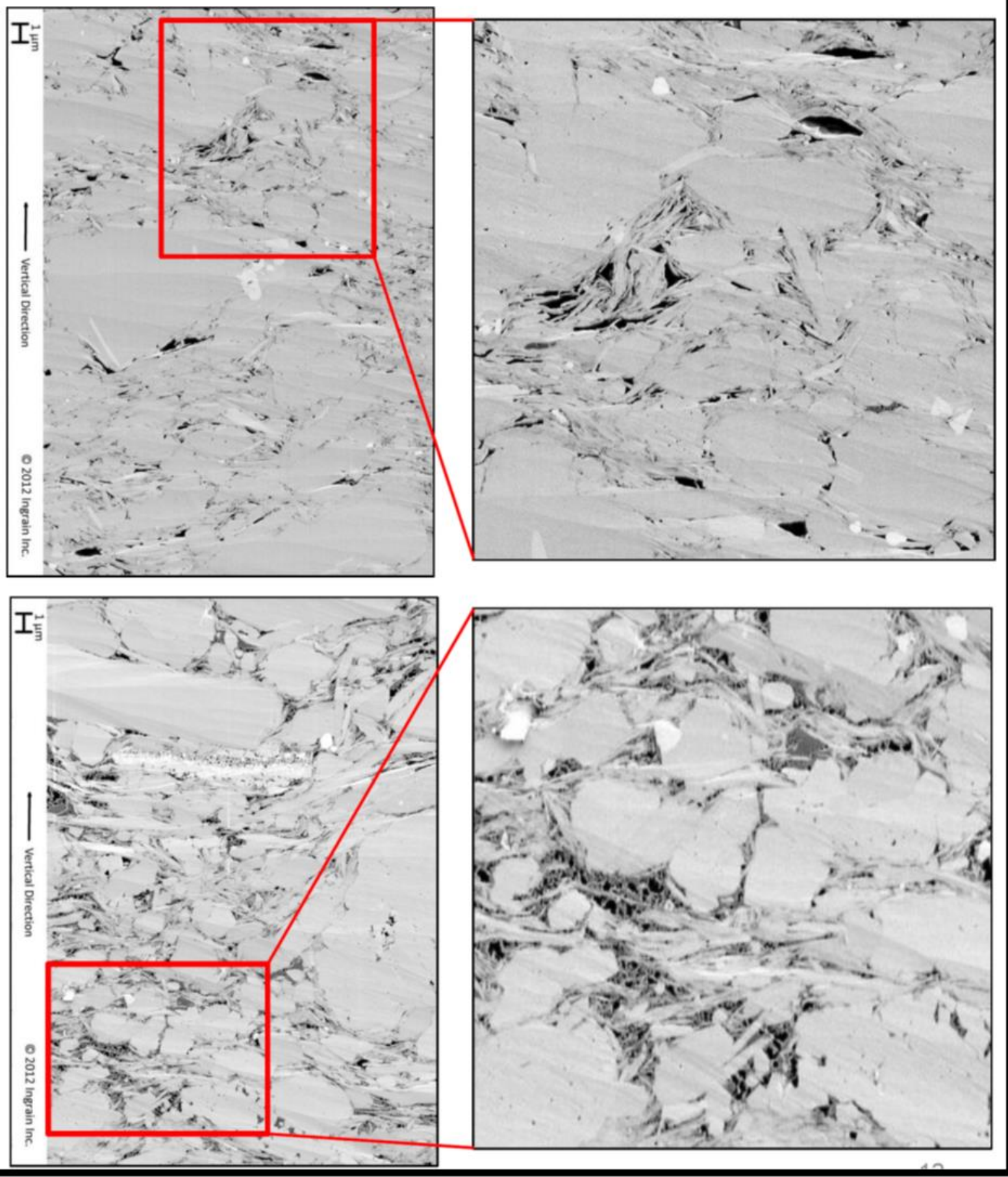

Figure 2.13. The Point Pleasant Formation contains interparticle and organic matter pores. The upper Point Pleasant more commonly contains interparticle pore space (Plug 2HA), while the lower Point Pleasant more commonly contains organic matter pore space (Plug 3HA). 


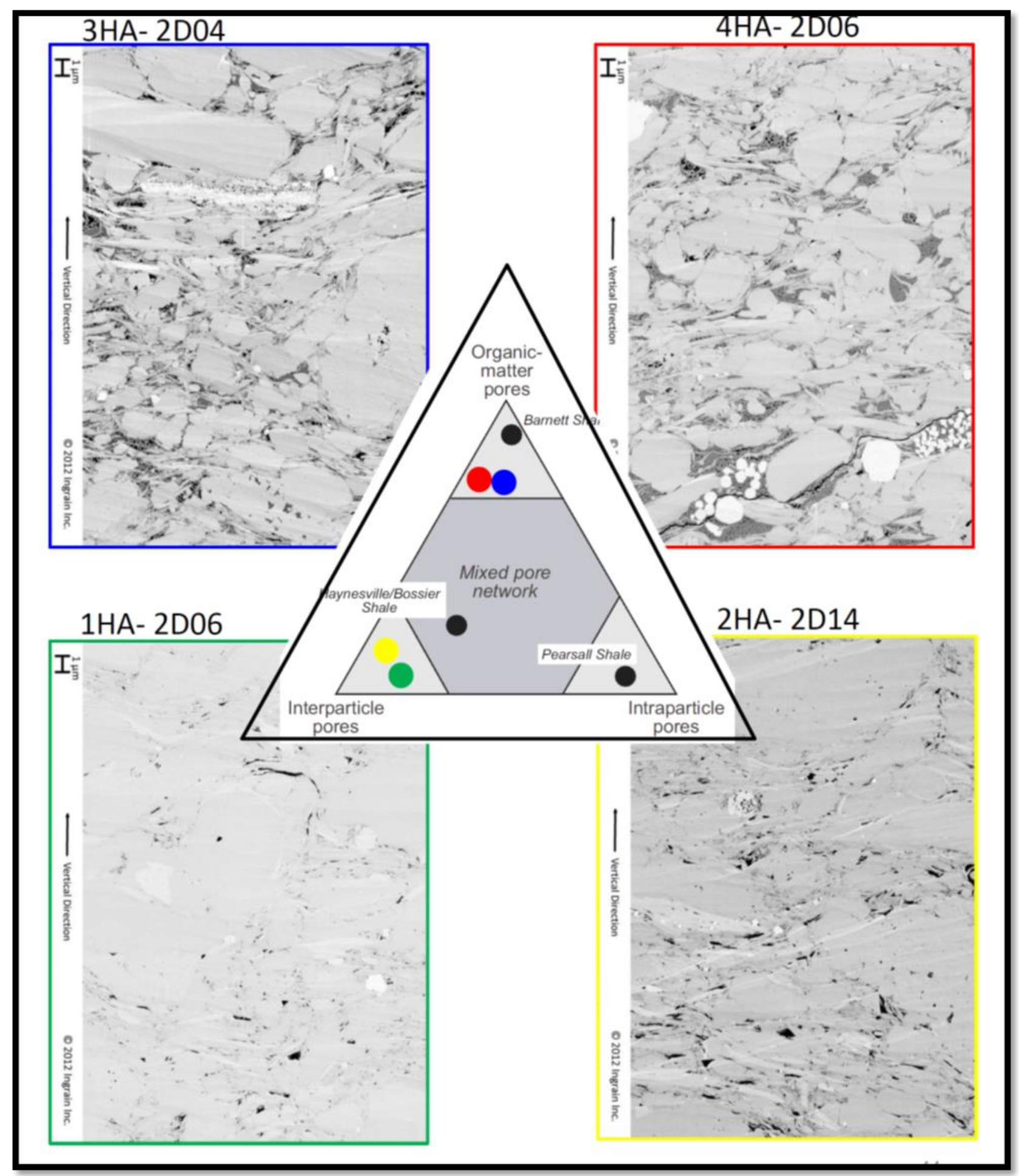

Figure 2.14. Ingrain analysis results show that the Point Pleasant is dominated by interparticle pores and organic matter pores. Interparticle pores are more common in the upper Point Pleasant (1HA and 2HA), while organic matter pores are more common in the lower Point Pleasant (3HA and 4HA). The organic matter pore types makes the Point Pleasant similar to the pore types of the Barnett Shale. 
The Utica Shale interval for the Palmer core is represented as a black-grey calcareous, silty shale, interbedded with light-grey fossiliferous limestone. The formation contains thin, normally graded beds as it transitions from fossiliferous limestone to calcareous silty shale or marlstone. Scour marks are found at the base of depositional surfaces (Figure 2.15). Fossiliferous portions are dominated by graptolites, trilobites, ostracod carapaces, articulated brachiopods, gastropods, crinoid ossicles, and are occasionally bioturbated. In thin section, these fossil fragments can be seen aligned parallel to bedding (Figure 2.16).

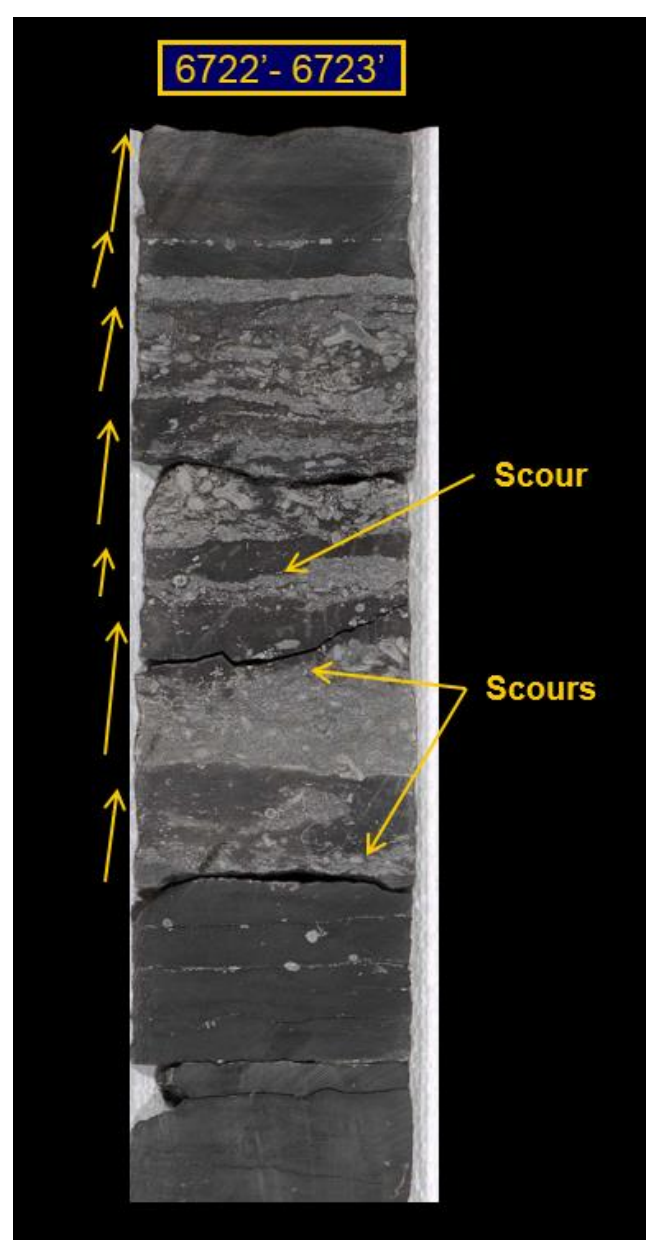

Figure 2.15. Scour marks are found at the base of depositional sequences within the Palmer core's Utica Shale. 


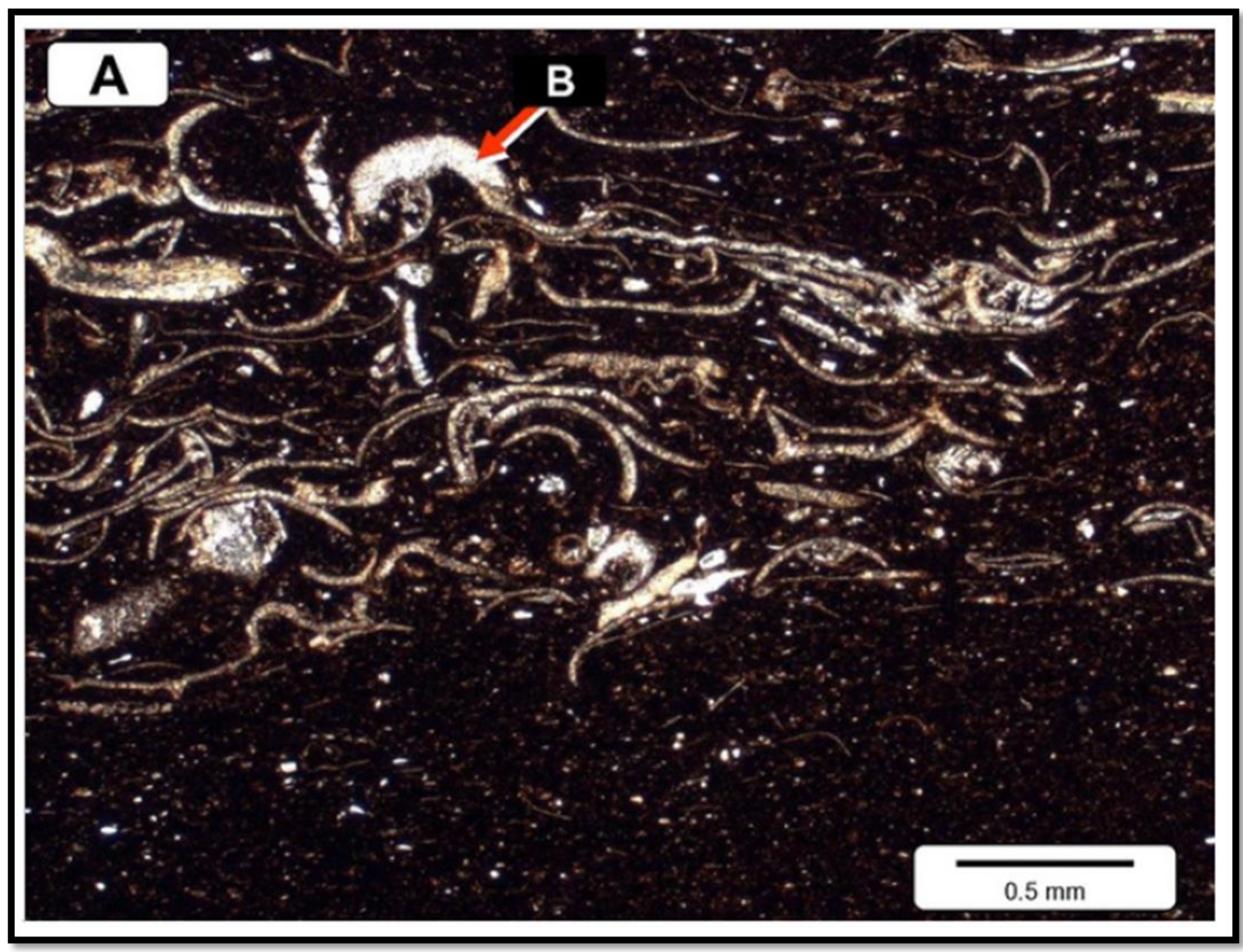

Figure 2.16. Thin section of the Palmer's Utica Shale taken at 6,772.00 feet. Dark organic calcareous siltstone is intercalated with argillaceous, bioclastic limestone. Ostracod carapaces (curved shells) and brachiopod (B) fragments are visible 


\section{Point Pleasant Formation}

The entire Point Pleasant Formation was available for examination from the Palmer core. It is described as an organic-rich formation, interbedded with dark-grey argillaceous limestone and light-grey fossiliferous limestone. The formation displays fine planar laminations with erosional scour marks at the base of depositional surfaces and bioturbation consists of burrows containing reworked skeletal material, suggesting the presence of turbidite sequences (Figure 2.17). The Point Pleasant displays additional evidence for turbidite deposits, which are graded sequences composed of skeletal grainstones at the depositional base. The fossiliferous limestone portions are dominated by fragmented brachiopods, echinoderms, bryozoans, and ostracods carapaces (Figure 2.18).

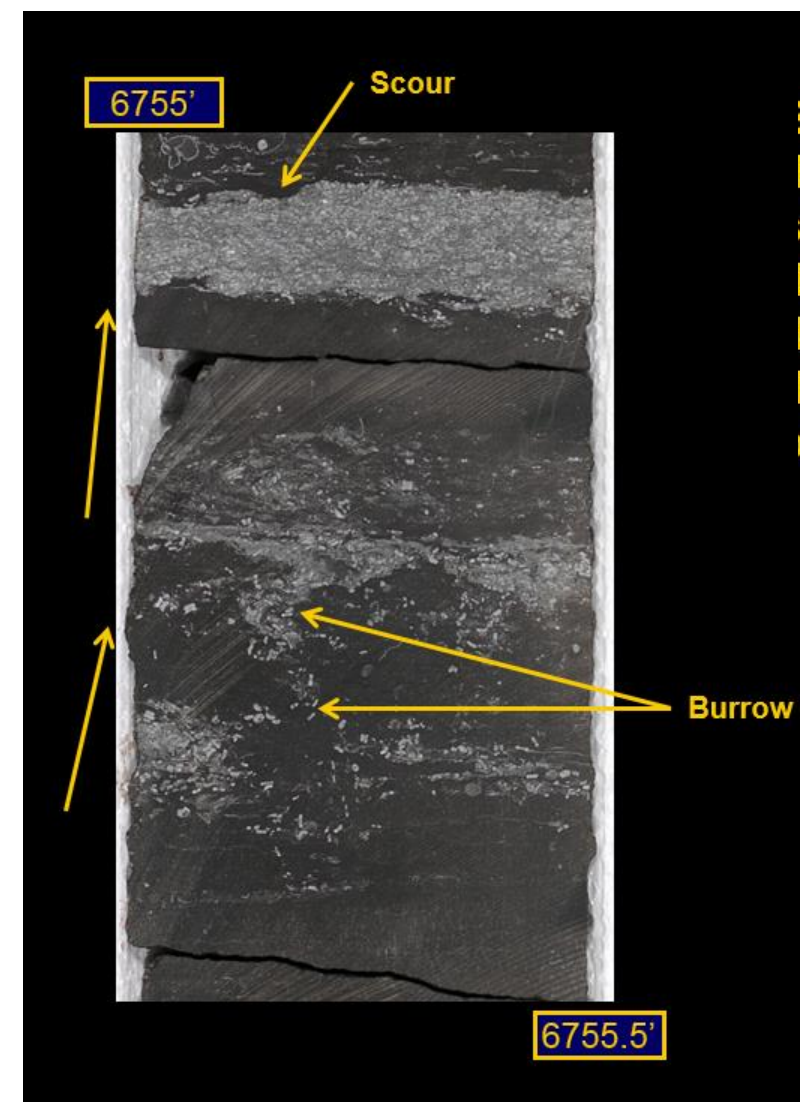

Figure 2.17. Scour marks can be found within the Palmer's Point Pleasant Formation representing the base of depositional sequences. Bioturbation is also present in the core and shows the reworking of skeletal debris within burrows. 


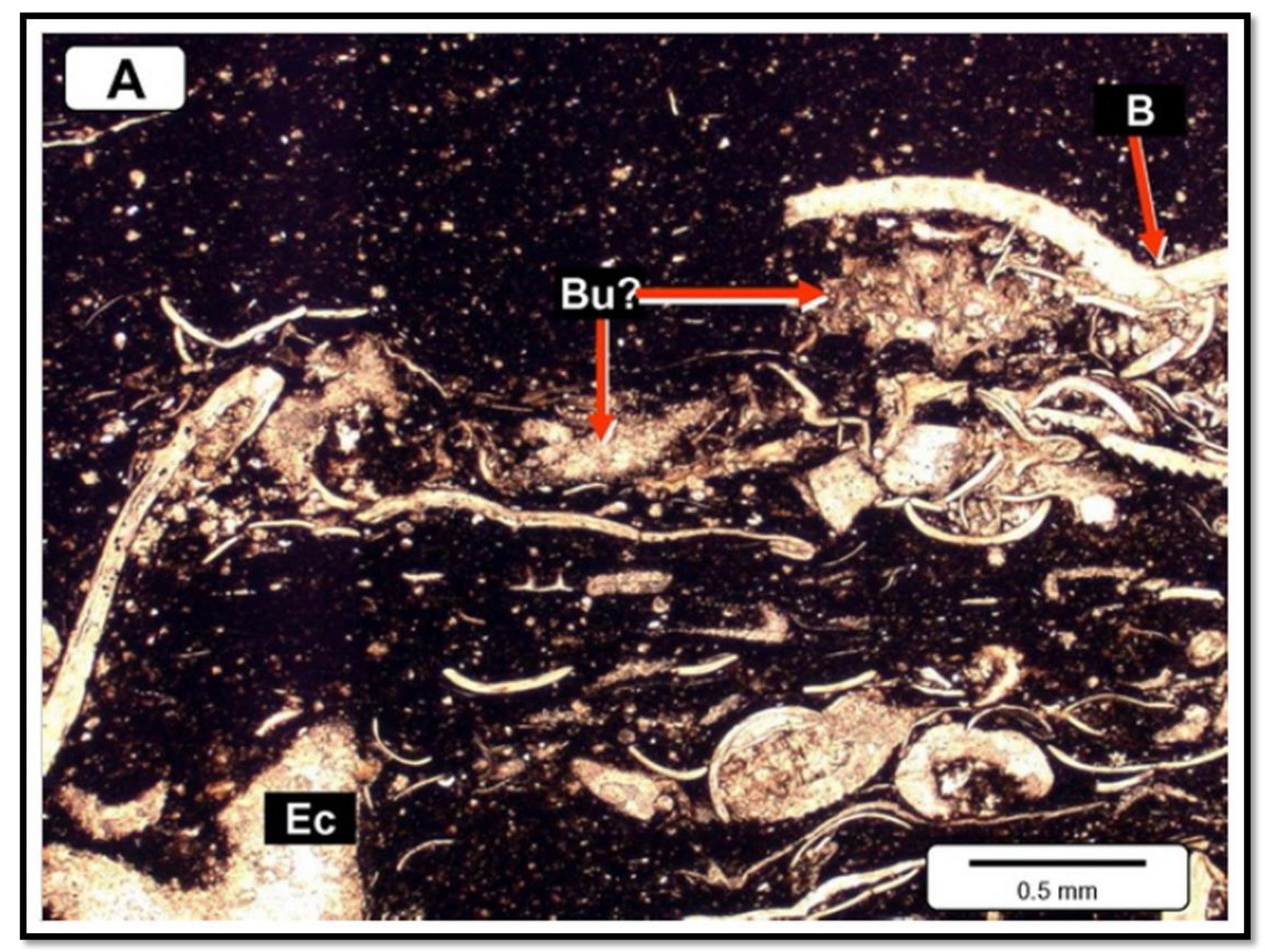

Figure 2.18. Thin section of the Palmer's Point Pleasant Formation taken at 6,823.50 feet. This sample is dark, organic-rich, burrowed, argillaceous calciclastic marlstone. What appears to be lenticular compacted burrows (Bu?) composed of detrital quartz and calcite grains are apparent. Brachiopod (B), echinoderm (Ec), and ostracod (curved carapace) fragments are visible. 


\section{Trenton Limestone}

The upper Trenton Limestone, including the Lexington and Logana submembers were available for core analysis. The Lexington-Trenton interval is represented by grey fossiliferous and calciclastic limestone, interbedded with black-grey calcareous shale and argillaceous limestone. Thin beds of fining upward fossiliferous limestone are predominately found within the Lexington and Logana submembers. Throughout the entire interval, the formation contains planar to wavy laminations, rip-up clasts, calcite and pyrite nodules, starved ripples, and bioturbation (Figure 2.19). Between the calcareous shale and the fossiliferous limestone, sharp erosional contacts were noted. The fossiliferous limestone portions are dominated by fragmented brachiopods, bryozoans, ostracods, and crinoid ossicles (Figure 2.20). As depth increases within the Trenton Limestone, the composition moves from a dark organic-rich argillaceous limestone (Figure 2.20) to packstones and grainstones, composed almost entirely of calcite (Figure 2.21). 


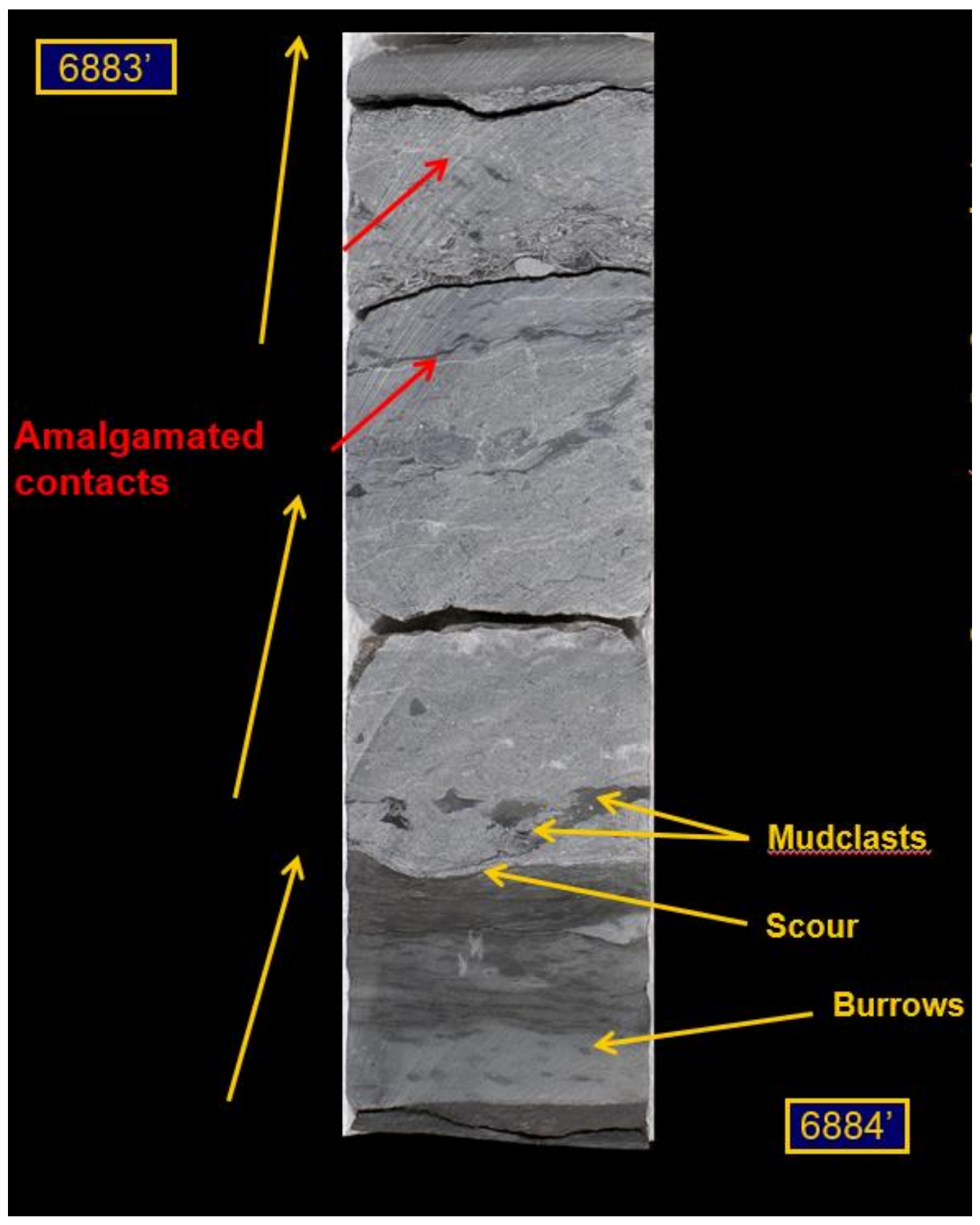

Figure 2.19. The Palmer core's Trenton interval contains evidence for mudclasts, scour marks, and burrows in localized locations. Sequences of amalgamated contacts are also present. 


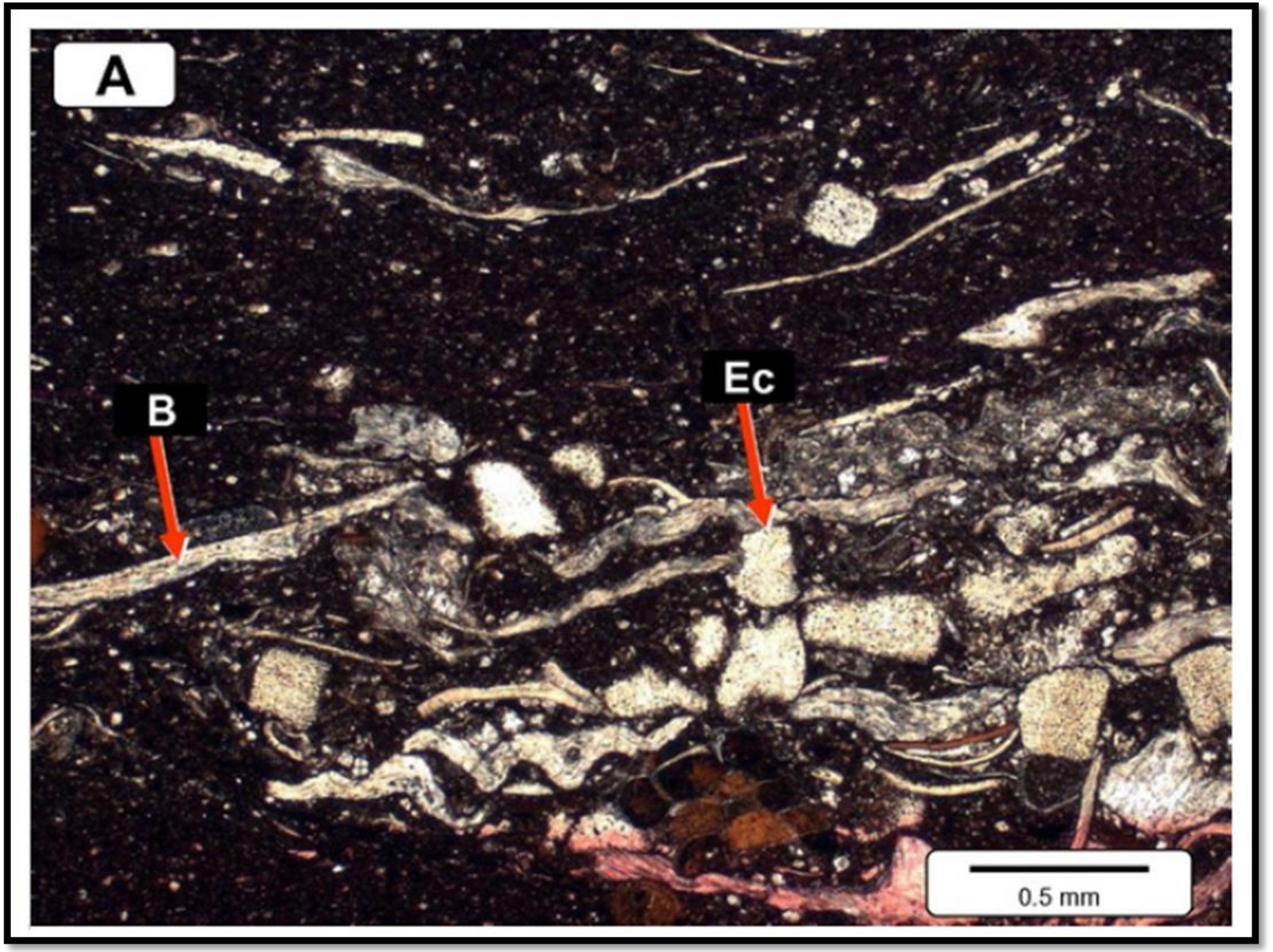

Figure 2.20. Fragments of echinoderms (Ec), brachiopods (B), and ostracods (curved carapace) are visible in this dark organic-rich, argillaceous limestone taken within the upper Trenton Limestone of the Palmer core at 6,862.50 feet. Within this sample, the clay content for the upper Trenton is $28.1 \%$ with a calcite content of $52.3 \%$. 


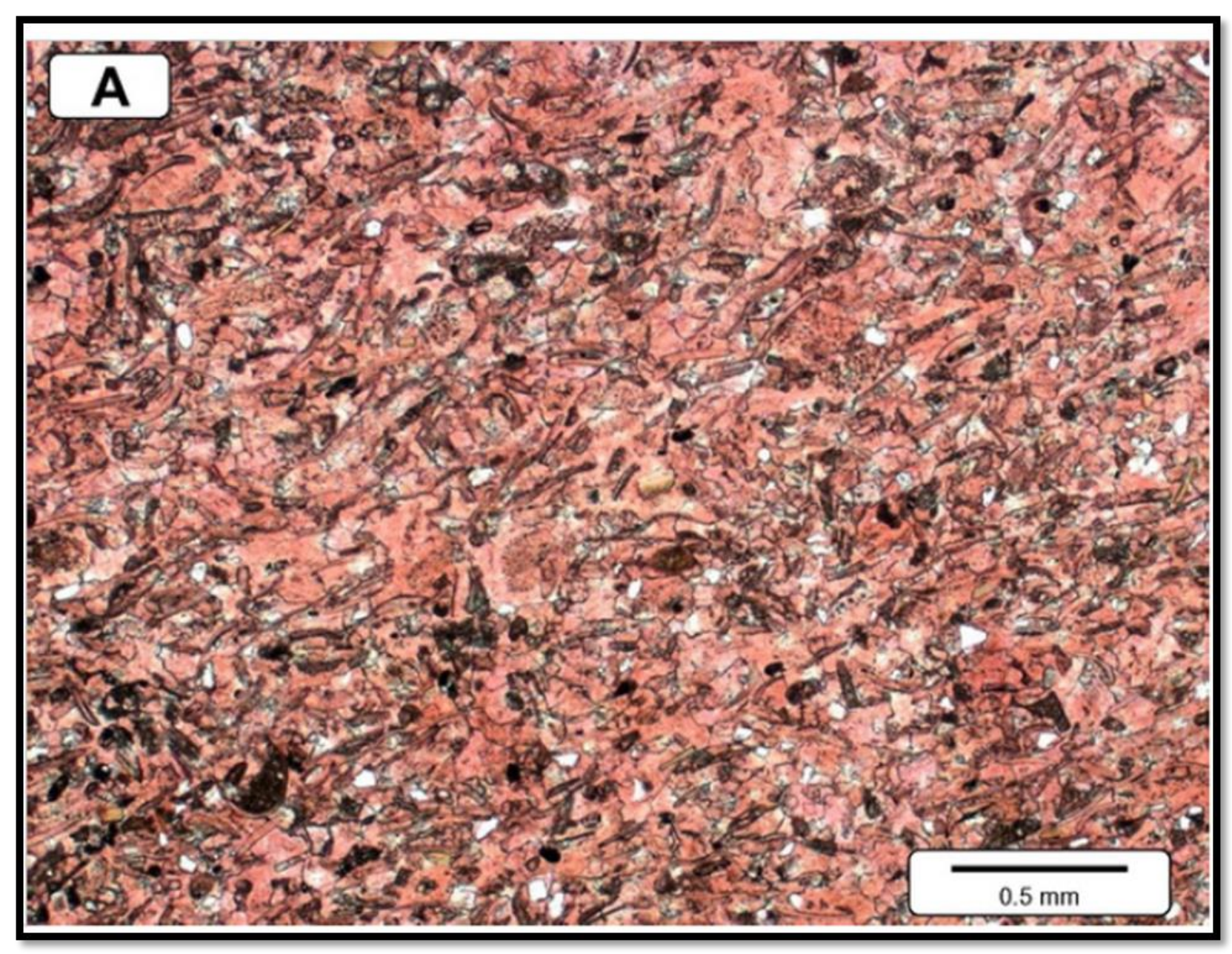

Figure 2.21. Thin section of the Trenton Limestone taken near the bottom of the Palmer core at 6,887.50 feet. This grainstone is composed of recrystallized fossil fragments cemented by micrite and calcite spar. Skeletal grains, primarily brachiopod fragments, are the allochems in this grainstone and are the most abundant bioclasts. Calcite content within this sample is $92.1 \%$ and is visibly noted by the red appearance brought on by Alizeran Red-S staining. Clay content has been diminished to $2 \%$. 


\section{Lithofacies Correlation}

Upon completion of the core analysis, a set of logs was created in Petra to represent the observed lithologies. By further subdividing the mineralogy and lithologies logs based on the Mohawkian and Cincinnatian third-order sequences, trends become apparent (Figure 2.22).

TSTs are marked by relative rises in clay content and decreases in carbonate content due to increases in deltaic influence. Inversely, RSTs are marked by relative decreases in clay content and increases in carbonate content. Additionally, quartz content can be seen increasing during the TSTs and decreasing during the RSTs. Then, pyrite is only present during the M6 sequence. Pyrite was observed increasing during the TST and decreasing during the RST. Similarly, trends were also apparent when lithologies were compared to the third-order sequences. The M5 RST contains fossiliferous limestone, which abruptly changes to argillaceous limestone at the M5 SB and continues through the M6 TST and RST. This abrupt change is brought on by a potential unconformity between the underlying Trenton Limestone and the overlying Logana submember. Finally, at the M6 SB there is another abrupt change in lithology brought on by a potential unconformity. Here, lithology changes from the argillaceous limestone of the M6 RST to the calcareous shale of the C1 TST. 


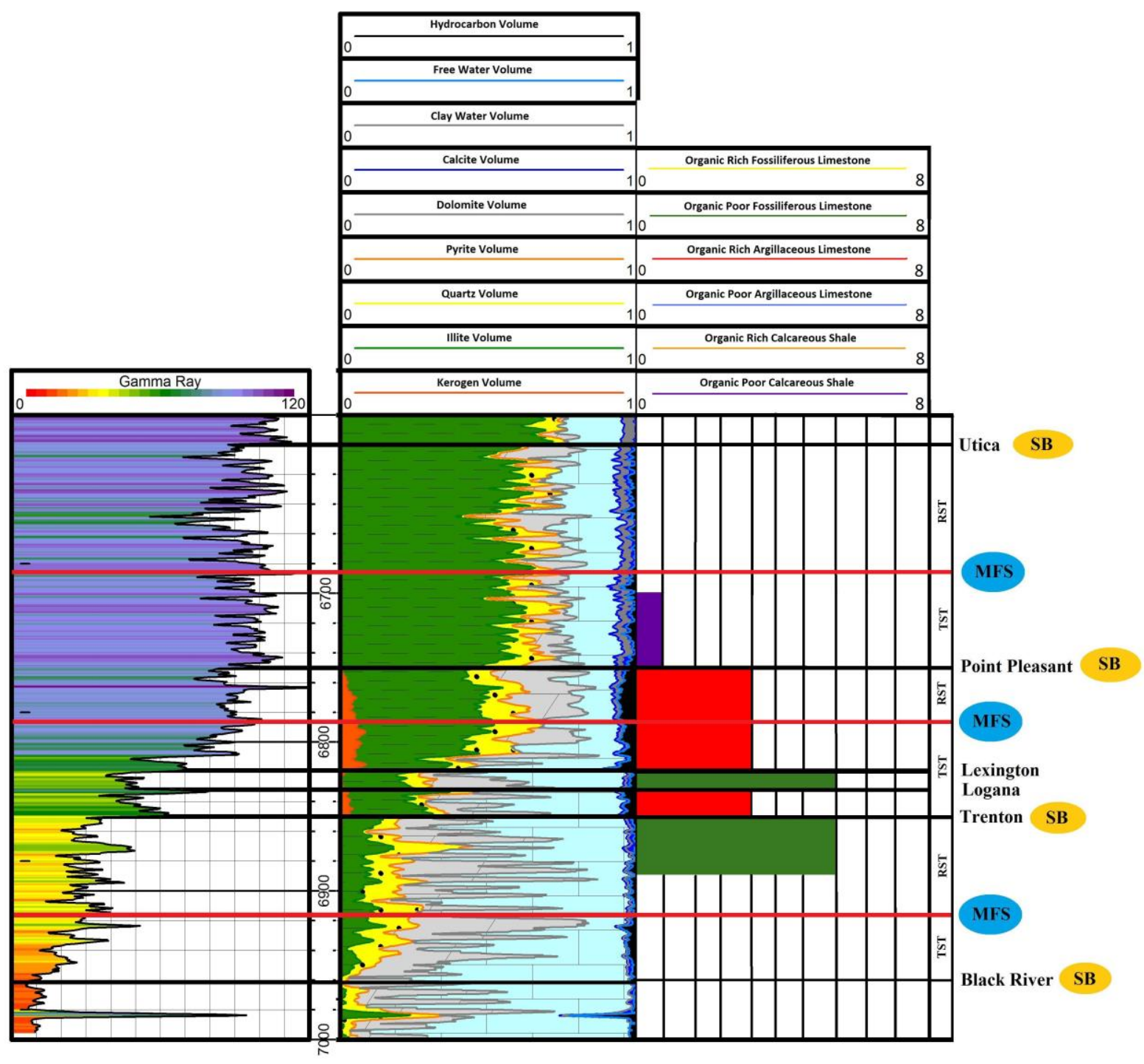

Figure 2.22. Well log cross section of the mineralogy composition for the Palmer 44-20 based on mineralogy logs and the lithology log created from core observations. The mineralogy and lithology is compared to the gamma ray log and is subdivided based on the Mohawkian and Cincinnatian third-order sequences. 


\section{Subsurface Well Log Stratigraphy}

Using well logs from Ohio, several cross sectional basin models were created in order to identify changes in lithology and composition throughout the state and the study interval (Figure 2.23).

Basin model observations show that the M5 sequence is a relatively clean carbonate (low gamma ray) sequence throughout the entire state, but may show interbedded layers of slightly higher gamma ray limestone in such places as Tuscarawas County in east central Ohio (Figure 2.24 and 2.26). To the east and southeast, the M6 becomes more calcareous at the base and appears to be at a maximum calcareous level within east central Ohio, in counties such as Tuscarawas and Holmes Counties (Figure 2.26 and 2.27). These increases in calcareous content refer to more extensive interbedding of argillaceous and fossiliferous limestones. The C1 sequence refers to the Utica Shale in both western and eastern Ohio. However, the Utica is slightly more clay dominated in northern and western Ohio, as apparent by higher gamma ray (Figure 2.24 and 2.26).

Together, these trends in lithology represent the paleogeography of Ordovician Ohio. To the west, gamma ray values can be seen increasing in the Utica Shale, representing a deepening of sea level with increased clay content (Figure 2.26). Moving to the east and northeast, formation boundaries begin to dip down and gamma ray values increase as the cross sections move across the Point Pleasant and Pennsylvanian sub-basins, respectively. Finally near to the northeast corner of Ohio, gamma ray values begin to increase and a structural high becomes apparent in the basin models, indicating the presence of the Trenton platform (Figure 2.25). 


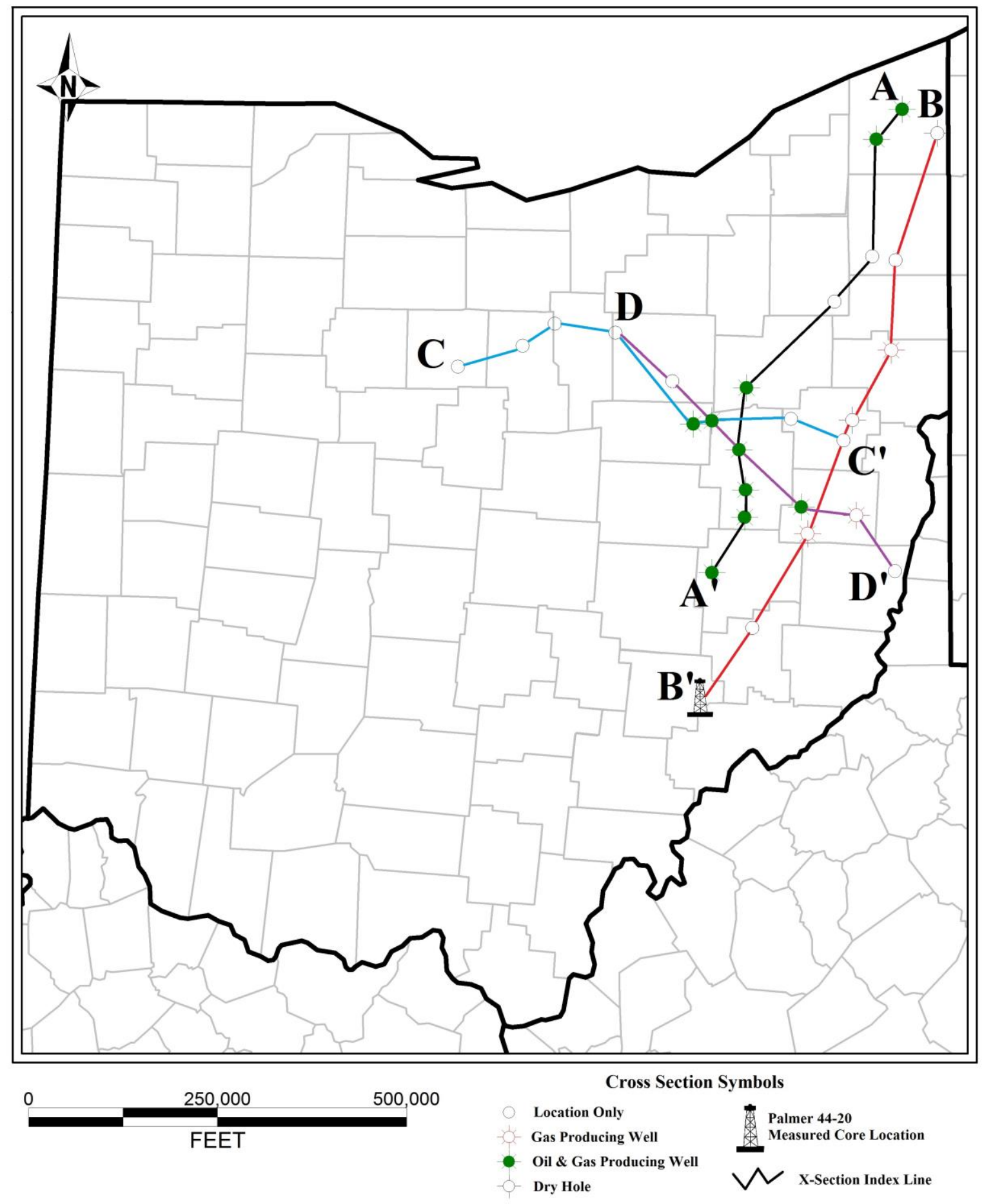

Figure 2.23. Map of the study area in eastern Ohio, showing locations of cross section index lines used to well log stratigraphy basin wide analysis. 


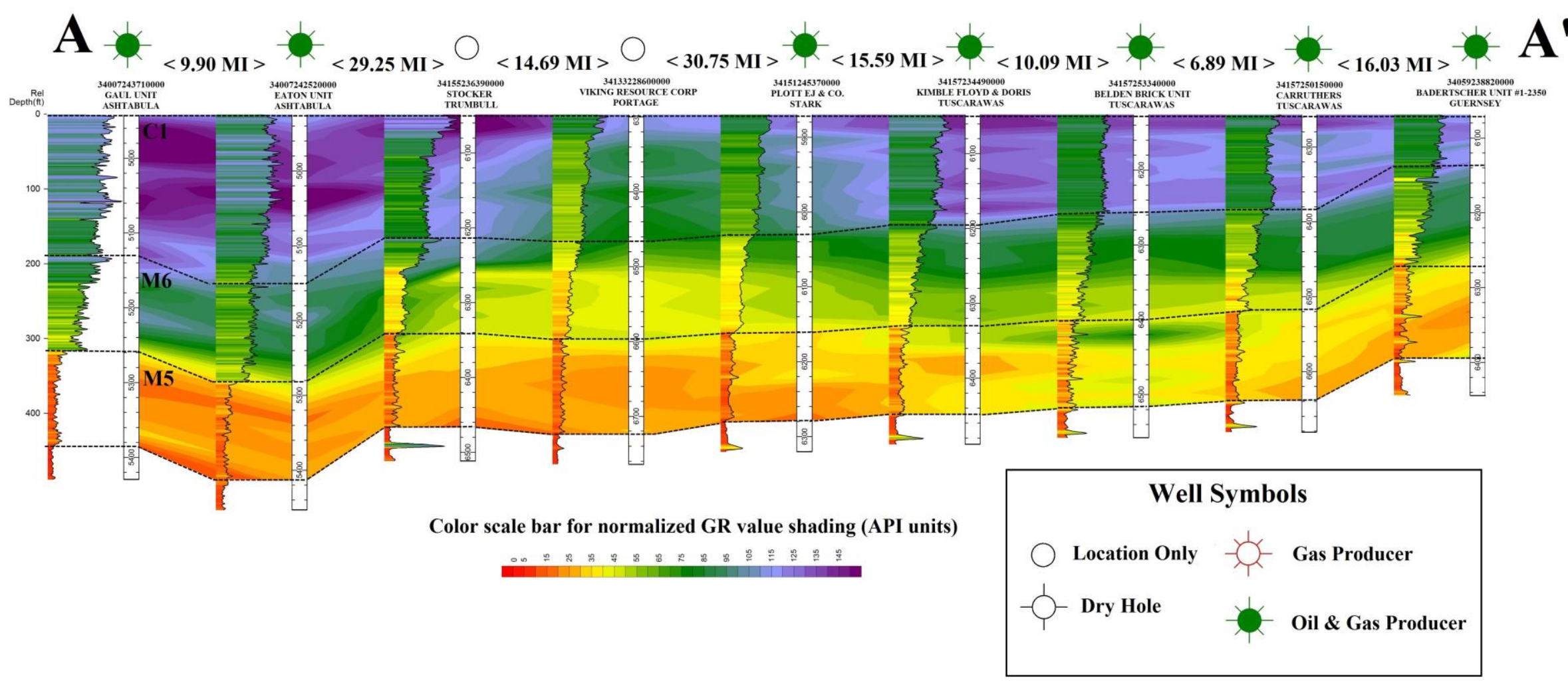

Figure 2.24. Basin cross section A-A' representing northern Ohio (Ashtabula County) to southern Ohio (Gurnsey County). Deepening of the formations and increased gamma ray values within Ashtabula County represent the Pennsylvanian sub-basin, while increased gamma ray influence within Tuscarawas and Gurnsey counties indicate the Point Pleasant sub-basin. 


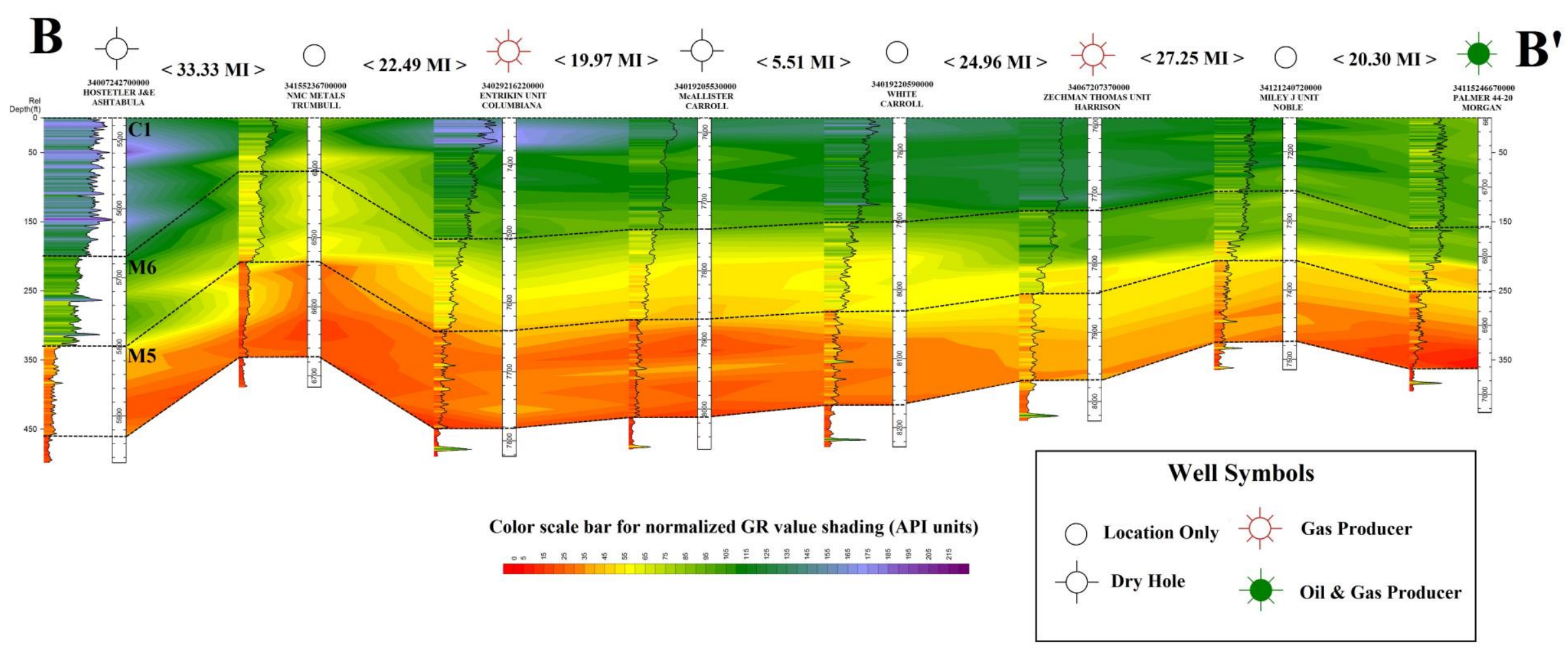

Figure 2.25. Basin cross section B-B' representing northern (Ashtabula County) to southern (Morgan County) Ohio. The Trenton Platform can be identified as a structural high within Trumbull County's Trenton-Utica interval, which is dominated by lower gamma ray and a higher calcareous influence. Gamma ray values then increase as the cross section moves south into the Point Pleasant subbasin of Columbiana, Carroll, Harrison, Noble, and Morgan counties. Lower gamma ray within Morgan County and the Palmer 44-20 may represent influence from the southern Lexington Platform. 


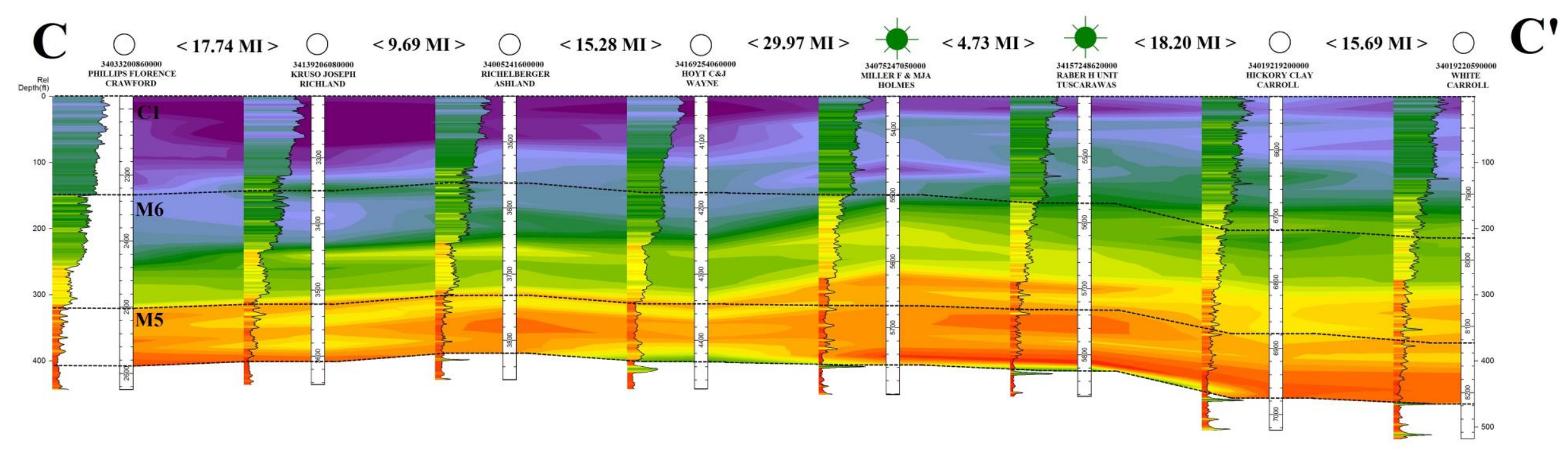

Color scale bar for normalized GR value shading (API units)

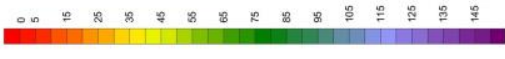

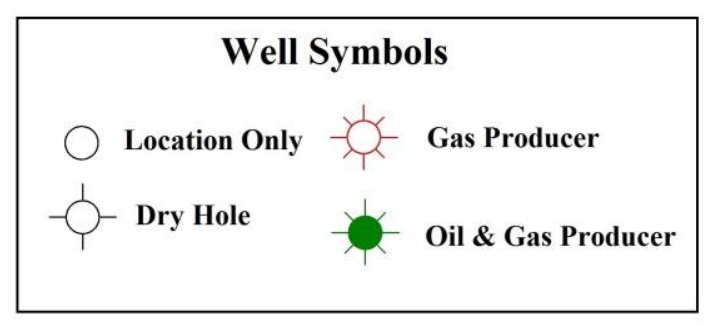

Figure 2.26. Basin cross section C-C' representing western (Crawford County) to eastern (Carroll County) Ohio. High gamma ray values of the Utica and Point Pleasant of Crawford, Richland, Ashland, and Wayne counties represent a deepening of water and an increase in clay influence. Moving from west to east, formations decrease in depth, representing the transition from the intercontinental sea of western Ohio to the Point Pleasant sub-basin of eastern Ohio. 


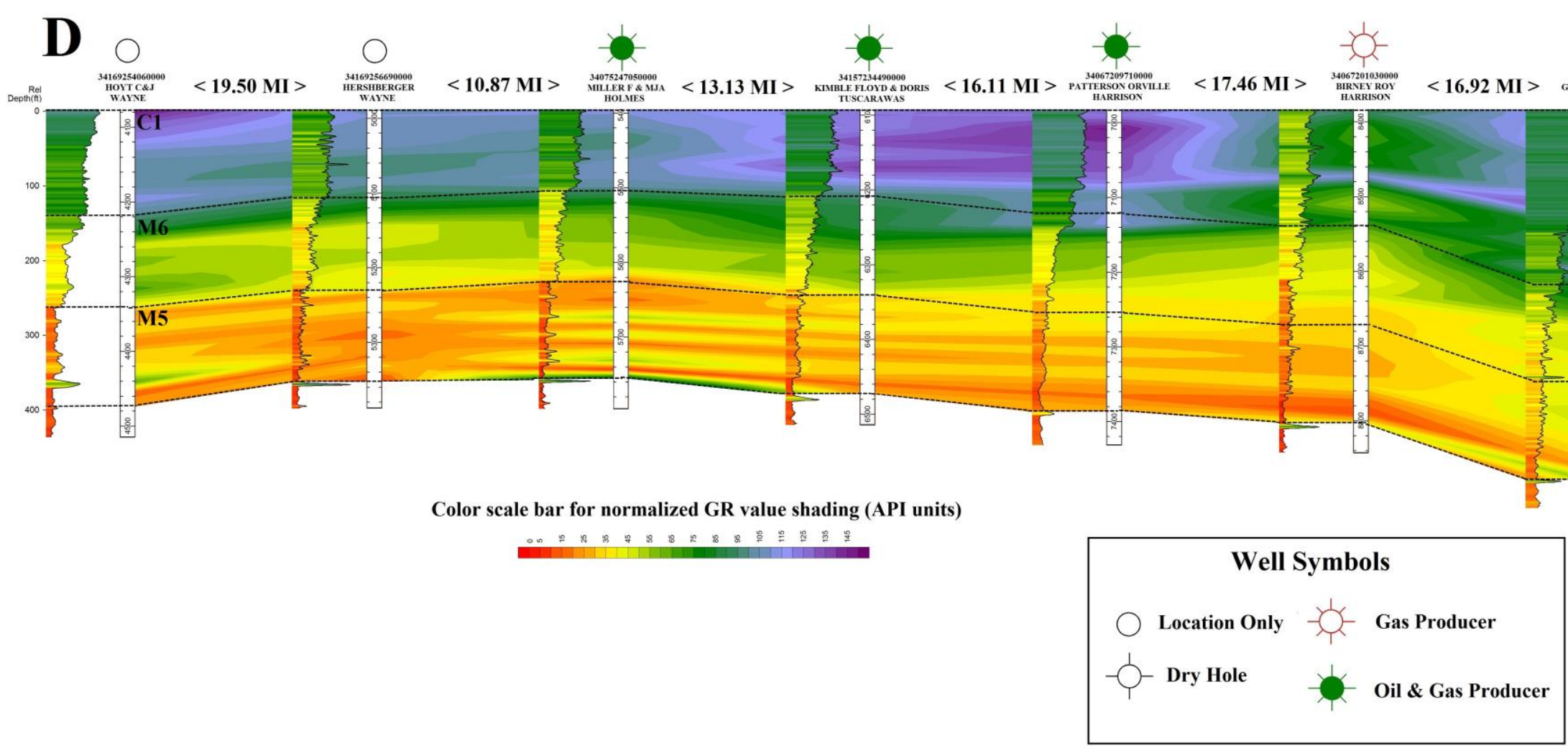

Figure 2.27. Basin cross section D-D' representing northwest (Wayne County) to southeast (Belmont County) Ohio. Moving from northwest to southeast, formations decrease in depth, representing the transition from the intercontinental sea of western Ohio to the Point Pleasant sub-basin of eastern Ohio. 


\section{Discussion - Depositional Environment}

Upon careful observations of the Palmer core, it was determined that the Trenton-Utica interval represents a transgressive sequence. This environment was most likely a carbonate shelf to middle ramp environment, 100 feet (30 meters) deep or less (Figure 2.28). The higher clay content in both the Utica and Point Pleasant represent increased deltaic influence and perhaps a more distal portion of a carbonate ramp, while higher carbonate content in the Trenton represents a shallower carbonate shelf environment. Collectively, this model would support a transgressive sequence from the Trenton Limestone to the Utica Shale.

The abundance of fossils present in the limestone suggests water that was shallow, exposed to sunlight, and well oxygenated. However, the fragmented fossil debris and the storm bedding suggest an environment above storm wave base and frequented by storm generated currents. During these storm events, sediments and skeletal material may have been amalgamated and transported down the carbonate ramp into a deeper marine environment in turbidity currents. This would have resulted in the deposition of fragmented skeletal debris, stacked normal graded tempestites, and erosional surfaces at the base of depositional sequences, above which coarse fossiliferous limestone is common.

This contradicts the previously held notion that shales must be deposited in calm, warm environments. However, flume studies performed by the Indiana University Shale Research Lab have demonstrated that shales do not need to be deposited in low energy settings to form their characteristic fine planar laminations (Schieber et al., 2007). During shale flume studies, clay particles were seen forming floccules, of which the largest and most stables floccules were transported in bedload. Floccules were seen forming regardless of salinity in a wide range of different clay minerals. As flow velocity decreases beneath the critical flow velocity, floccules accumulate into migration ripples. The critical velocity is dependent on the suspended sediment 
concentration, but typically was seen between $35-20 \mathrm{~cm} / \mathrm{s}$. Ripples then migrate, getting deposited on top of other ripples, forming beds. Compaction of these beds results in thin beds that look like finely laminated shales in the rock record (Schieber et al., 2007).

The results of these experiments suggest that floccule ripples of mud are not much different than sand ripples, with the exception of the amount of water and that migration speed is slower due to the cohesive forces of clay. This leads to the idea that many ancient shales may have been deposited in swift moving water, rather than low energy or suspension environments.

Despite the evidence for an environment rich with life, this area may have been subjected to seasonal anoxia due to frequent algal blooms. During the 'Great Ordovician Biodiversification Event,' phytoplankton widely diversified (Servais et al., 2008, 2009). The Ordovician was a time marked by high sea level and continental separation, volcanic and orogenic activity, and high atmospheric carbon dioxide. These conditions allowed for more available ecospace, deposition of nutrients into the oceans, and a warmer greenhouse climate. All of these factors contributed to the biodiversification of phytoplankton (Servais et al., 2008, 2009). With such a tremendous evolution of phytoplankton, large algal bloom may have formed. Similar to today, if large enough, these blooms may have caused seasonal anoxia as they decomposed and reduced the oxygen dissolved in water. 


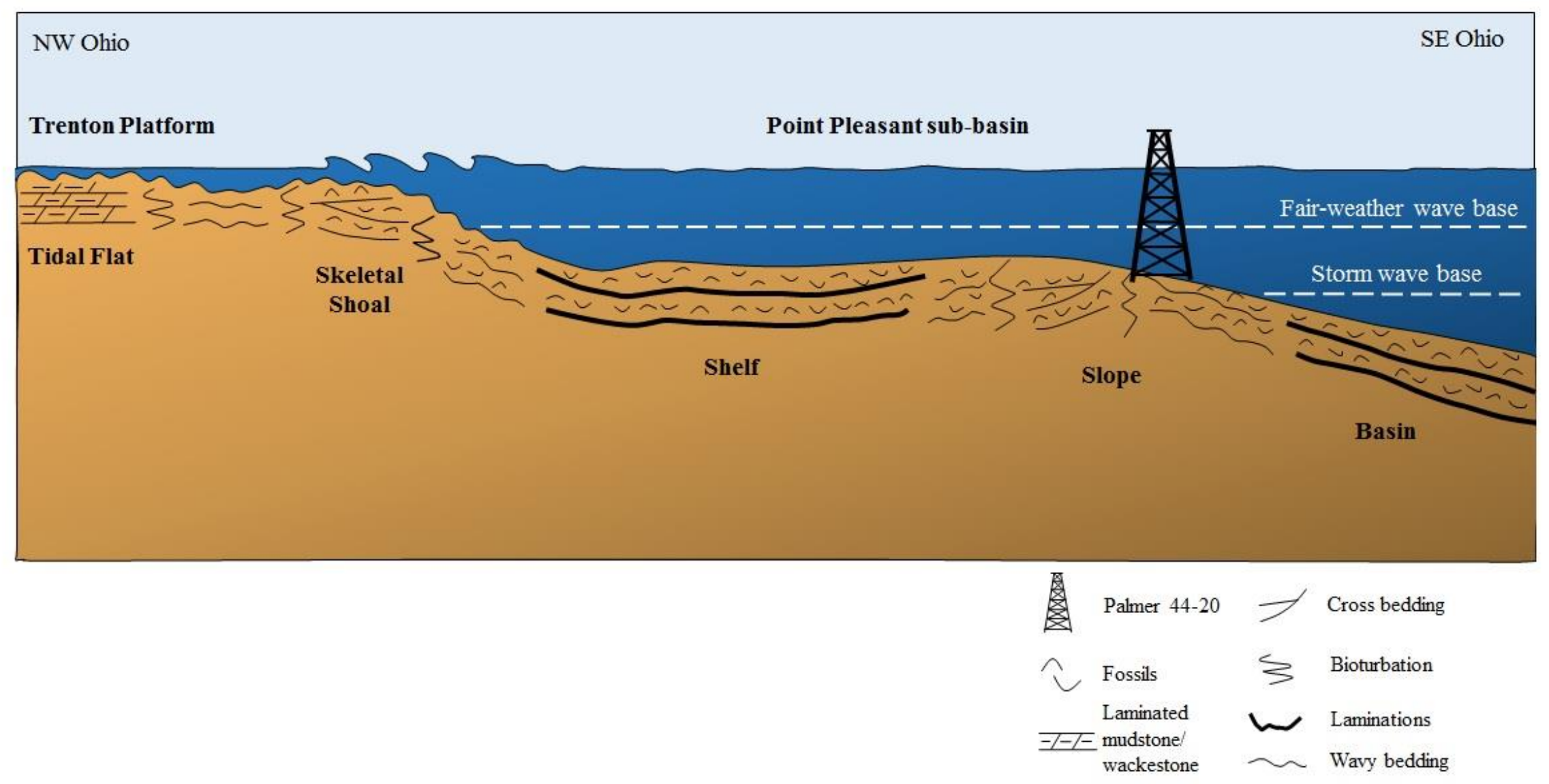

Figure 2.28. Depositional environment for the Point Pleasant Formation, modified from Pope and Read (1997). The environment for the Palmer well is interpreted to be a carbonate shelf to middle ramp environment, above storm wave base where the sediment deposited would be frequently disturbed by storm currents. 


\section{Chapter 3: Total Organic Carbon Modeling}

Technological advancements in recent years in horizontal drilling and hydraulic fracturing techniques have shifted focus in Ohio from conventional reservoirs to unconventional, organically rich shale reservoirs. Total organic content (TOC) is the main component for shale gas systems, and thus is an important factor to model when evaluating a potential reservoir. This chapter will focus on various methods used to model TOC and will then determine organic-rich intervals within the Palmer, as well as determine where Ohio's Point Pleasant Formation is most organically rich.

\section{Methodology}

In order to determine where organic-rich zones reside within the Point Pleasant, core and well log data were integrated together using several petrophysical equations in order to model TOC. These methods include gamma ray, bulk density, the Passey et al. (1990) method, and the Schmoker (1979 and 1980) method. The results from each of these tests were then compared against TOC data taken from the core in order to evaluate any correlation. The four methods were then compared based on their correlation coefficients and the best methods were then extrapolated in order to generate a regional picture for TOC richness within the state of Ohio.

\section{Gamma Ray Correlation}

Boyce (2010) concluded that organic-rich zones within the Marcellus can be identified by using the gamma ray log due to the Marcellus' organic material being rich in uranium. Gamma ray was cross plotted against core TOC data. Little success was found using this method within the Trenton-Utica interval (Figure 3.1). This will be discussed in more detail later in this chapter. 
The next method involves creating a cross plot of the bulk density (RhoB) log and comparing it to TOC values. When organic material is added to rocks, the overall density will decrease. In the case of the Point Pleasant Formation, the density of the carbonate rock material alone would be approximately $2.7 \mathrm{~g} / \mathrm{cc}$, however when organic material is added, density values of less than $2.6 \mathrm{~g} / \mathrm{cc}$ are generally regarded as organic-rich intervals. When TOC is compared to the bulk density, a strong to very strong correlation is found between them demonstrating that the most organic-rich intervals fall within the lower Point Pleasant Formation and Logana submember (Figure 3.2). 


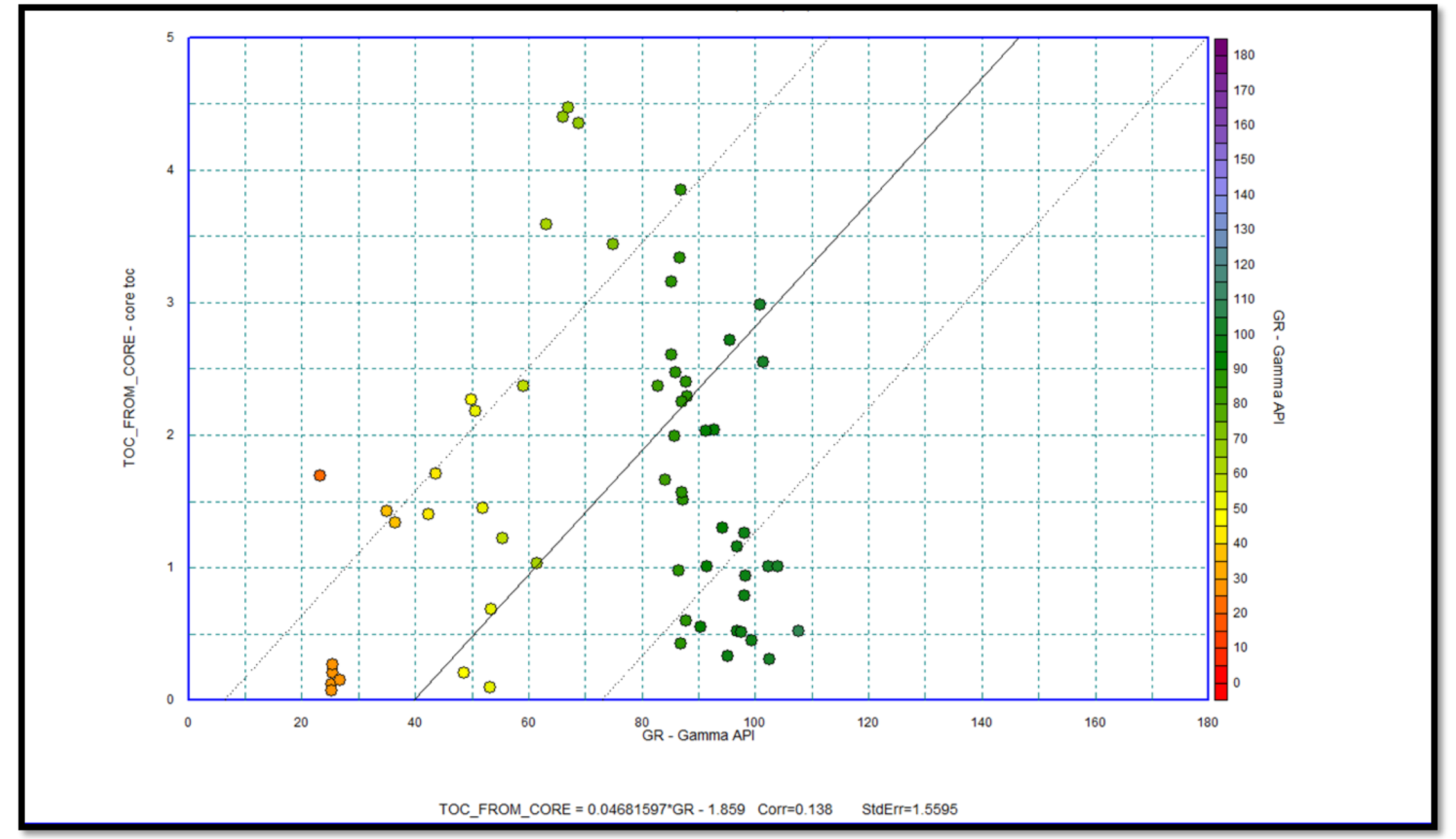

Figure 3.1. Gamma ray correlation graph depicting the correlation between core TOC data and gamma ray for the Trenton-Utica interval. A correlation of 0.138 was found, representing no relationship between the TOC data and gamma ray values. 


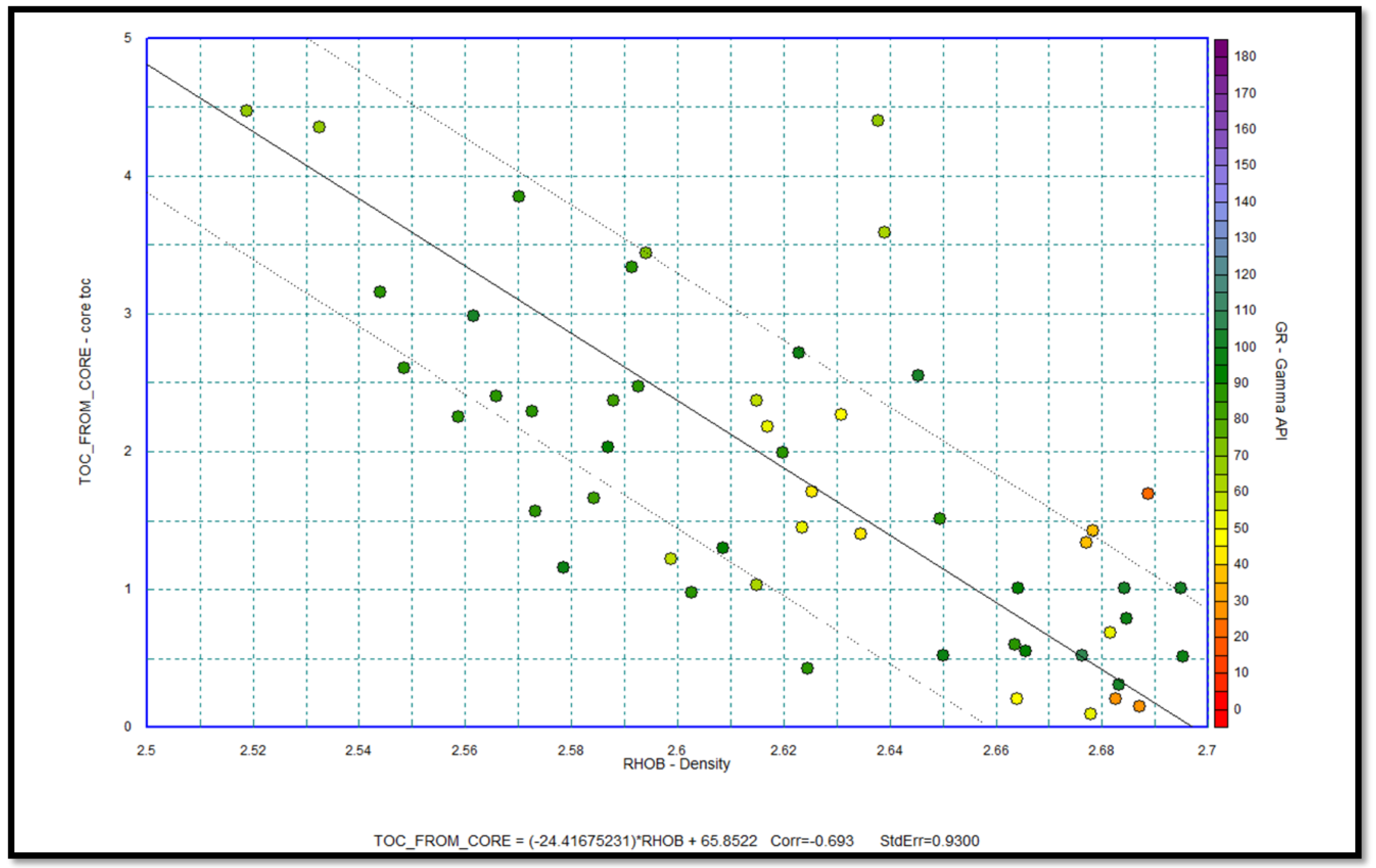

Figure 3.2. Bulk density correlation graph depicting the correlation between the core TOC data and RhoB for the Trenton-Utica interval. A correlation of -0.693 was found, representing a strong relationship between the two. 


\section{Passey Method}

The methodology of Passey et al. (1990) was also used for TOC modeling. This was completed by overlaying and base-lining the resistivity and sonic logs to calculate $\Delta \log \mathrm{R}$ (Figure 3.3). The two curves are overlain in water saturated, or hydrocarbon-poor zones. In hydrocarbon-rich zones, there is a separation between the two curves, reflecting increased resistivity in response to hydrocarbon presence and increased apparent porosity due to the low velocity of kerogen. The magnitude of the separation between the sonic and resistivtiy curves can be used to eastimate TOC in reservoirs.

The algebraic expression for calculating $\Delta \log \mathrm{R}$ from the sonic resistivity overlay is

$$
\Delta \log R=\log \left(\frac{\mathrm{R}}{\mathrm{R} \_ \text {baseline }}\right)+0.02 *\left(\Delta \mathrm{t}-\Delta \mathrm{t}_{\text {baseline }}\right)
$$

where $\Delta \log \mathrm{R}$ is the curve separation measured from the overlaying of resistivity and sonic $\operatorname{logs}, \mathrm{R}$ is the resistivity measure in ohm-m by the logging tool, $\Delta \mathrm{t}$ is the sonic measure in microseconds per foot, $\mathrm{R} \_$baseline is the resistivity corresponding to the $\Delta \mathrm{t}$ baseline value when the curves are baselined in non-organically rich shale, and 0.02 is based on the ratio of -50 microseconds per foot per one resistivity cycle (Passey, 1990).

Once calculated, $\Delta \log \mathrm{R}$ can be used to create a log curve for TOC. The equation for calculating TOC in shale from $\Delta \log R$ is

$$
T O C=\triangle \log R * 10^{2.3 .97-0.1688 * \operatorname{LOM}}
$$

where TOC is the total organic content measured in weight percent and LOM is the level of organic matuirty (Passey, 1990). Level of maturity is dependent on each formation and each well's location. Because a set value has yet to be determined using this method for the Point Pleasant Formation, various LOM values were estimated in this study in order to create a Passey 
curve that best fits both the core TOC data with the highest correlation through the Trenton-Utica interval.

Based on the correlation results, a LOM value of 13.0 was chosen for the Trenton-Utica interval, representing wet gas. Althought a LOM value of 14.0 was found to produce a lower standard of error (Figure 3.4), when compared to the well log for TOC from the core, the Passey 14.0 curve appeared to deviate further than when other LOM values were used (Figure 3.5). When the core TOC data is compared to the computed Passey 13.0 curve, the results show the two values overlying one another, thus va lidating the Passey method for TOC modeling within the Point Pleasant (Figure 3.6).

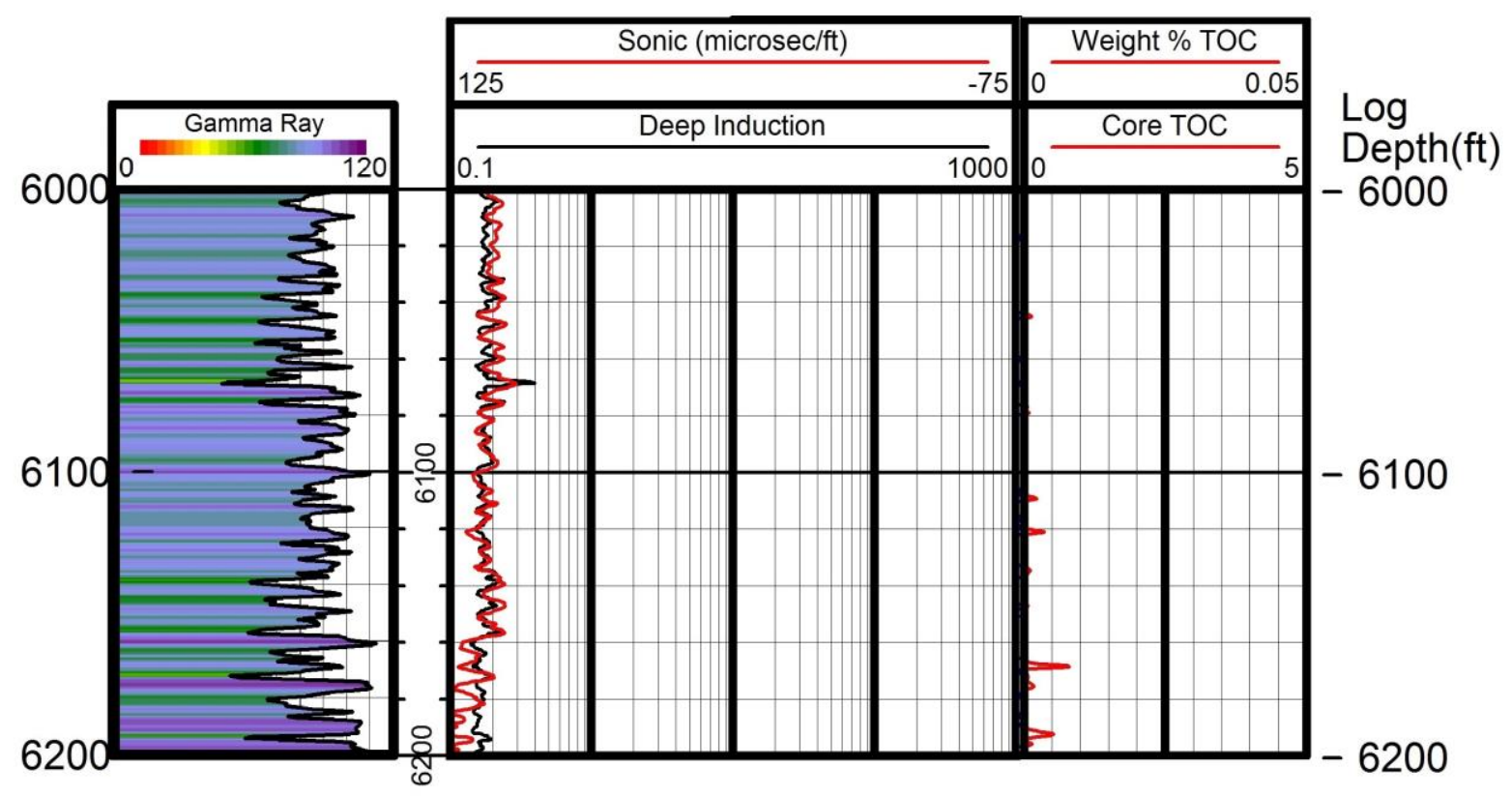

Figure 3.3. In order to determine the delta $\log \mathrm{R}$ values for the Palmer well, the sonic and resistivity logs were overlain in an organic-poor area of the Queenston Shale. Baseline values for the delta $\log \mathrm{R}$ equation were determined from the overlying of these logs. 


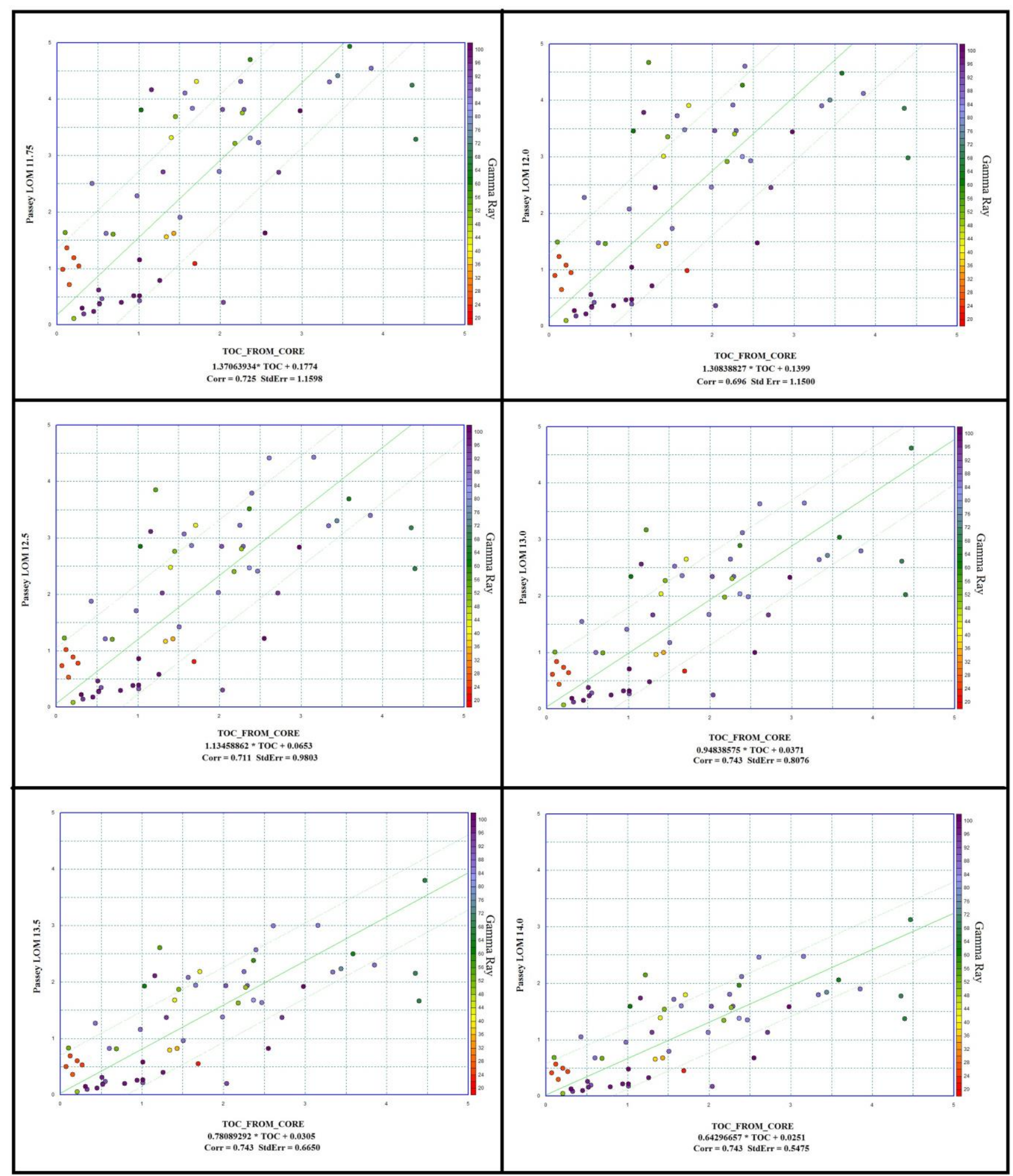

Figure 3.4. Various levels of maturity (LOM) were used in order to calculate the Passey TOC method. The LOM values were compared to core TOC data in order to determine a correlation coefficient. 


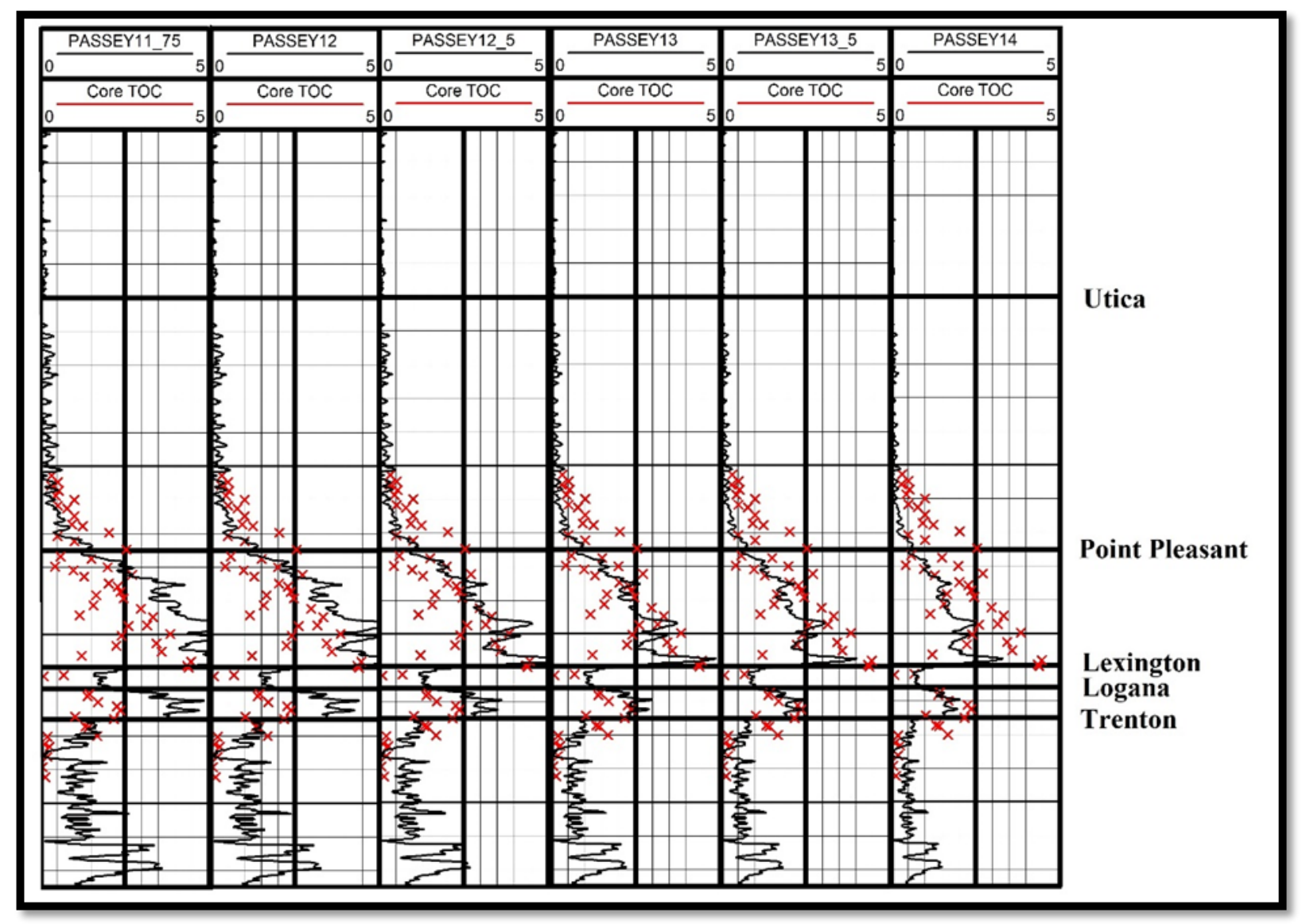

Figure 3.5. Various levels of maturity (LOM) were used to calculate the Passey TOC method. The LOM values were compared to core TOC data as well logs in order find which LOM overlaid the TOC data best. A LOM value of 13.0 was found to produce the best results. 


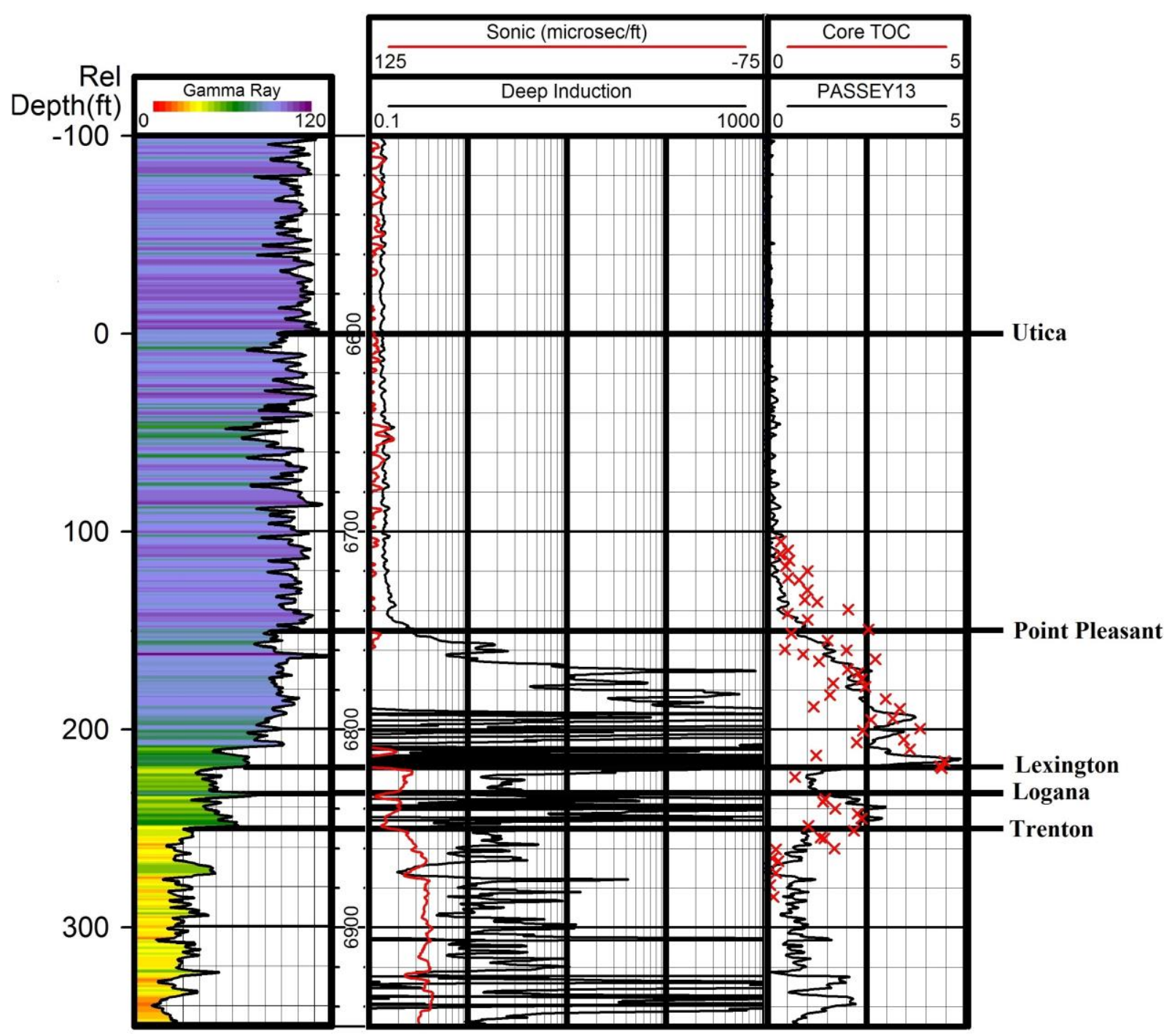

Figure 3.6. Core TOC data is compared to the computed Passey curve in cross section showing a good fit, validating the Passey method for TOC modeling within the Ordovician Point Pleasant. Small variations between the two TOC curves seen above may occur due to inaccuracies during sampling. Additional errors may also be accounted to inconsistencies from converting from core depth to $\log$ depth. 


\section{Schmoker Method}

The final TOC calculation used for modeling is based on an approach for Devonian shale using bulk density logs (Schmoker, 1979; Schmoker, 1980). The Schmoker method was later refined for the Bakken Shale based on the response of the bulk density log to low-density organic material (Schmoker, 1983). The equation for calculating the Schmoker method is

$$
\text { TOC }=(154.497 / \text { RhoB })-57.261
$$

Where RhoB is the bulk density in $\mathrm{g} / \mathrm{cc}$ and TOC is reported in weight percent. This equation assumes a constant composition and porosity throughout the formation and has been refined based on specific environments. When the Schmoker results are compared to the core TOC data, strong to very strong correlations are found and when the log curves are compared they overlay one another, showing that this method can be successful for modeling TOC within Ordovician shales (Figure 3.7 and 3.8). 


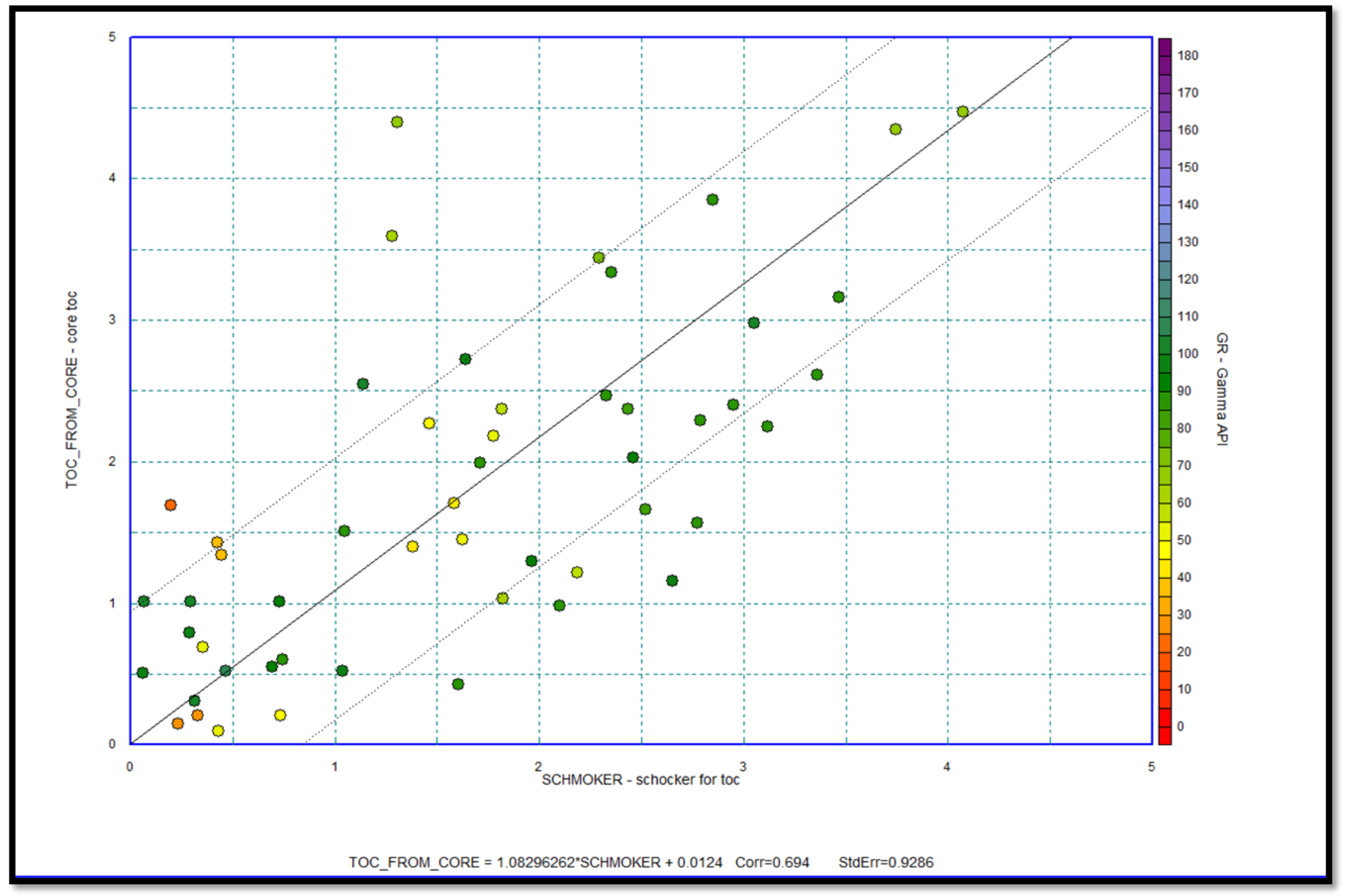

Figure 3.7. Correlation cross plots were created to compare the relationship between core TOC data and the computed Schmoker curve. The results indicate a correlation of 0.694 , representing a strong relationship. 


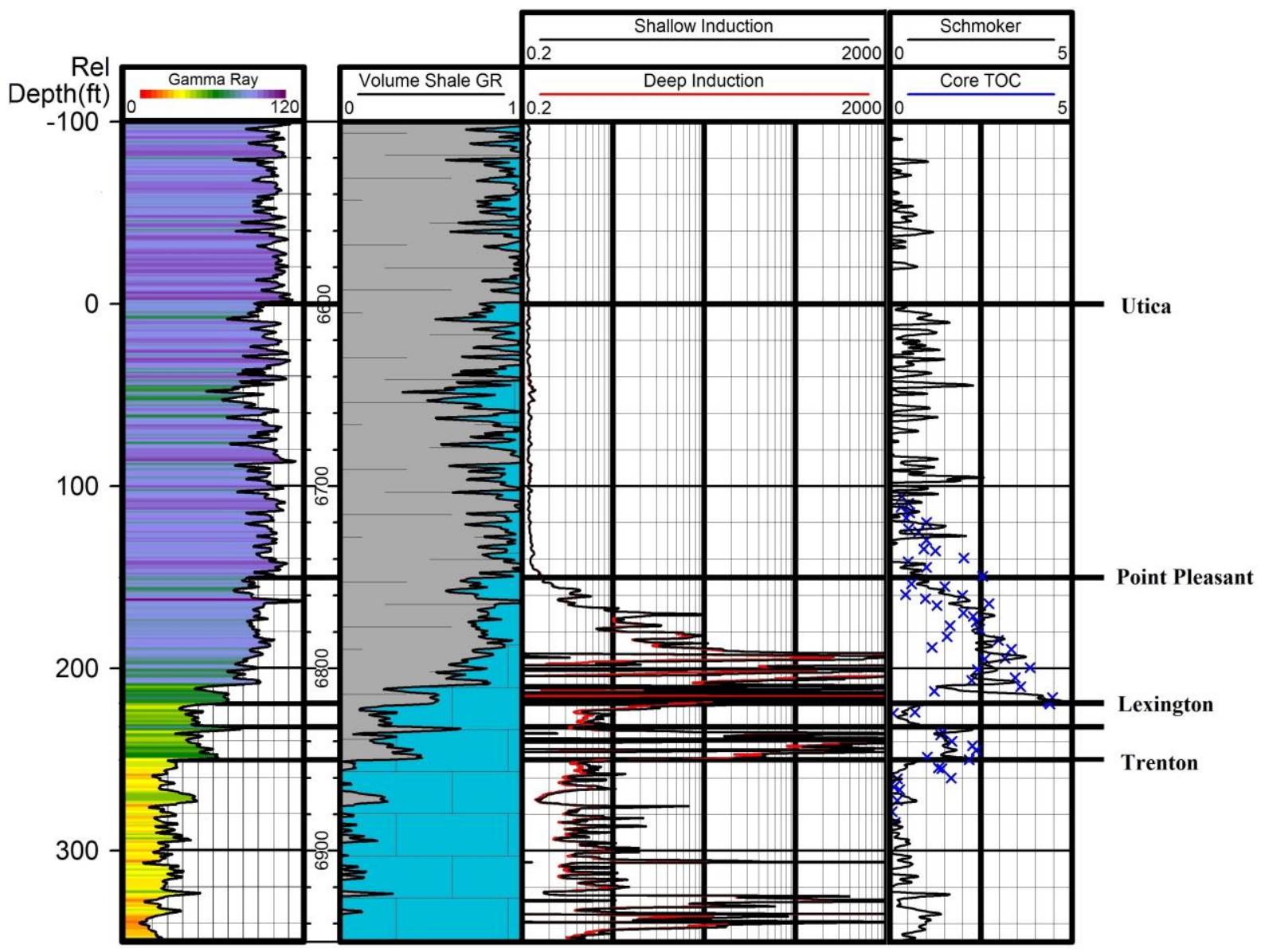

Figure 3.8. Core TOC data is compared to the computed Schmoker curve in cross section showing a good fit, validating the Schmoker method for TOC modeling within the Ordovician Point Pleasant. Small variations between the two TOC curves seen above may occur due to inaccuracies during sampling. Additional errors may also be accounted to inconsistencies from converting from core depth to log depth. 


\section{Which Method is the Best?}

In order to determine which of the four methods of TOC modeling is best for predicting organic-rich intervals within the Trenton-Utica interval, various cross plots were created for the Palmer well using both the core TOC data and the log TOC data. These X-Y cross plots were then fitted with a line of best fit and refer to a correlation coefficient (CORR) (Table 3.1). The following guidelines were used in order to characterize relationships:

$$
\begin{gathered}
\text { +/- 1.0-0.8 Very Strong Relationship } \\
\text { +/- 0.6-0.8 Strong Relationship } \\
\text { +/- 0.4-0.6 Moderate Relationship } \\
\text { +/- 0.2-0.4 Weak Relationship } \\
\text { +/- 0.0-0.2 No Relationship }
\end{gathered}
$$

\begin{tabular}{|c|c|c|c|c|}
\hline TOC from Core & Gamma Ray & Density & Passey & Schmoker \\
\hline $\begin{array}{c}\text { Utica C1 } \\
\text { Sequence }\end{array}$ & -0.046 & -0.484 & 0.711 & 0.486 \\
\hline Point Pleasant & -0.337 & -0.572 & 0.638 & 0.576 \\
\hline Lexington & 0.994 & -0.980 & 0.990 & 0.980 \\
\hline Logana & -0.013 & -0.080 & 0.281 & 0.080 \\
\hline M6 Sequence & 0.098 & -0.563 & 0.615 & 0.565 \\
\hline $\begin{array}{c}\text { Trenton M5 } \\
\text { Sequence }\end{array}$ & 0.448 & -0.509 & 0.735 & 0.511 \\
\hline $\begin{array}{c}\text { Utica-Trenton } \\
\text { Interval }\end{array}$ & 0.138 & -0.693 & 0.743 & 0.694 \\
\hline
\end{tabular}

Table 3.1. TOC modeling correlation results. X-Y cross plots were created with a line of best fit using each of the four TOC modeling techniques and comparing it to the core TOC data for the Trenton-Utica interval.

Although some internal trends exist, little success was found using the gamma ray modeling technique for the Trenton-Utica interval. Unlike the Marcellus Shale, the Point Pleasant lacks the necessary radioactive elements within its organic material to make this approach successful. 
Strong relationships were found using the remaining methods. The Passey method was expected to show the strongest relationship due to the fact it was specifically fitted with a LOM value that would produce the best fitting Passey curve to the TOC data. The Schmoker and density methods both produced relatively similar correlation relationships without altering their petrophysical equations.

\section{Shell Layer Correlation}

While coring, it was noted that gas was seen emanating from shell rich layers within the Palmer core. It was then questioned, is there a way to correlate these shell and TOC rich layers to other well logs? If found successful, it may allow drillers in the future to more easily determine well bore placement within TOC rich zones. In order to do this, a log based on shell rich zones was created based on observations of the Palmer core. The core was examined in 0.1 foot intervals and quantitatively classified based on the appearance of shells. The following numerical system was used

$$
\begin{gathered}
0-10 \% \text { Shells }=0 \\
10-25 \% \text { Shells }=0.25 \\
25-50 \% \text { Shells }=0.50 \\
50-75 \% \text { Shells }=0.75 \\
75-100 \% \text { Shells }=1.00
\end{gathered}
$$

After the entire core was quantified in this manner, depth was converted from core depth to well log depth in order to better correlate with other well logs.

To begin with, the created shell log was compared to the calculated calcite log. Due to the shell log's values being arbitrarily assigned instead of calculated, the two log curves do not match up perfectly, although similarities between the two logs can still be seen (Figure 3.9). The two curves can both be seen decreasing in mud rich zones, and then peaking in shell or calcite rich zones. It is important to note potential errors with this method of correlation. First, this 
particular method is very subjective. There are no mathematical calculations used in order to determine the values assigned to the shell log. Instead, observation of the slabbed core were based on human perception to estimate the amount of shells seen from that slabbed portion and then used to place it into one of the five categories. Additionally, approximately one foot long sections of the core were missing throughout the entire interval. This resulted in gaps within the created shell log, which may result in the appearance of the log decreasing, when in fact the value may have increased.

Based on the cross sectional correlation between the two logs, the shell log corresponds well with the calcite log. Furthermore, based on core and thin section analysis, it was determined that the majority of the calcite noted in the Palmer core is the result of fossiliferous inclusions. Due to this, the calcite log will be used for all further shell correlations, as it is less subjective and has a more accurate and complete log that will ensure better correlation results.

The calcite log was compared to the various other well logs in the Palmer dataset. X-Y cross plots were created in order to determine a correlation coefficient over the Trenton-Utica interval. In order to be deemed successful, the correlation should work in both organic-rich and organic-poor zones, as well as shell-rich and shell-poor zones. The goal is to find a well log that can predict the organic and shell-rich zones.

Based on the results, no correlations were found to have a strong or very strong relationship. Instead, the majority were determined to show no relationship. Table 3.2 summarizes the results for the strongest correlations. These correlations were found to be weak to moderate, but will be investigated further. 


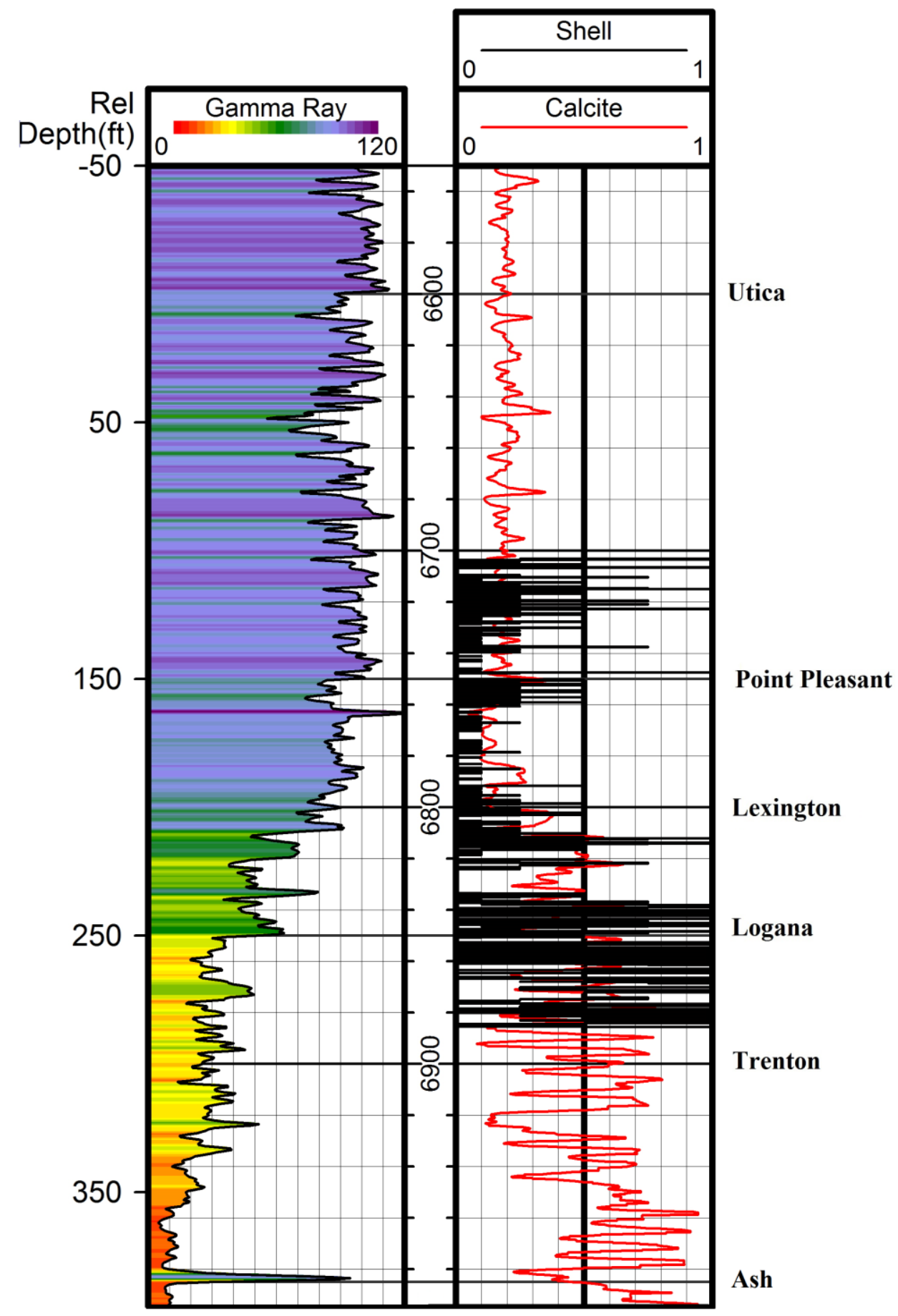

Figure 3.9. The created shell log was compared to the calculated calcite log. Despite potential errors, it was believed that the shell log corresponds well with the calcite log. The remainder of the shell correlation tests will use the calcite $\log$, as it represents a more accurate and complete record. 


\begin{tabular}{|c|c|c|c|c|}
\hline Formation & Deep & Core & Total & Volume \\
Induction & TOC & Porosity & Hydrocarbons \\
\hline Utica & 0.052 & 0.742 & 0.065 & 0.124 \\
\hline Point Pl. & 0.458 & 0.398 & -0.553 & -0.373 \\
\hline Lexington & 0.485 & 0.907 & -0.716 & -0.569 \\
\hline Logana & -0.028 & 0.747 & -0.396 & -0.581 \\
\hline Trenton & 0.197 & 0.392 & -0.481 & -0.304 \\
\hline
\end{tabular}

Table 3.2 The calcite log for the Palmer's Trenton-Utica interval was compared to both common and advanced logs within the Palmer dataset. Of all the X-Y cross plots, none of them produced strong relationships. The strongest correlations are shown here, with the strongest relationship within the Point Pleasant being -0.533 .

Deep induction is unlikely to show areas of high shell and TOC content. Despite this, it is already known to show zones of potential hydrocarbons. Deep induction measures resistivity or the resistance to electrical charge. Water, by nature, likes to hold onto electrical charge, resulting in low resistivity values. Hydrocarbons, on the other hand, tend to resist electrical charge, resulting in high resistivity values.

When the Point Pleasant Formation is analyzed, it is divided into two zones, the organicpoor upper section, and the organic-rich lower section. Although shells are found throughout the Point Pleasant, hydrocarbons generally only occur in the lower section. In this case, the resistivity tool is picking up the resistant charge of the hydrocarbons, not the shells. When the Trenton-Utica interval is analyzed, resistivity peaks occur regardless of shell content and instead is only affected by the fluid present (Figure 3.10). 
Core TOC was found to have a moderate relationship within the Point Pleasant, although it too is unlikely to indicate shell and TOC-rich zones. Core TOC data is taken in discrete intervals throughout the core, and thus does not represent a continuous measurement (Figure 3.11). As a result, it offers far fewer points needed in order to fit a line of best fit. The fewer the points, the easier it will be to fit with a correlation coefficient. Additionally, this will not help during the drilling process, as core TOC data collection occurs in the lab, long after the drilling process, and coring is an expensive process that many companies will not invest in for every well.

Total porosity (averaged neutron and density porosities) was found to have the highest correlation within the Palmer's Point Pleasant Formation (Figure 3.12). Neutron porosity is a measure of the average hydrogen density present within a volume, which is strongly affected by porosity filling fluids (water or hydrocarbons). Density porosity, on the other hand, measures the change in matrix density and formation bulk density.

Using either of these methods fails to accurately predict rich zones of shells and TOC. Neutron and density porosities can be used to determine potential hydrocarbon bearing zones, when they cross over one another creating a fluid effect, or can predict limestone zones when the two logs overlie one another. However, figure 3.12 shows this method of correlation is unsuccessful for an argillaceous limestone like the Point Pleasant. Due to the high concentrations of calcite and clay, the density and neutron porosity logs do not overlie one another since it is not a true limestone, but also do not create a fluid effect to indicate hydrocarbon presence.

As a result, the porosity-calcite correlation relationship appears to be a coincidence within the Point Pleasant. Simply looking at the neutron and density porosity logs cannot be used by themselves in order to predict shells and TOC within the Point Pleasant. 
Similarly, the relationship between the volume of hydrocarbons and calcite also appears to be a coincidence, as it fails to work across the entire Trenton-Utica interval (Figure 3.13). When the Point Pleasant is analyzed shell content is high and volume of hydrocarbons is high, but the two are not dependent upon each other. Hydrocarbons present are related to the amount of TOC present. As a result, it is possible to have a high volume of hydrocarbons, but a low amount of fossiliferous content.

Based on these results, little success was found for the TOC and shell correlation. Additional work is needed in order to confidently determine if any well logs can successfully determine zones of shell and TOC-rich intervals. The results produced here failed to determine that any well log within the Palmer data-set could accurately predict TOC and shell rich zones throughout the Trenton-Utica interval. Some internal trends were found, however the method lacks reproducibility throughout all formations. Instead, if the Point Pleasant was solely focused on, shell content could be considered a constant, or further examined with the weight percent of calcite log. From there, resistivity logs or the weight percent of TOC log could be used to focus in on specific zones within the Point Pleasant Formation. 


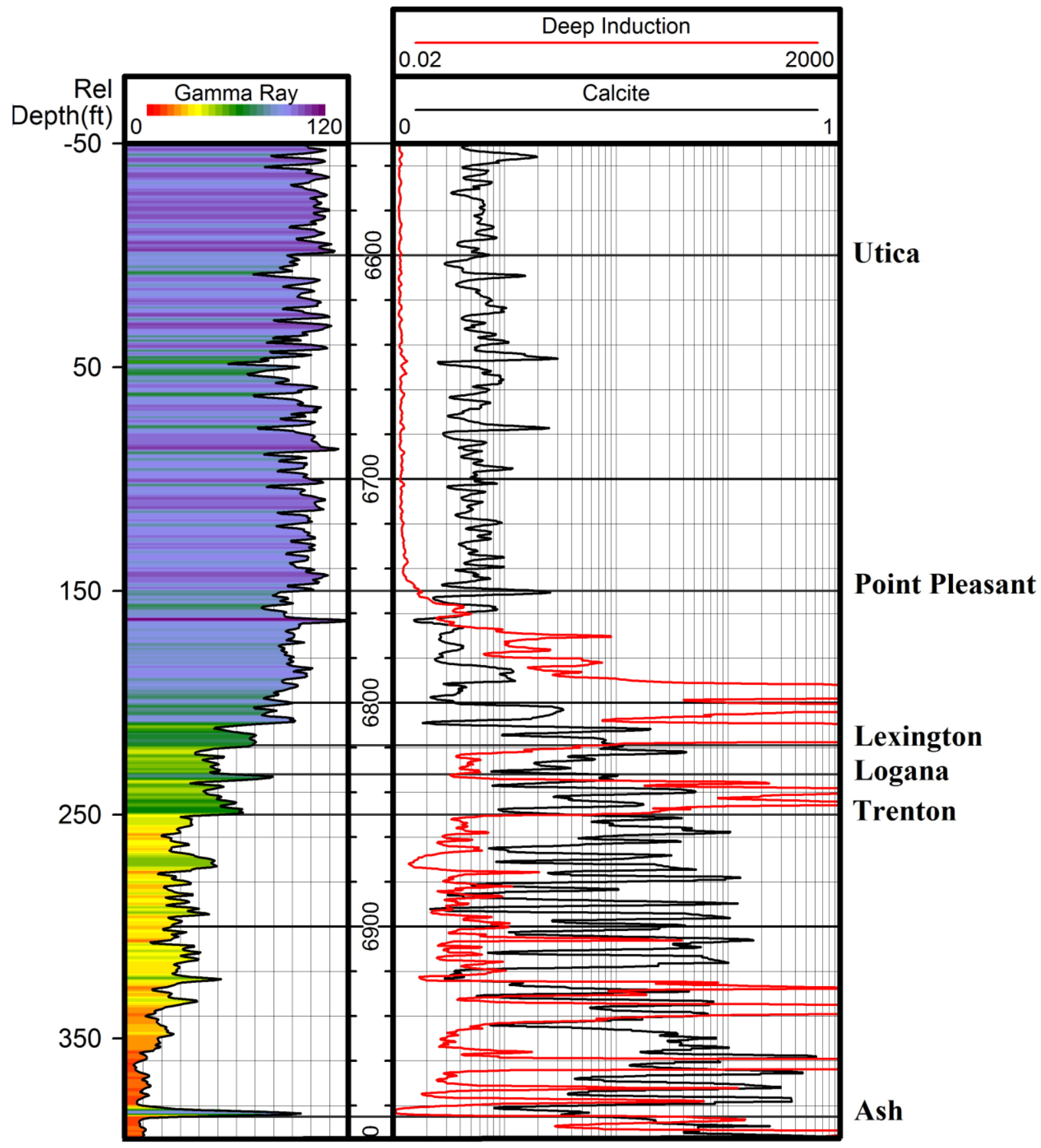

Figure 3.10. When compared, the calcite and deep induction logs showed a moderate relationship when the two were compared using X-Y cross plots. The deep induction log was then compared in cross section to compare the two logs across the entire Trenton-Utica interval. When analyzed in this manner the calcite-deep induction method fails to work for the entire interval. High calcite zones occur in both high and low hydrocarbon potential zones. 


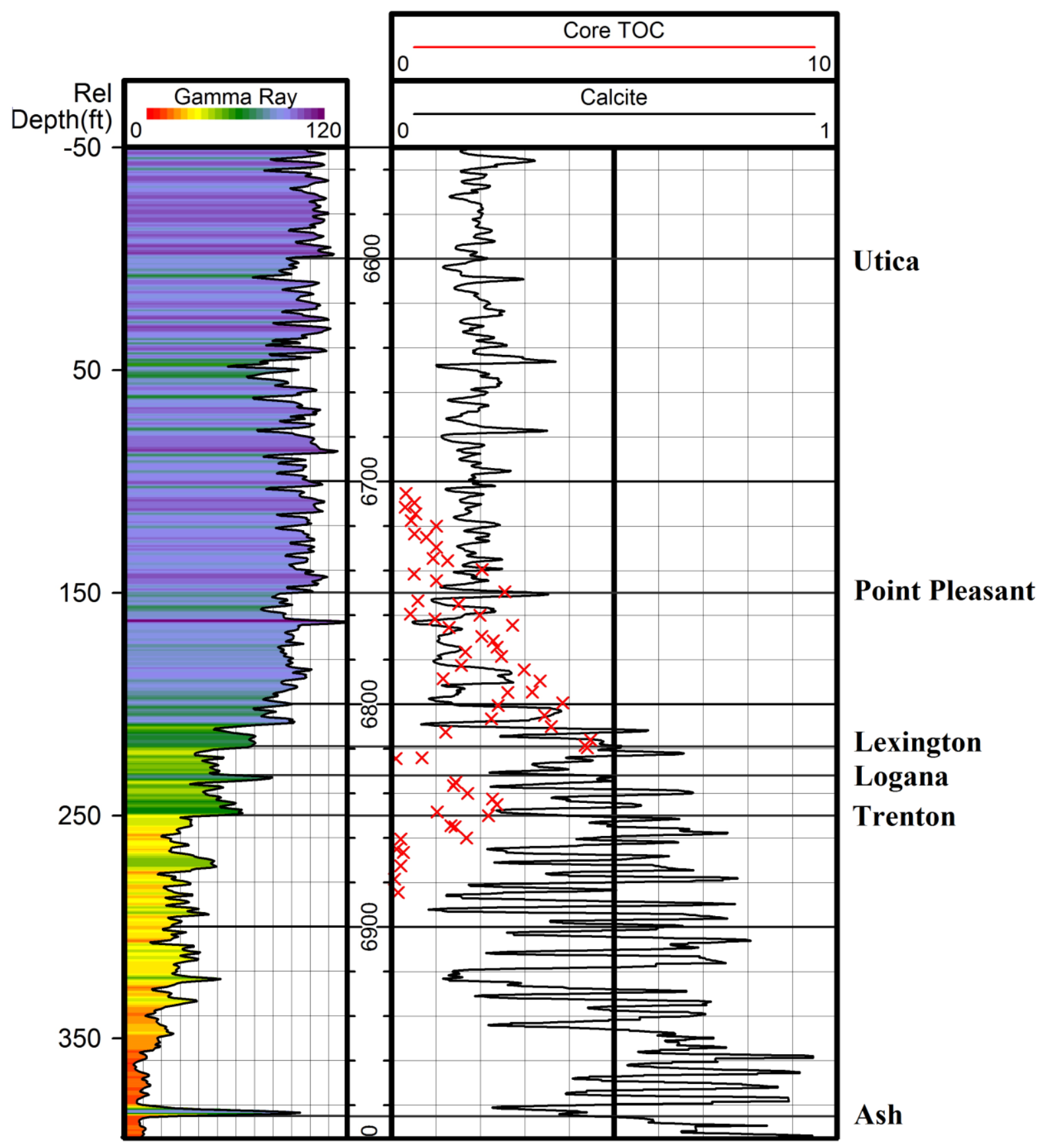

Figure 3.11. When compared, the calcite and core TOC logs showed a moderate relationship when the two were compared using X-Y cross plots. The core TOC log was then compared in cross section to compare the two logs across the entire Trenton-Utica interval. When analyzed in this manner the calcite-deep induction method fails to work for the entire interval. High calcite zones occur in both high and low TOC areas. 


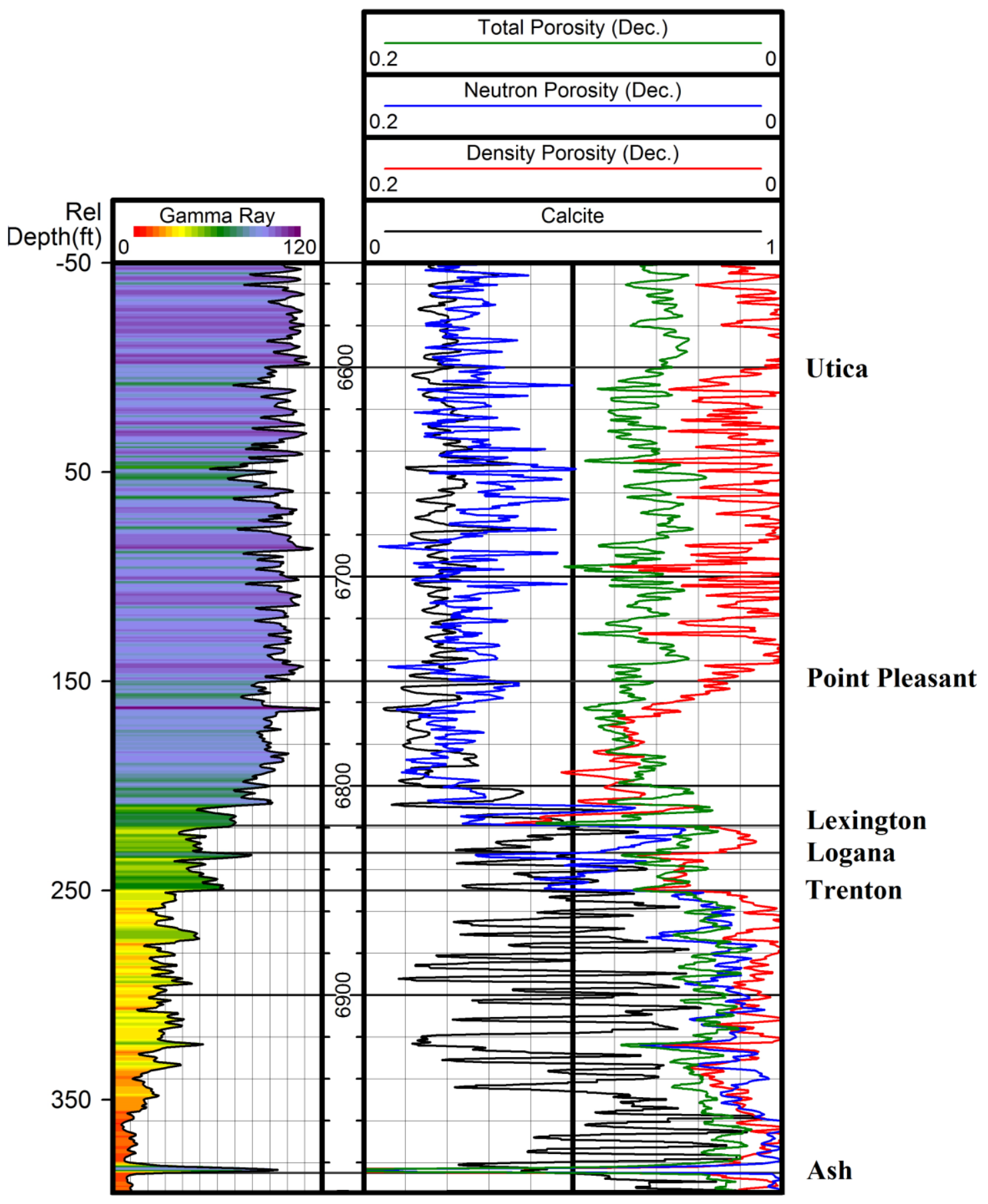

Figure 3.12. When compared, the calcite and total porosity logs showed a moderate relationship when the two were compared using X-Y cross plots. The total porosity log was then compared in cross section to compare the two logs across the entire Trenton-Utica interval. When analyzed in this manner the calcite-deep induction method fails to work for the entire interval. High calcite zones occur in both high and low porosity zones. 


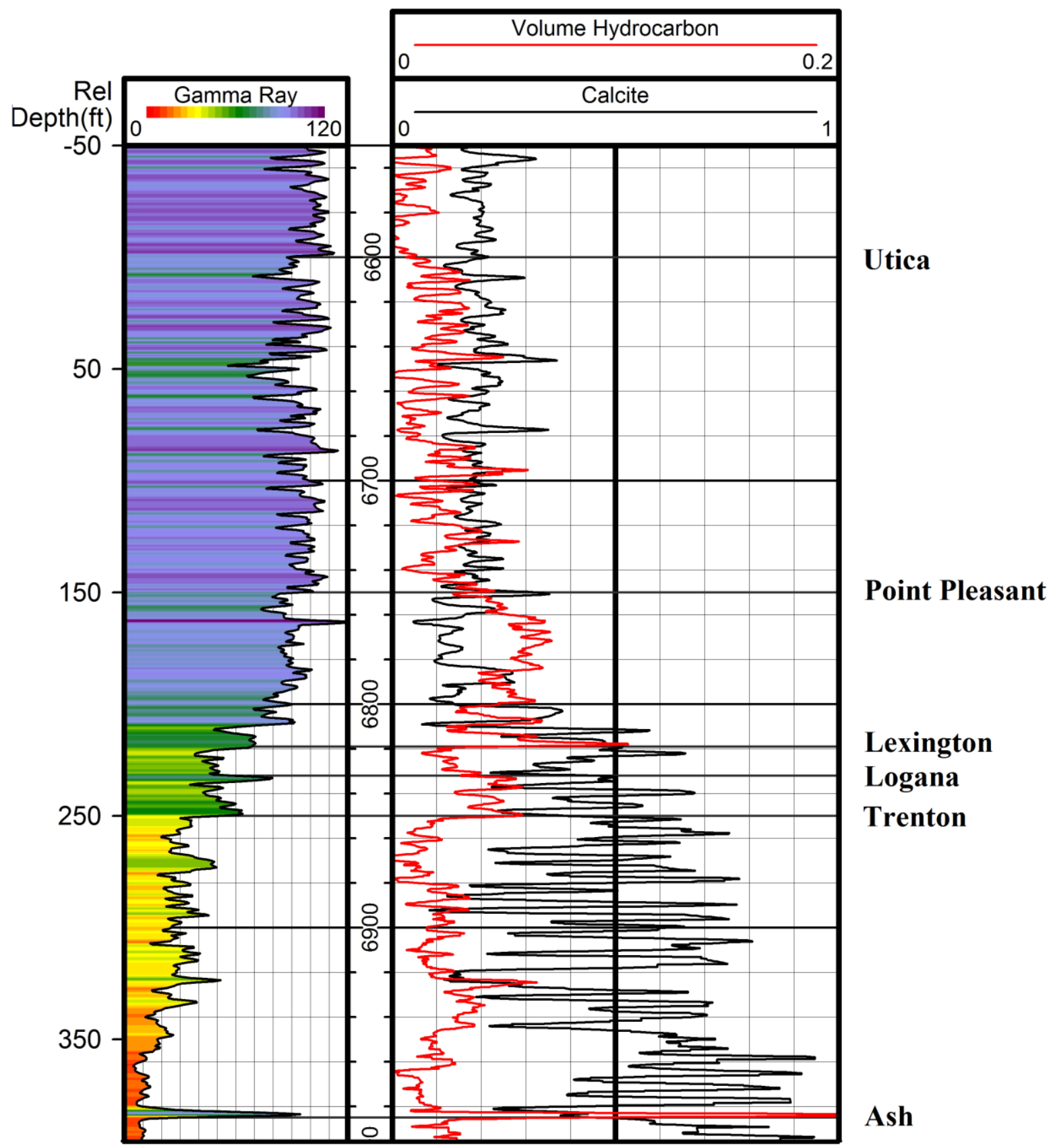

Figure 3.13. When compared, the calcite and volume hydrocarbon logs showed a moderate relationship when the two were compared using X-Y cross plots. The total hydrocarbon log was then compared in cross section to compare the two logs across the entire Trenton-Utica interval. When analyzed in this manner the method fails to work for the entire interval. High calcite zones occur in both high and low hydrocarbon volume areas. 


\section{Regional Maps and Interpretations}

Based on the results from TOC modeling, the most organic-rich facies were found in the Point Pleasant and Logana, or collectively as the M6 Sequence. However, in order to determine sweet spots for this sequence, the total number of feet representing potential organic-rich zones needed to be determined and mapped.

This concept was modeled using both the bulk density and Schmoker TOC methods. The Passey method was not considered for mapping since variables within the equation were changed to match the core TOC values from the Palmer well during modeling. Instead, the density and Schmoker methods produced very strong correlations during mapping without the need for alteration.

First, the bulk density logs for the study interval were used to map out facies containing potential organic-rich material. As specified earlier, densities of less than $2.6 \mathrm{~g} / \mathrm{cc}$ within carbonate material indicate the potential for organics. The total number of feet for the M6 Sequence that contained densities of 2.6 or less was calculated and contoured (Figure 3.14).

Similarly, the Schmoker equation was computed for every well within the study area and a series of maps were prepared using the results. In order to determine the varying degrees of organic-richness within eastern Ohio’s M6 Sequence, maps were created using minimum TOC cut off values of 2-5\% (Figure 3.15-3.18).

In both cases the largest intervals for low density or high TOC facies appear to correspond to the Point Pleasant and Pennsylvanian sub-basins. Organic-rich facies trend perpendicular to depositional strike due to cross-strike lineaments, which created large downdropped fault blocks, resulting in the creation of the Point Pleasant sub-basin and Sebree Trough (McClain, 2013). The distribution is the result of the paleogeographic location of the trough, subbasin, and platform features. The resulting sub-basin and trough features allowed organic rich 
material to be deposited into these areas of deeper water, while cleaner carbonate-rich facies were deposited contemporaneously on the flanking Trenton and Lexington platforms. 


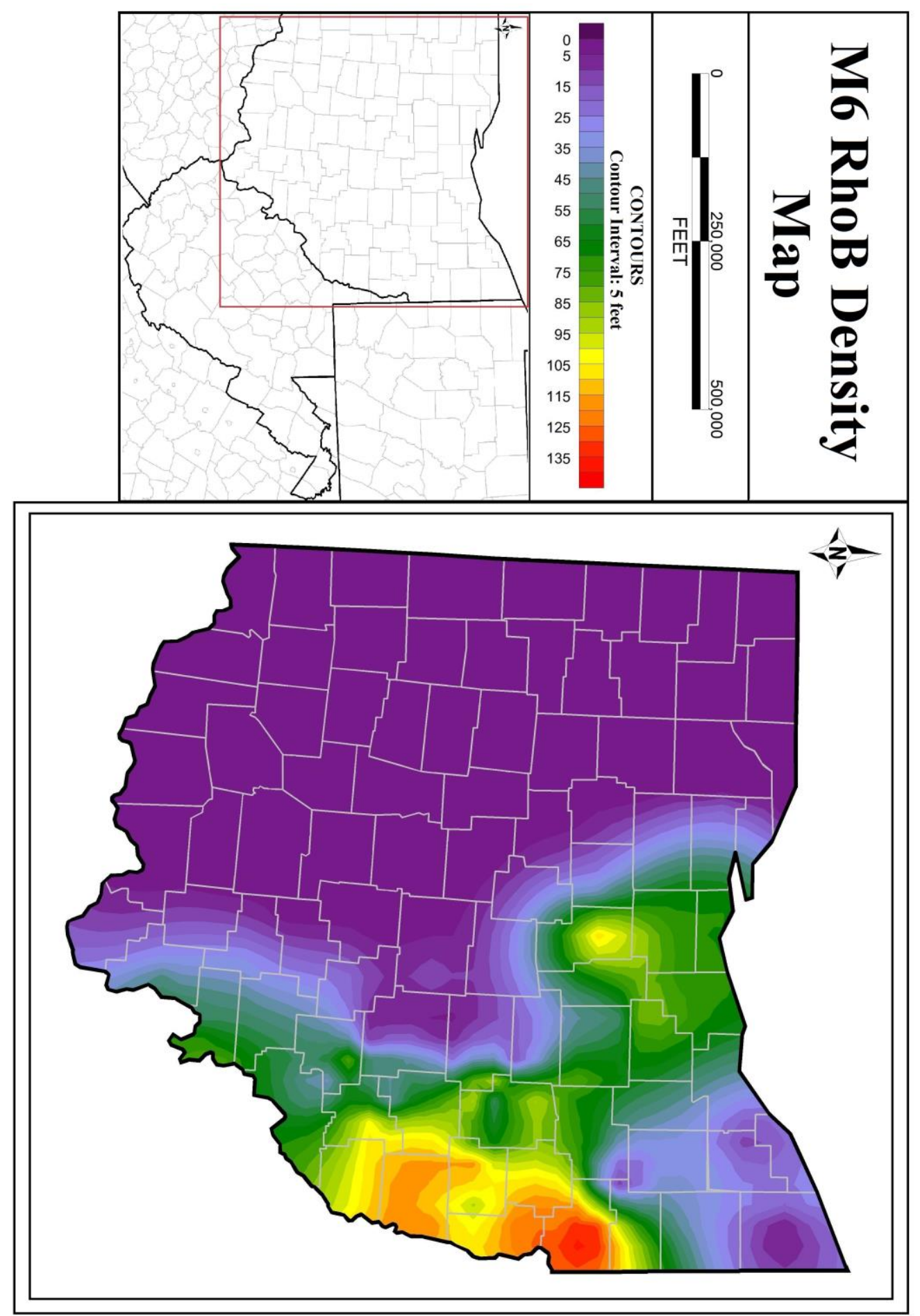

Figure 3.14. RhoB density contour map indicating the number of feet with rock densities of less than $2.6 \mathrm{~g} / \mathrm{cc}$ for the M6 Sequence. The largest volumes correspond to the Point Pleasant and Pennsylvanian sub-basins. 


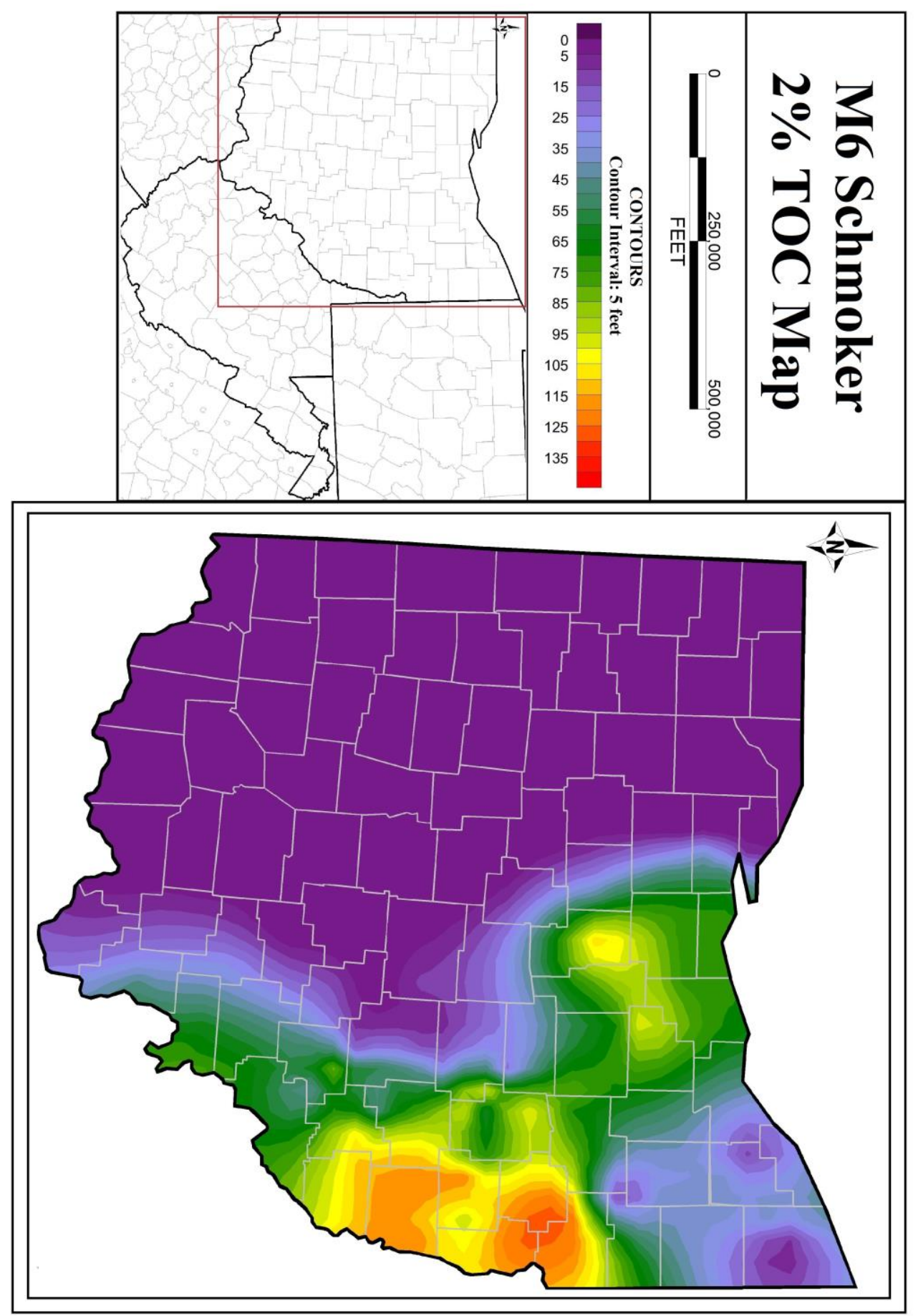

Figure 3.15. Schmoker TOC contour map indicating the number of feet with TOC values of greater than 2\% for the M6 Sequence. The largest volumes correspond to the Point Pleasant and Pennsylvanian sub-basins. 


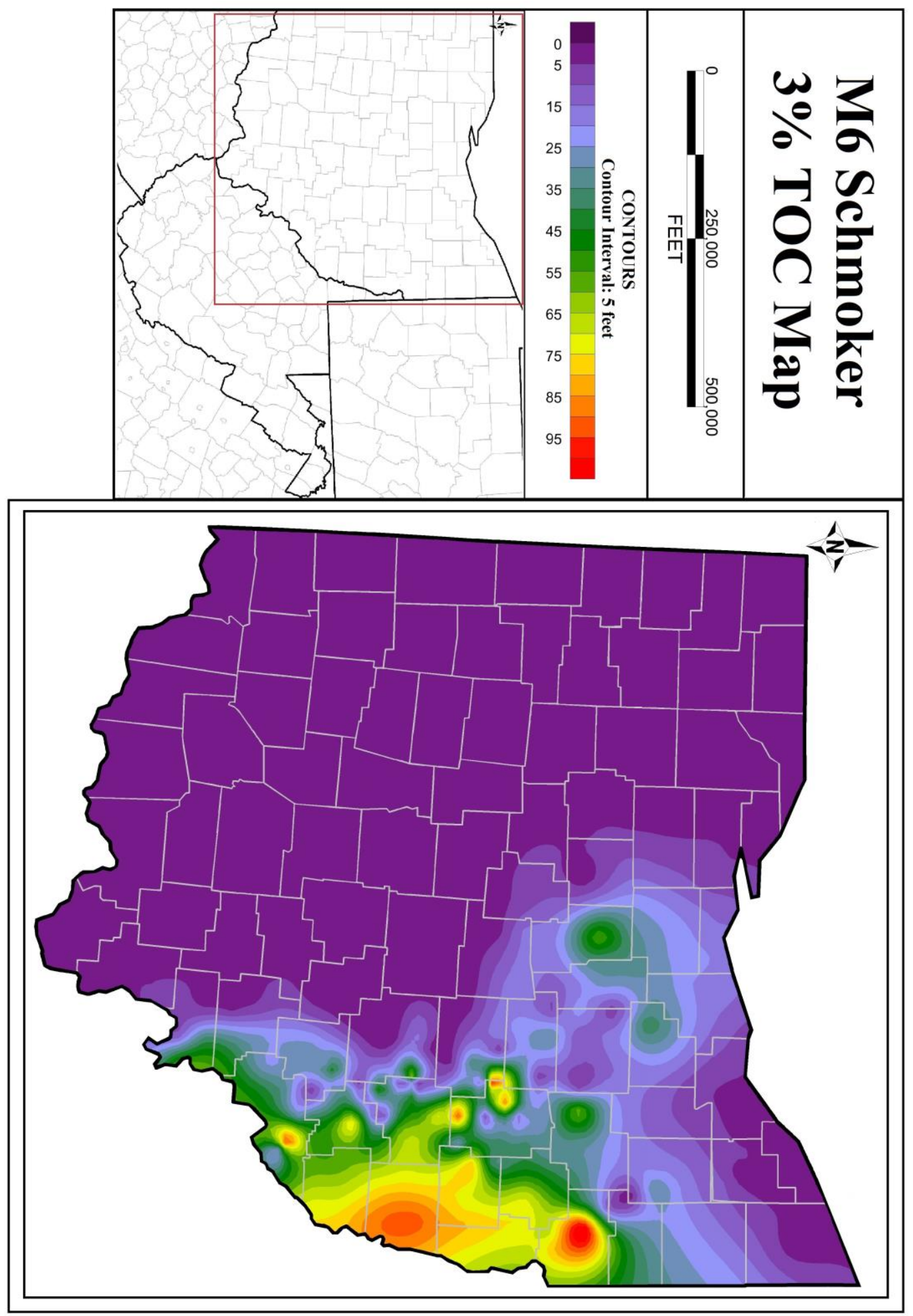

Figure 3.16. Schmoker TOC contour map indicating the number of feet with TOC values of greater than 3\% for the M6 Sequence. The largest volumes correspond to the Point Pleasant and Pennsylvanian sub-basins. 


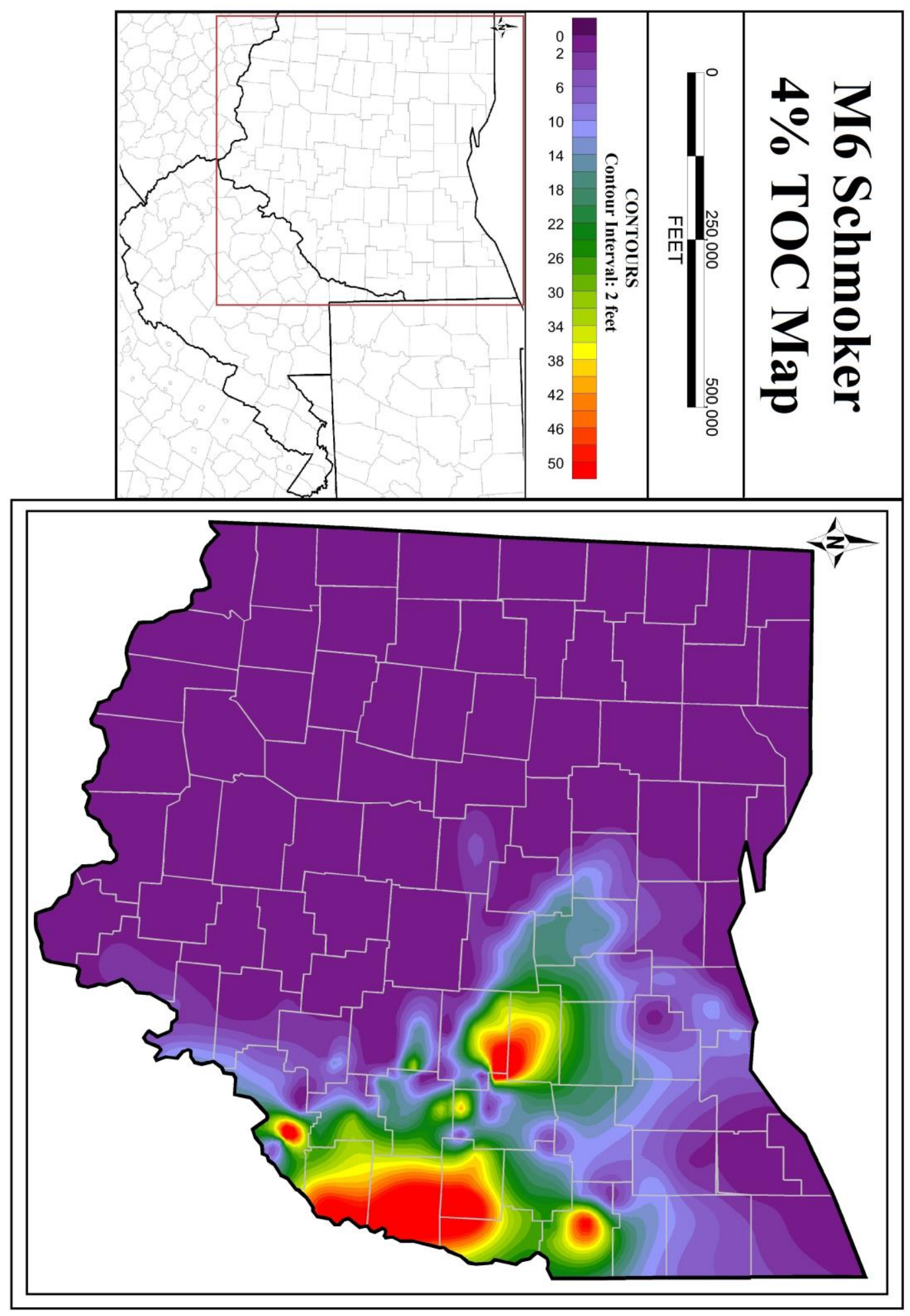

Figure 3.17. Schmoker TOC contour map indicating the number of feet with TOC values of greater than $4 \%$ for the M6 Sequence. The largest volumes correspond to the Point Pleasant and Pennsylvanian sub-basins. 


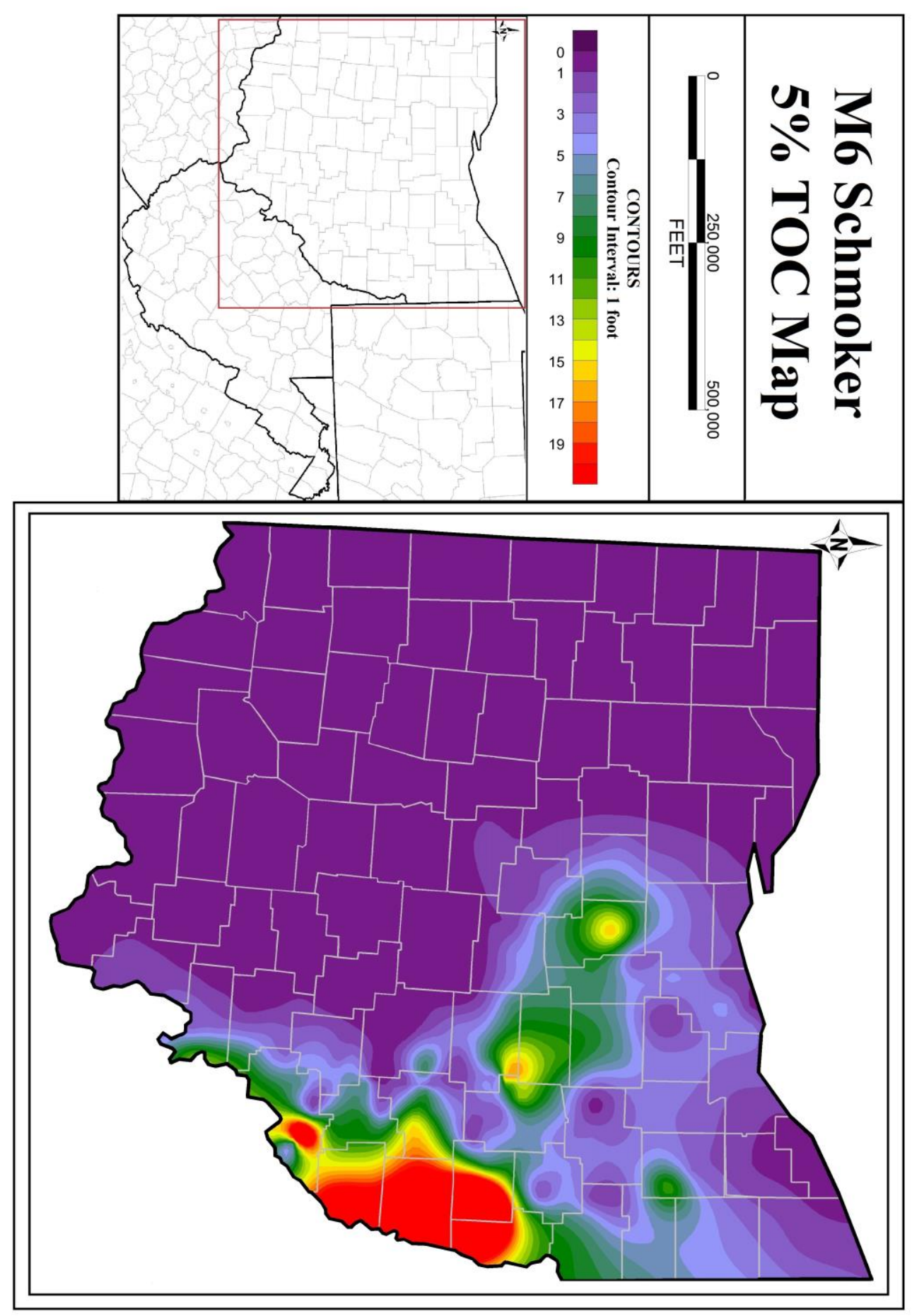

Figure 3.18. Schmoker TOC contour map indicating the number of feet with TOC values of greater than 5\% for the M6 Sequence. The largest volumes correspond to the Point Pleasant and Pennsylvanian sub-basins. 


\section{Chapter 4: Geomechanics \& Geochemistry}

When attempting to understand unconventional reservoirs, it is important to understand the permeability and the fluids in place. Due to the fact that unconventional systems are very tightly compressed shale or mudstone, hydraulic fracturing techniques are typically employed in order to enhance permeability and flow rates. Mineral composition and the presence of organic materials influence not only the fluid saturation, but also the effectiveness of hydraulic fracturing. As a result, this chapter will focus on several models used to predict ductile and brittle lithologies within the Trenton-Utica interval, as well as determining kerogen type and maturity.

Collectively, these subjects can be referred to as geomechanics and geochemistry. By indentifying brittle and ductile rocks, as well as understanding fluid saturation, it can lead to more efficient well locations and completions.

\section{Methodology}

In order to determine where brittle zones reside within the Point Pleasant, mineralogy logs, Poisson's ratio, and Young's modulus were integrated together using several petrophysical equations in order to model a lithology's response to fracturing. These methods include a mineralogy based method from Jarvie et al. (2007) and Wang and Gale (2009), and a method that employs Poisson's ratio and Young's modulus from Rickman et al. (2008). Brittleness results were then compared to mineralogy and lithofacies to determine potential trends.

Following that, pyrolysis data calculated by Core Laboratories was combined in several kerogen graphs in order to interpret the type of kerogen and its maturity. Understanding the kerogen within the Palmer's Point Pleasant Formation will help to interpret the hydrocarbons in place, as well as the original organic material from which the hydrocarbons formed. 
The Rickman et al. (2008) approach to brittleness was calculated through the use of Poisson's Ratio and Young's Modulus. These two components are combined to demonstrate the rock's ability to fail under stress (Poisson's Ratio) and maintain fractures (Young's Modulus). Ductile shales tend to create good seals, trapping the hydrocarbons and preventing migration out of the more brittle rocks below. Brittle shale is more likely to be naturally fractured and will also be more likely to respond well to hydraulic fracturing.

Young's Modulus and Poisson's Ratio logs were first converted to convey brittleness by using the maximum and minimum values for both logs within the Trenton-Utica interval. The algebraic expressions for converting Young's Modulus and Poisson's Ratio are

$$
\begin{aligned}
Y M \text { Brittleness } & =\frac{Y M-Y M_{\min }}{Y M_{\max }-Y M_{\min }} \\
P R \text { Brittleness } & =\frac{P R-P R_{\max }}{P R_{\min }-P R_{\max }}
\end{aligned}
$$

YM refers to the Young's Modulus log and PR is the Poisson's Ratio log, and where the min and max refer to the minimum and maximum values for each log. Once the brittleness values are calculated, they can be used to create an average brittleness log. The equation for calculating the average brittleness is

$$
\text { Average Brittleness }=\frac{Y M \text { Brittleness }+ \text { PR Brittleness }}{2}
$$

Brittle rocks are expressed as those with high Young's Modulus and low Poisson's Ratio values (Figure 4.1). When displayed as a well log, the average brittleness can also be used to determine brittle and ductile zones within the study interval. Average brittleness values of less than $40 \%$ are regarded as ductile, while values greater than $40 \%$ are regarded as brittle (Figure 
4.2). In both cases, the Point Pleasant is determined to be far more brittle than the overlying Utica Shale. 


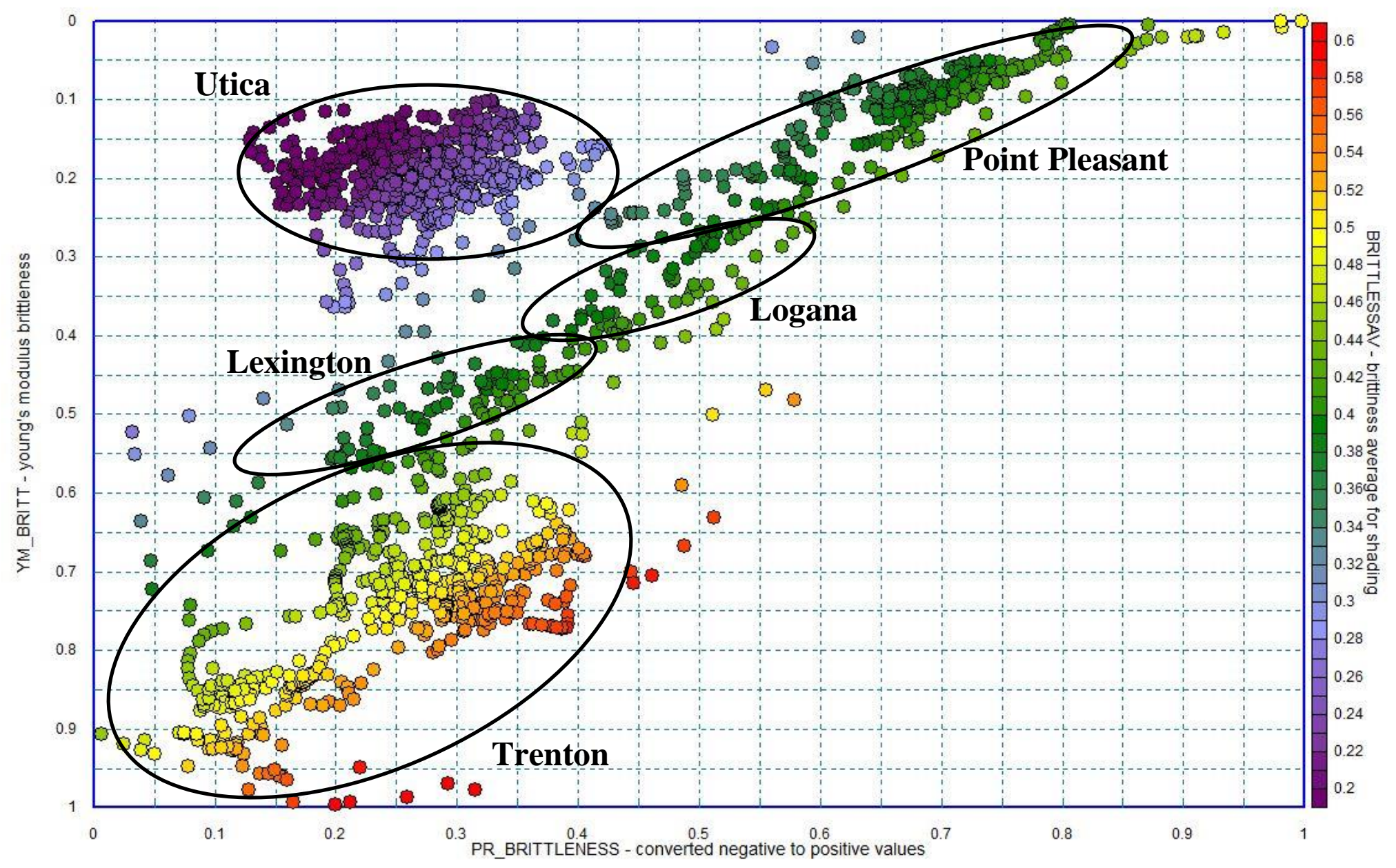

Figure 4.1. Cross plot using the calculated brittleness values for Young's Modulus and Poisson's Ratio. When shaded by an average brittleness value, the Point Pleasant is determined to be more brittle than the Utica Shale. 


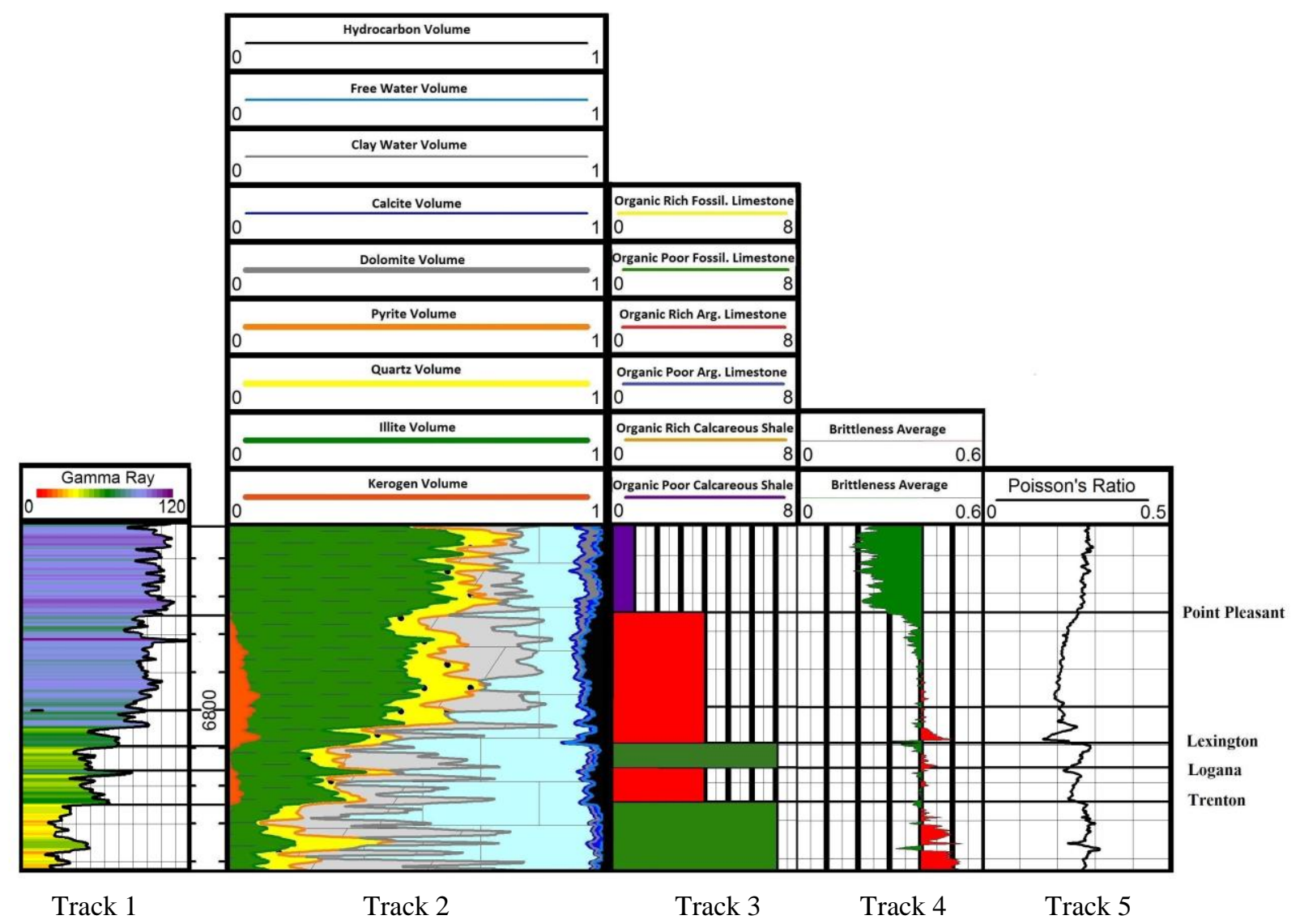

Figure 4.2. Well log comparing the average brittleness computed from Poisson's Ratio and Young's Modulus (track 4) to the mineralogy and lithology for the Palmer well. The results indicate that the Utica Shale is far more ductile than the Point Pleasant Formation. 


\section{Mineralogy Brittleness Method}

Mineralogy has also been proposed as a means to model brittleness based on a calculated brittleness index (BI). The higher the BI, the more brittle the rock will be. Jarvie et al. (2007), and Wang and Gale (2009) proposed methods for calculating the brittleness based on rock composition. In these methods, the most brittle minerals are divided by the sum of the constituent minerals.

The Jarvie method estimates BI by using quartz as the most brittle mineral and dividing that by the sum of quartz, calcite, and clay. The algebraic expression of the Jarvie method is

$$
B I_{\text {Jarvie }}=\frac{\text { Quartz }}{\text { Quartz+Calcite }+ \text { Clay }}
$$

In contrast, Wang and Gale's method includes dolomite as a major brittleness component. The quartz and dolomite are then divided by the sum of quartz, dolomite, calcite, clay, and TOC. The Wang and Gale equation is expressed as

$$
B I_{\text {Wang \& Gale }}=\frac{\text { Quartz }+ \text { Dolomite }}{\text { Quartz }+ \text { Dolomite }+ \text { Calcite }+ \text { Clay }+ \text { TOC }}
$$

The results for these two methods differ slightly due to the addition of dolomite as a brittle mineral in the Wang and Gale method (Figure 4.3). If values of less than $30 \%$ are considered ductile, the Jarvie method indicates that no rocks within the Trenton-Utica interval are sufficiently brittle for hydraulic fracturing. In contrast, the Wang and Gale method indicates small peaks within the Trenton-Point Pleasant interval. The more brittle rocks appear to be dominated by lithologies rich in calcite, such as the fossiliferous limestone and argillaceous limestone. The calcareous shale of the Utica appears far more ductile than the calcareous shale of the Logana submember, this is most likely due to the relative amount of clay to calcite in both formations. 


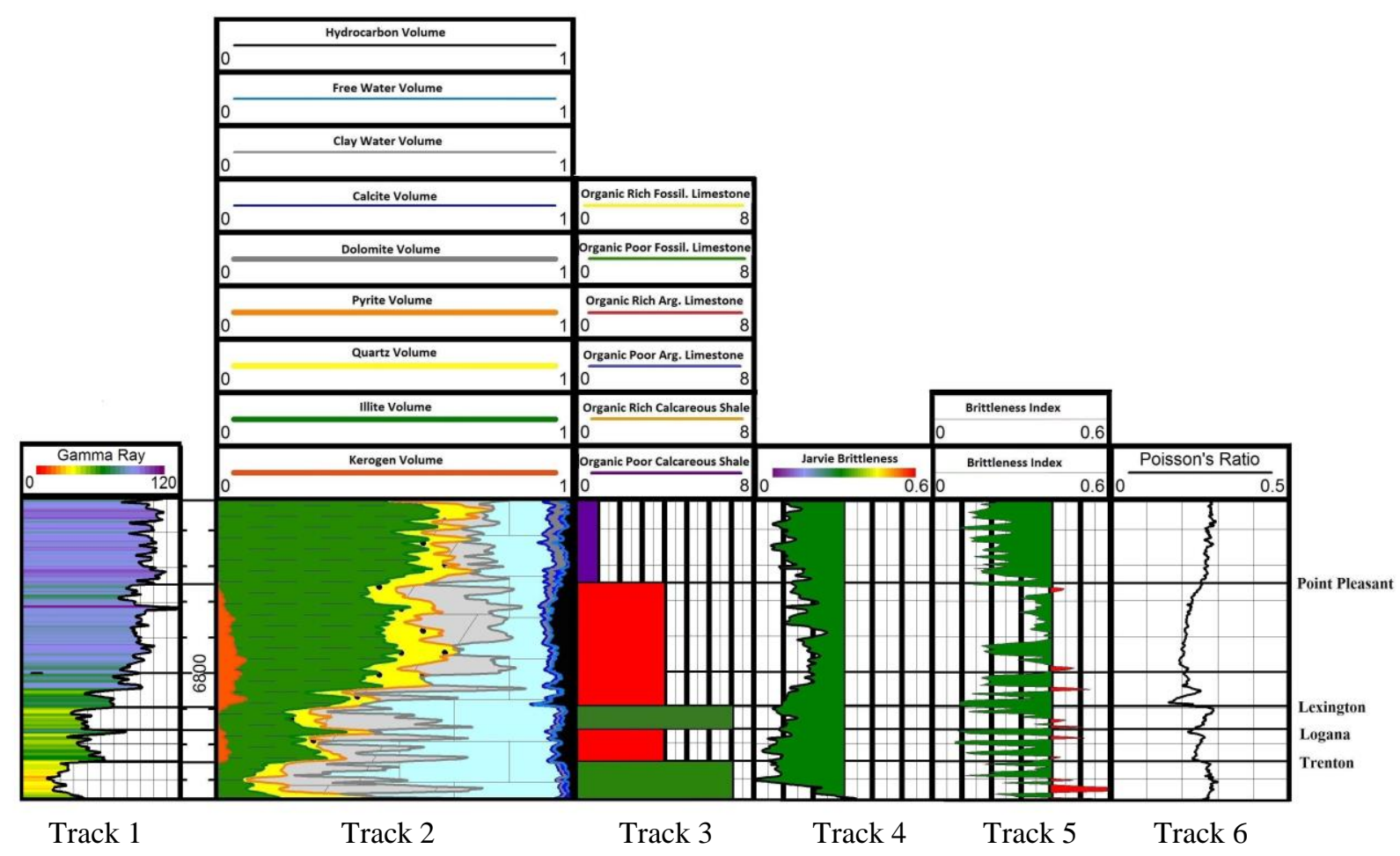

Figure 4.3. Well log comparing the brittleness index (BI) values for the Jarvie (track4) and Wang and Gale (track 5) approaches to the mineralogy and lithology of the Palmer well.

Based on the results, I proposed a third method for modeling brittleness. This method involved identifying the tenacity of the major minerals within the Trenton-Utica interval based on the Moh's hardness scale and classifying them as brittle or ductile. In this method, I considered all minerals with hardness of three or greater to be brittle and all of those with hardness of two or less to be ductile. Then, the most brittle minerals were placed in the numerator and divided by the sum of the constituent minerals. Additionally, I chose to include the weight percent of kerogen in the calculation for brittleness instead of TOC. The equation for this method is identified as

$$
B I_{\text {Schubert }}=\frac{\text { Quartz }+ \text { Dolomite }+ \text { Calcite }+ \text { Pyrite }}{\text { Quartz }+ \text { Dolomite }+ \text { Calcite }+ \text { Pyrite }+ \text { Calcite }+ \text { Kerogen }}
$$


Of the three methods for brittleness based on mineralogy, my method shows the largest quantity of brittle rocks (Figure 4.4). This is due to the fact that calcite, dolomite, quartz, and pyrite were assumed to be brittle minerals, while only clay and kerogen were assumed to be ductile. When the minerals are separated in this manner, the majority of the mineralogy for the Trenton-Point Pleasant interval is dominated by these brittle minerals. Additionally, this method assumed the most brittle rocks occur in the fossiliferous limestone (brittle but strong) and argillaceous limestone (brittle but weak). Just like with the Wang and Gale method, brittleness values differ within the calcareous shale of the Utica and the Logana submember. Again, this is most likely due to the relative amount of clay and calcite in each formation.

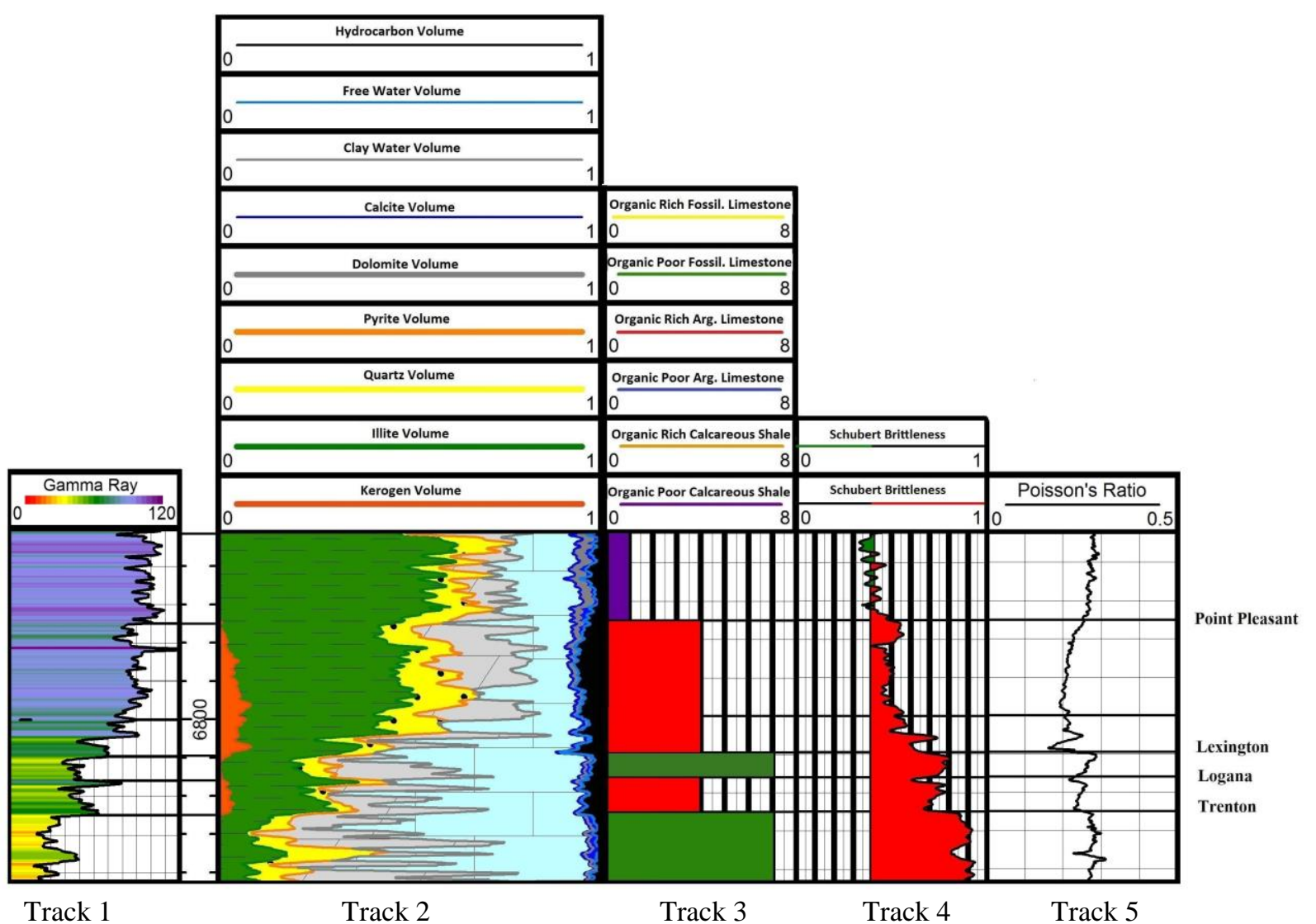

Figure 4.4. Well log comparing the computed brittleness index (BI) factor produced in this study based on mineral tenacity and comparing it to mineralogy and lithology of the Palmer well. 


\section{Geochemistry}

Water Saturation

The Archie method, modeled after Crain (1986), was calculated in Petra to determine apparent water resistivity at formation temperature $(\mathrm{Rw})$ for the Palmer well. In order to do this, a Pickett plot was generated using average porosity (AVPOR) and formation resistivity (LLD). In order to generate a Pickett plot exponents for cementation, saturation, and tortuosity must be determined.

For the Archie equation, the cementation, saturation, and tortuosity exponents were taken as 2.0, 2.0, and 2.3, respectively. From there, Rw was adjusted in order to fit the $100 \%$ water saturation line to the clean carbonate and water bearing Trenton Limestone (Figure 4.5).

The most organic-rich and high porosity facies occur within the Point Pleasant and Logana submember. The Pickett plot also shows a transition zone between the Point Pleasant and the Utica. Here, porosity remains consistent, while resistivity decreases, representing an increase in water saturation. During hydrocarbon creation in the Point Pleasant, water was driven off resulting in the formation becoming extremely dry, containing approximately $10-20 \%$ water.

Additionally, the logs for the Palmer well also reflect the extremely low water saturation in the Point Pleasant, where hydrocarbons dominate pore space. Water saturation was modeled using the Archie method, Simandoux method, and effective water saturation. When the three methods are compared, they display similar results to the Pickett plot, with lowest water saturation occurring within the Point Pleasant and Logana (Figure 4.6). Additional logs can be used in conjunction with the water saturation models to predict water and hydrocarbon bearing zones. The resistivity curve in the Point Pleasant and Logana show strong peak values when compared to the Utica Shale and Trenton Limestone. These peaks represent the potential for hydrocarbon presence. Further supporting evidence can be seen in the density log and core TOC 
data. Deviations in the density log in the Point Pleasant and Logana represent the addition of organic material into the rock matrix. Then, by comparing the core TOC data to the log for weight percent of TOC, the greatest TOC is seen occurring in the Point Pleasant and Logana submember, which then sharply decreases within the Trenton Limestone and Lexington submember.

The overlying Utica Shale does show marginal TOC, particularly in the lower section with values approximately from 1-3\%. This is likely due to dilution from increased deposition of clay and clastic materials, as seen in the increased shale volume. 


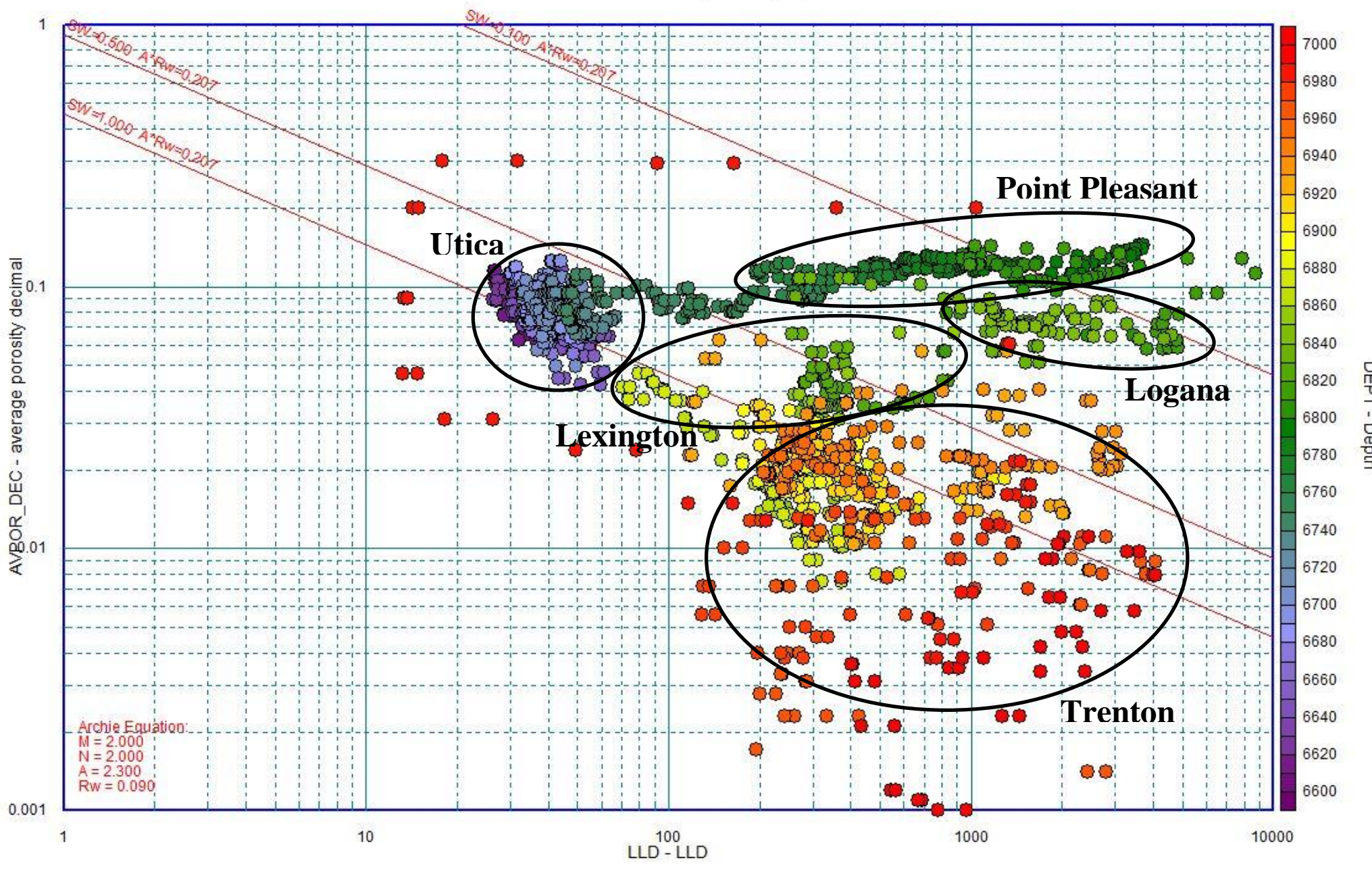

Figure 4.5. Pickett plot for the Trenton-Utica interval, calculated using average porosity and deep induction resistivity. 


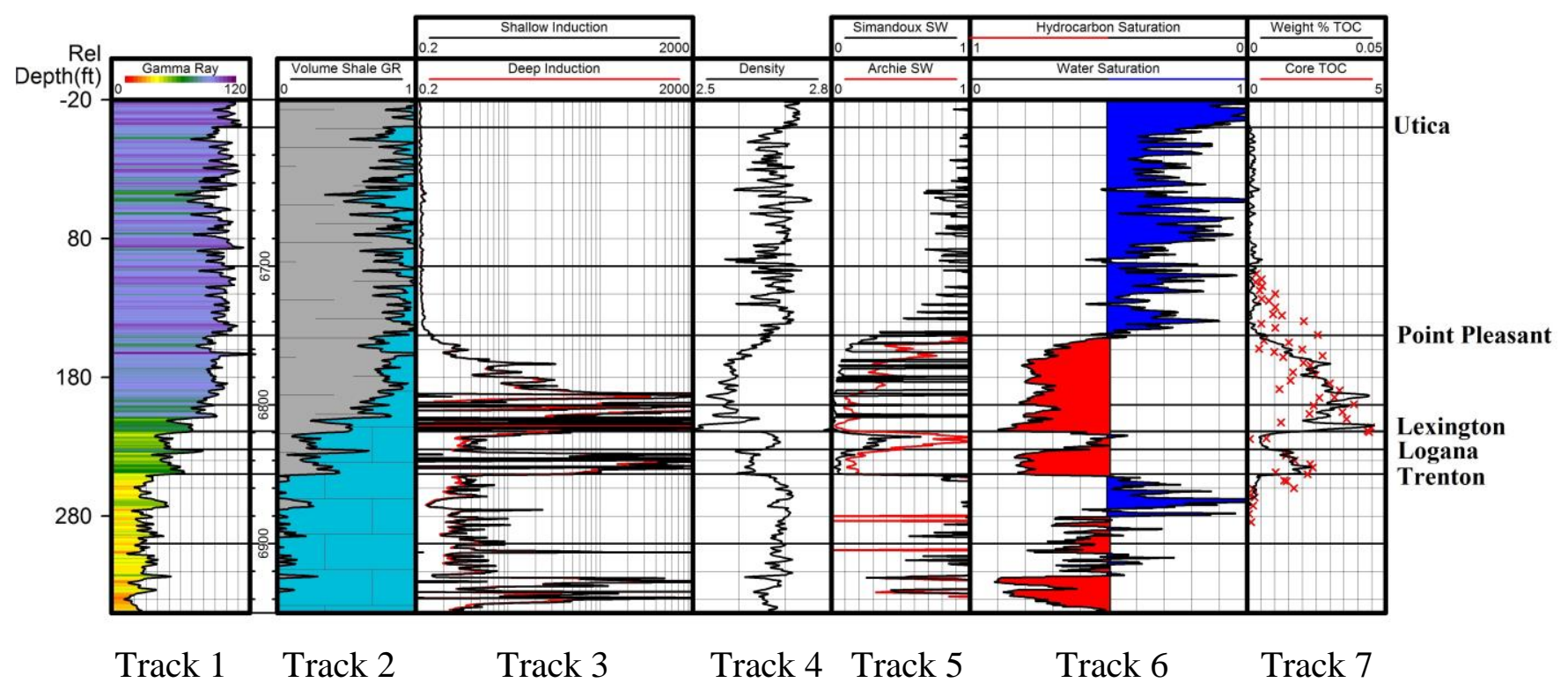

Figure 4.6. Well log cross section comparing the water saturation models of Archie, Simandoux, and effective water saturation (Tracks 4 and 5) to resistivity (Track 3), density (Track 4), and TOC (Track 7). Hydrocarbon saturation appears greatest in the Point Pleasant where water saturation decreases, resistivity increases, and density decreases.

Pyrolysis

Kerogen is the naturally occurring, solid, insoluble organic matter that occurs in source rocks and can yield oil and natural gas upon heating. Rock-Eval pyrolysis is a method to determine the hydrocarbon generating potential of source rocks and can be used to interpret details on the kerogen quality and maturity. During this process, the sample rock is heated in the absence of oxygen to volatize organic compounds from 100-850 degrees Celsius (212-1562 degrees Fahrenheit). In the first stage, any free oil and gas previously generated by the bitumen are distilled and released from the rock. During the second stage, hydrocarbon compounds are generated through thermal cracking of the insoluble kerogen. As temperatures rise, the kerogen releases carbon dioxide in addition to hydrocarbons (McCarthy et al., 2011). Results are given as S1 and S2 peaks. 
$\mathrm{S} 1$ corresponds to the amount of free hydrocarbons within the sample without cracking the kerogen during the first stage of heating. S2 corresponds to the remaining insoluble organic kerogen within the sample. These hydrocarbons result from the cracking of kerogen during the second stage of heating (McCarthy et al., 2011). In theory, S1 increases with increasing thermal maturity, while S2 decreases with increasing thermal maturity. However as maturity increases, much of the free hydrocarbons are cracked to lighter gaseous components (methane, ethane, propane, etc.) and escape before pyrolysis is performed (Barker, 1974).

\section{Kerogen Type and Maturity}

Rock-Eval geochemistry data was used in this study to evaluate the kerogen type and maturity of the Trenton-Utica interval for the Palmer well.

First, a kerogen type and maturity plot was created using the hydrogen index (HI) and maximum temperature (Tmax) (Figure 4.7). The HI is derived from the ratio of hydrogen to TOC contained within the kerogen and is algebraically defined as

$$
H I=\frac{S 2}{T O C} * 100
$$

$\mathrm{HI}$ is a parameter used to characterize the origin of organic matter. Marine organisms and algae, in general, are composed of lipid and protein-rich organic matter, where the ratio of hydrogen to carbon is higher than in carbohydrate-rich land plants (McCarthy et al., 2011). Tmax is the temperature at which the most hydrocarbons are released during the cracking of kerogen during pyrolysis and is used to indicate the stage of maturation of organic matter.

Results indicate that the Palmer's Trenton-Utica interval contains type III kerogen. Type III kerogen is derived primarily from terrigenous plant debris, which has been deposited in shallow to deep marine or nonmarine environments (McCarthy et al., 2011). Type III kerogen 
typically has a lower HI than type I or type II, and consequently generally indicates the presence of dry gas. However, plants did not appear until the Devonian and thus could not be the cause of the Ordovician kerogen. Unlike typical type III kerogen, the Ordovician kerogen represents a type III-like kerogen. This type of source rock is mainly composed of macro algae, benthic brown algae, acritarchs, cryptospores, and arthropods (Zhang et al., 2000; Zhao et al., 2000). The Ordovician organic matter is very similar to the humic organic matter formed from the existence of terrigenous plant debris. However, the type III-like kerogen has a simple molecular structure and lacks lignin and cellulose which would be needed to form the humic type (Zhao et al., 2000).

When a kerogen quality plot was created using S2 and TOC data, the result indicated similar results to that of the kerogen type and maturity plot in Figure 4.7. This plot also indicates the Trenton-Utica interval contains Type III kerogen which is most likely to produce gas (Figure 4.8).

Finally, a kerogen conversion and maturity plot was generated using the production index (PI) and Tmax (Figure 4.9). PI is derived from the relationship between hydrocarbons generated during the first and second stages of pyrolysis. The algebraic equation for PI is

$$
P I=\frac{S 1}{S 1+S 2}
$$

The relationship is used to characterize the evolution of organic matter because PI tends to gradually increase with depth for fine grained rocks. It also tends to increase with source rock maturation prior to hydrocarbon expulsion, as thermally degradable components in kerogen are converted to free hydrocarbons (McCarthy et al., 2011). Results for this plot indicate that the rocks within the Trenton-Utica interval fall within the oil to wet gas generating zones. 


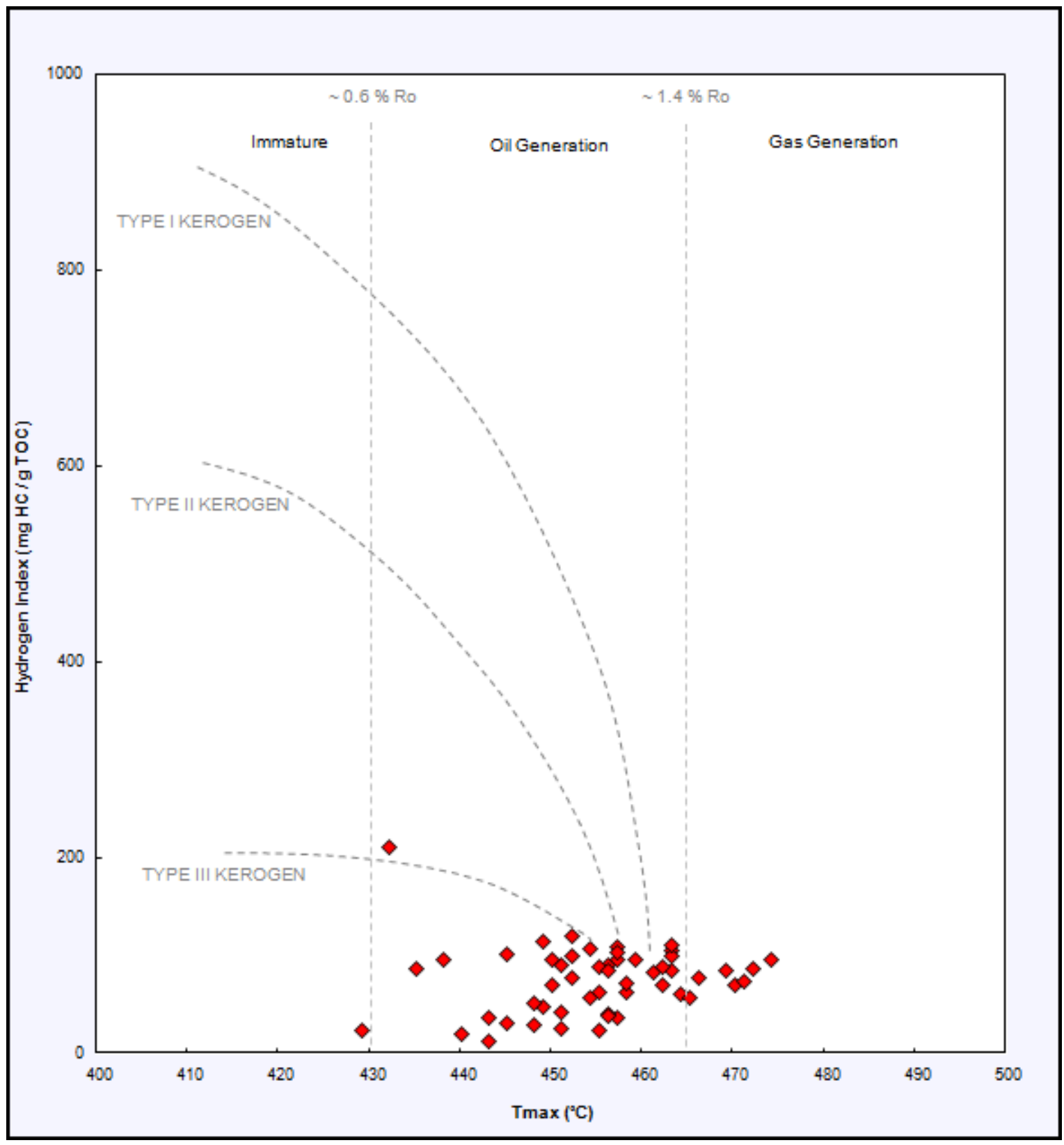

Figure 4.7. Pyrolysis graph depicting the relationship between the Hydrogen Index (HI) and the Maximum Temperature (Tmax) for the Trenton-Utica interval. Results indicate the kerogen within the study interval is Type III kerogen, which is derived from terrigenous plant debris and generally produces dry gas. However, the kerogen of the Ordovician Point Pleasant represents a type III-like kerogen, produced from macro algae, brown algae, acritarchs, cryptospores, and arthropods (Zhang et al., 2000; Zhao et al., 2000). 


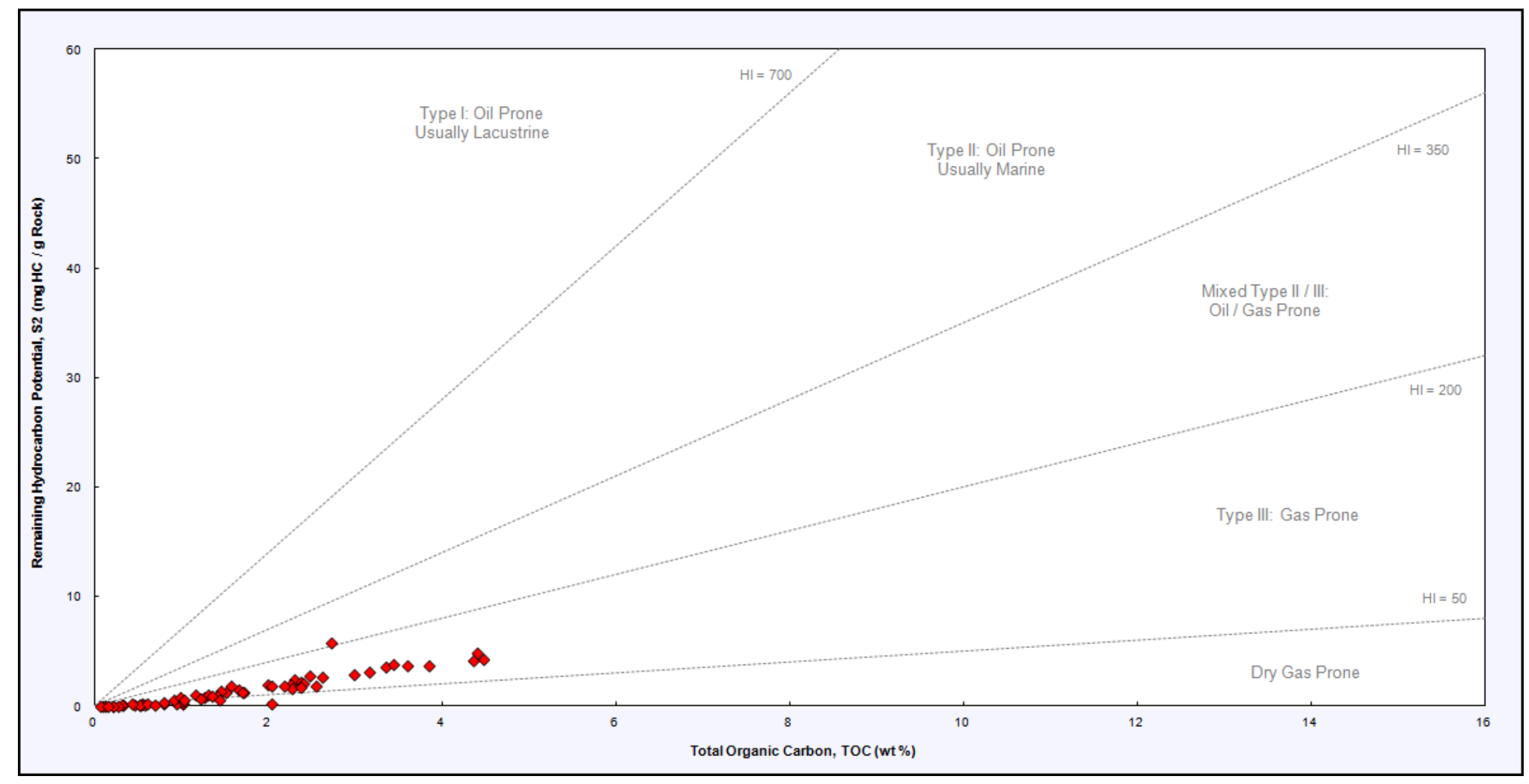

Figure 4.8. Pyrloysis graph depicting the relationship between $\mathrm{S} 2$ and TOC data for the Trenton-Utica interval. Results indicate the kerogen within the study interval is Type III kerogen and is typically prone to produce gas. However, the Ordovician lacked the existence of plants. Instead, the Ordovician Point Pleasant contains type III-like kerogen which is very similar to the humic organic matter produced after the existence of high plants (Zhao et al., 2000). 


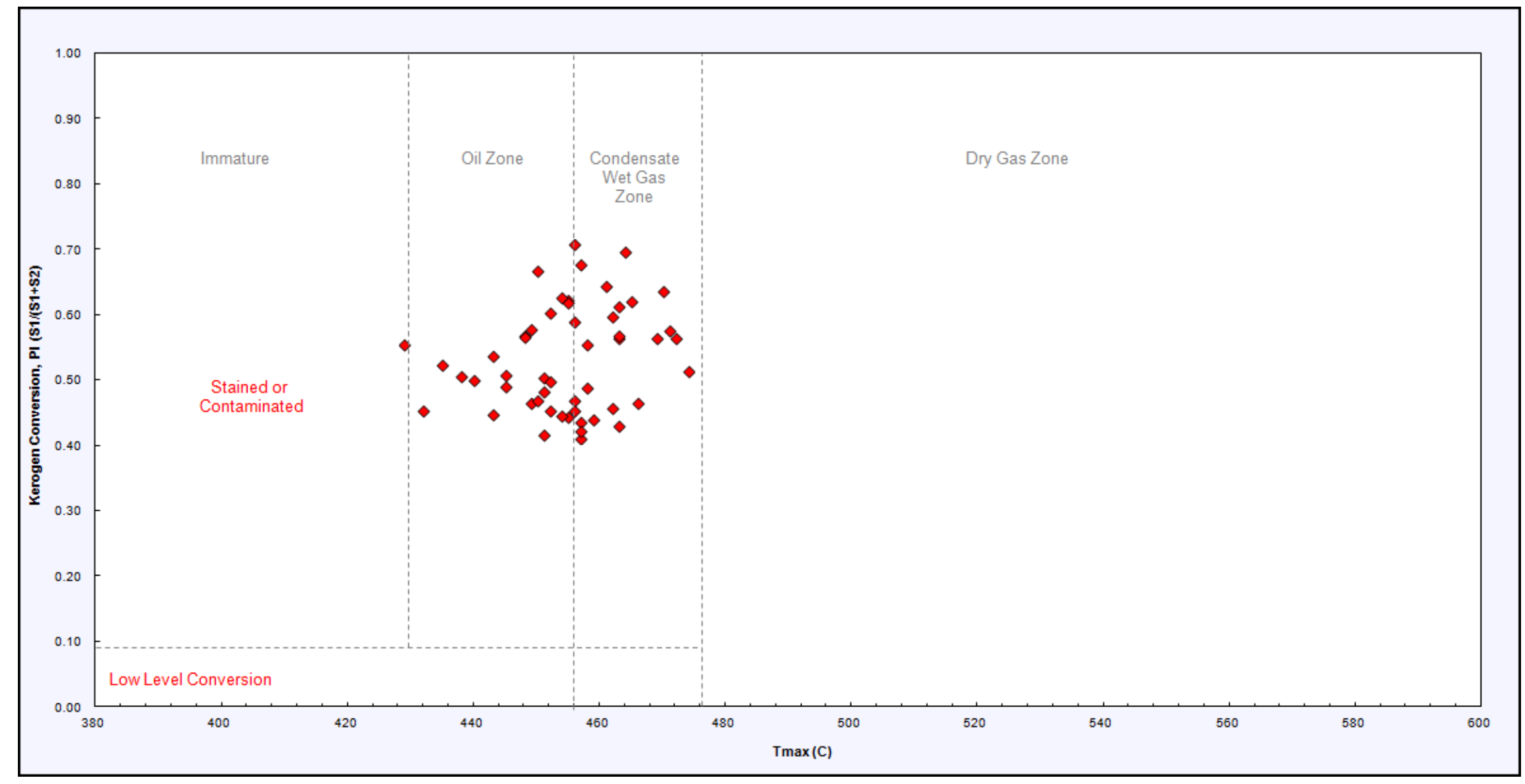

Figure 4.9. Pyrolysis graph depicting the relationship between the Production Index (PI) and the Maximum Temperature (Tmax) for the Trenton-Utica interval. Results indicate the kerogen within the study interval falls within the oil to wet gas producing zone. 


\section{Summary \& Conclusions}

Through the sequence stratigraphy and depositional environment study, I have determined:

- The Trenton-Utica interval is part of a large second-order sequence that can be further divided into three third-order sequences based on Holland and Patzowsky $(1996,1997)$.

- Lithofacies observed based on core observations were seen correlating to the maximum flooding surfaces (MFS) and sequence boundaries (SB) of the three third-order sequences of the Trenton-Utica interval for the Palmer well.

- Four potential unconformities were noted within the Trenton-Utica interval of the Palmer well, noted by abrupt changes in gamma ray, density, porosity, and other logs.

- The thorium-potassium relationship indicates the presence of mixed layer clays, brought on by a combination of illite and chlorite.

- Thorium-uranium relationships can be used to identify oxidizing and reducing environments. When this method is employed for the Palmer well, a large reducing event can be seen corresponding to the lower Point Pleasant's higher TOC content. As oxygen values increase in the upper Point Pleasant, TOC values begin to decline.

- The highest kerogen values for the Trenton-Utica interval were found in lithologies containing nearly equal proportions of carbonate and clay content, with little siliciclastic influence. This was consistent for both XRD and SEM mineralogy results.

- The Point Pleasant's organic-rich lower section contains organic matter porosity. This makes the Point Pleasant more similar to the lower Eagle Ford Shale and Barnett Shale, rather than the Marcellus. 
- Based on core observations, the Utica Shale for the Palmer well is a black-grey calcareous, silty shale, interbedded with light-grey fossiliferous limestone.

- The Point Pleasant Formation for the Palmer well is a dark-grey argillaceous limestone interbedded with light-grey fossiliferous limestone.

- The Trenton Limestone for the Palmer well is composed of fossiliferous limestone and calciclastic limestone.

- The Trenton-Utica interval is dominated by burrows of reworked skeletal material, scour marks, and fossil fragments. Together these indicate the presence of turbidity sequences.

- Basin models indicate the paleogeography of Ordovician Ohio, mapping out the location of the Trenton Platform, the Pennsylvanian sub-basin, and the Point Pleasant sub-basin.

- It is assumed that the depositional environment for the Trenton-Utica interval was a carbonate shelf to middle ramp environment, 100 feet (30 meters) deep or less, frequently disturbed by storm currents.

- The large presence of fossil remains indicates a well oxygenated environment, but the presence of pyrite and thorium-uranium results may indicate that this environment was subjected to seasonal anoxia brought on by large algal blooms.

Through the TOC modeling study, I have determined:

- Although effective in the Marcellus Shale, gamma ray was found to be an ineffective way for predicting TOC within the Point Pleasant. The Point Pleasant lacks the strong gamma ray signature brought on by radioactive elements within the organic matter.

- Cross plot correlation between density and TOC shows a strong correlation, suggesting density as an effective manner for modeling TOC with the exception of those logs with unreliable density readings. 
- When used with a level of maturity (LOM) of 13.0, the delta log R method of Passey et al. (1990) showed a strong correlation when compared to core TOC data. Thermal maturity must be accounted for because resistivity of the source rock varies with LOM. Despite this, the Passey method was found to be an effective way to model TOC within the Palmer well.

- TOC modeling based on Schmoker $(1979,1980)$ was also observed to model TOC well.

- The Schmoker and density cross plot methods showed the strongest correlation to core TOC data without manipulating the equation as with the Passey method.

- Although a variety of well logs can be used to predict the presence of organics or the presence of calcite, no logs were found to predict shell and TOC rich zones.

- Most organic-rich zones within the Point Pleasant occur within east central Ohio near the border of Ohio and Pennsylvania.

- Organic matter preservation appears greatest within the Point Pleasant sub-basin where organic material was confined by deeper waters.

- Marginal zones of organic matter preservation were also identified in the Pennsylvanian sub-basin.

Through the geomechanics and geochemistry study, I determined:

- The most brittle zones within the Trenton-Utica interval are those dominated by calcite and dolomite, corresponding to the fossiliferous limestone and argillaceous limestone lithofacies.

- The overlying Utica Shale was found to be very ductile, allowing it to act as a reservoir seal to the Point Pleasant below. 
- Brittleness results using the Poisson's Ratio and Young's Modulus approach, as well as the mineralogy approach show brittle zones within the Point Pleasant, suggesting the Point Pleasant would respond well to hydraulic fracturing.

- My method for mineralogy brittleness showed the most liberal modeling of brittle zones, while the Jarvie et al. (2007) method was the most conservative.

- Although the Point Pleasant and the Trenton were identified as brittle formations, the use of Poisson's Ratio may indicate the Point Pleasant being brittle but weak, while the Trenton is brittle but strong, based on their ability to fail under stress.

- Use of a Pickett plot suggests the most organic-rich and high porosity facies occur in the Point Pleasant and Logana submember.

- A transition zone was noted in the Pickett plot between the Point Pleasant and the Utica, representing water being driven off from the Point Pleasant during hydrocarbon creation. This resulted in the Point Pleasant becoming a very dry formation with approximately 10$20 \%$ water saturation.

- The Archie method, Simandoux method, and the effective water saturation log, along with the Pickett plot suggest the highest water saturation occurs in the Utica, Lexington, and Trenton.

- Kerogen graphs suggest the Palmer's Trenton-Utica interval is dominated by type III kerogen, produced from terrigenous plants. However, land plants did not evolve until the Devonian.

- Instead, the Ordovician interval is dominated by type III-like kerogen, produced from algae. This kerogen is very similar to the humic organic matter produced after the existence of high plants. 
- Pyrolysis results indicate that the kerogen within the study interval falls within the oil to wet gas producing zone. 


\section{References:}

Adams, J. A.S., and Weaver, C.E., 1958, Thorium to uranium ratios as indications of sedimentary processes-example of concept of geochemical facies: American Association of Petroleum Geologists Bulletin, v. 42, no. 2, p. 387-430.

Archie, G.E.,1942, The electrical resistivity log as an aid in determining some reservoir characteristics: Transactions of the American Institute of Mechanical Engineers: v. 146, p. 54-62.

Barker, C., 1974, Pyrolysis techniques for source-rock evaluation: AAPG Bulletin, v. 58, No. 11, p. 2349-2361.

Baker, J., 2011, Drilling Frenzy Reaches Tuscarawas Valley. The Canton Repository. Web 17 Nov. 2015. http://www.cantonrep.com/article/20110619/NEWS/306199956

Baker, J., 2011, Striking it Rich. The Times Reporter, p. A1.

Blakey, R., 2011, North American paleogeographic maps. Web 11 Feb. 2015. http://www2.nau.edu/rcb7/nam.html

Boyce, M. L., 2010, Sub-surface stratigraphy and petrophysical analysis of the Middle Devonian interval of the central Appalachian Basin; West Virginia and Southwest Pennsylvania, PhD Thesis, West Virginia University, Morgantown, West Virginia, 158 p.

Brett, C. E., McLaughlin, P. I., Cornell, S. R., and Baird, G. C., 2004, Comparative sequence stratigraphy of two classic upper Ordovician successions, Trenton shelf (New YorkOntario) and Lexington platform (Kentucky-Ohio): Implications for eustacy and local tectonism in eastern Laurentia: Paleogeography, Paleoclimatology, Paleoecology, v. 210, p. 295-329.

Crain, E. R., 1986, The Log Analysis Handbook Volume One - Quantitative Methods, Tulsa, Pennwell Books, p. 684.

Doveton, J.H., 1994, Geological log analysis using computer methods: Tulsa, AAPG Computer Applications in Geology, N0.2, p. 36-51.

Embry, A. F., 1995, Sequence boundaries and sequence hierarchies: problems and proposals, in R. J. Steel et al., eds., Sequence Stratigraphy on the Northwest European Margin: Norwegian Petroleum Society (NPF) Special Publication 5, p. 1-11.

Faill, R.T., 1997, A Geologic history of the North-Central Appalachians, Part 2: The Appalachian basin from Silurian through the Carboniferous, American Journal of Science, Vol. 297, p. 729-760. 
Gluyas, Jon, and Swarbrick, Richard. 2004, Petroleum Geoscience. Maiden, MA: Blackwell Publishing, p. 279.

Hansen, Michael. 1997. The Geology of Ohio-The Ordovician: Ohio Geology, Fall 1997.

Hickman et al., 2015, A Geologic Play Book for Utica Shale Appalachian Basin Exploration. Web 15 Nov. 2015. http://www.wvgs.wvnet.edu/utica/playbook/index/aspx

Holland, S. M., and Patzkowsky, M. E., 1996, Sequence stratigraphy and long-term paleoceanographic change in the middle and upper Ordovician of the eastern United States, in B. J. Witzke et al., eds., Paleozoic sequence stratigraphy: Views from the North American craton: Geological Society of America Special Paper 306, p. 117-129.

Holland, S. M., and Patzkowsky, M. E., 1997, Distal orogenic effects on peripheral bulge sedimentation: Middle and Upper Ordovician of the Nashville Dome: Journal of Sedimentary Research, v. 67, p. 250-263.

Holland, S. M., and Patzkowsky, M. E., 1998, Sequence Stratigraphy and relative sea-level history of the middle and upper Ordovician of the Nashville dome, Tennessee: Journal of Sedimentary Research, v. 68, no. 4, p. 684-699.

Jarvie et al., 2007, Unconventional shale-gas systems: the Mississippian Barnett Shale of NorthCentral Texas as one model for thermogenic shale-gas assessment: AAPG Bulletin, 91, 475-499.

McCarthy et al., 2011, Basic Petroleum Geochemistry for Source Rock Evaluation: Oilfield Review, v. 23, No. 2, p.32-43.

McClain, Taylor, 2013, Sequence Stratigraphy and Petrophysics of the late Ordovician UticaPoint Pleasant Interval in the Middle Appalachian Basin, Eastern Ohio and Western Pennsylvania, Master's Thesis, West Virginia University, Morgantown, West Virginia.

Ohio Department of Natural Resources. Maximum TOC Value per Well of the Upper Ordovician Shale Interval in Ohio, 2013. Web. 18. Jan. 2016. http://oilandgas.ohiodnr.gov/shale

Ohio Department of Natural Resources Utica Shale Files for Download. Web. 11 Feb. 2015. http://geosurvey.ohiodnr.gov/energy-resources/marcellus-utica-shales

Ohio Geological Survey Downloadable Maps of Ohio. Web 11 Feb. 2015. http://geosurvey.ohiodnr.gov/publications-maps-data/free-downloads/maps

Passey et al., 1990, A practical model for organic richness from porosity and resistivity logs: AAPG Bulletin, v. 74, p. 1777-1794.

Patchen, et al., 2006, A geologic play book for Trenton-Black River Appalachian basin exploration. 
Pope, M., and Read, J. F., 1997, High-resolution surface and subsurface sequence stratigraphy of Late Middle to Late Ordovician (Late Mohawkian-Cincinnatian) foreland basin rocks, Kentucky and Virginia: AAPG Bulletin, v. 81, no. 11, p. 1866-1893.

Quirein, J.A., Gardner, J.S., and Watson, J.T., 1982. Combined natural gamma-ray spectral/lithodensity measurements applied to complex lithology. SPE of AIME, 57th Annual Fall Technical Conf. and Exhibit. New Orleans, paper SPE 11143.

Rickman et al., 2008, A Practical Use of Shale Petrophysics for Stimulation Design Optimization: All shale Plays Are Not Clones of the Barnett Shale: SPE Paper 115258.

Rowley, D. H., and Kidd, W. S. F., 1991, Stratigraphic relationships and detrital composition of the Middle Ordovician flysch of western New England: implications for the evolution of the Taconic Orogeny: Journal of Geology, v. 89, p. 199-218.

Schieber, Juergen, Southard, J.B., and K. Thaisen, 2007, Accretion of mudstone beds from migrating floccule ripples, Science, v.318, p. 1760-1763.

Schmoker, J., 1979, Determination of Organic Content of Appalachian Devonian Shales from Formation-Density Logs, American Association of Petroleum Geologists Bulletin, v. 63, p. 1504-1537.

Schmoker, J., 1980, Organic Content of Devonian Shale in Western Appalachian Basin: American Association of Petroleum Geologists Bulletin, v. 64, p. 2156-2165.

Servais et al., 2008, The Ordovician biodiversification: Revolution in the oceanic trophic chain: Lethaia, v. 41, p. 99-109.

Servais et al., 2009, Understanding the Great Ordovician Biodiversification Event (GOBE): Influences of paleogeography, paleoclimate, or paleoecology. GSA Today 19, p. 4-9.

Simandoux, P., 1963, Dielectric measurements on porous media application to the measurement of water saturations: study of the behaviour of argillaceous formations: Revue de l'Institut Francais du Petrole 18, Supplementary Issue, p. 193-215.

Spencer, Jeff, and Camp, Mark, 2008, Ohio Oil and Gas. Charleston, SC: Arcadia Publishing.

Tourtelot, Harry. 1979, Black Shale-It's Deposition and Diagenesis: Clays and Clay Minerals, Vol. 27, no. 5, p. 313-321.

United States Geologic Survey (USGS), 2012. Web. 10 Feb. 2015. http://www.usgs.gov/newsroom/article.asp? ID=3419\&from=rss_home\#.VNoFlfnF-1c 
Vail, P. R., Mitchum, R. M. Jr., and Todd, R. G., 1977, Seismic stratigraphy and global changes of sea level, in C.E. Payton, ed., Seismic Stratigraphy: Applications to Hydrocarbon Exploration. AAPG Memoir 26, p. 49-212.

Wang, F.P., and J.F.W. Gale, 2009, Screening criteria for shale-gas systems: GCAGS Transactions, 59, 779-793.

Witzke, B. J., 1990, Paleoclimatic constraints for Paleozoic paleolatitudes of Laurentia and Euramerica, in W. S. McKerrow and C. R. Scotese, eds., Paleozoic Paleogeography and Biogeography Memoir, vol. 12, Geological Society of London, London, England, pp. 5774.

Zhang et al., 2000, Distinguishing Cambrian from Upper Ordovician source rocks: Evidence from sulfur isotopes and biomarkers in the Tarim Basin. Organic Geochemistry 40, 755768.

Zhao et al., 2000, Features of the type III-like source rock and its generated natural gas. Chinese Science Bulletin 45, 857-861. 


\section{Appendix A:}

Measured core log and facies descriptions for the Palmer 44-20 well, PDC Energy, Morgan County, Ohio, API 34013202770000 , Lat. $39.9784800^{\circ} \mathrm{N}$, Lng. $-80.8446300^{\circ} \mathrm{W}$. 


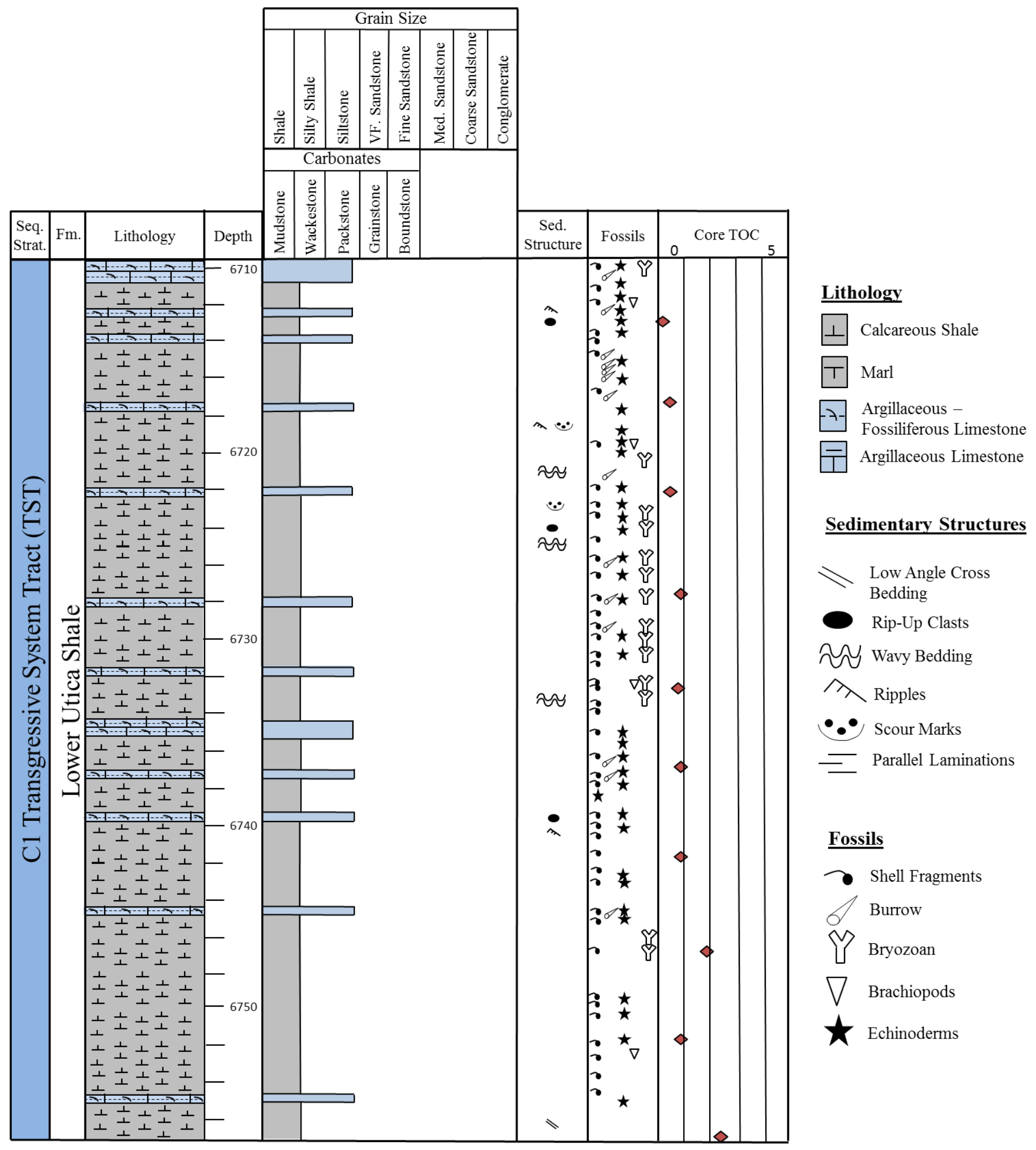




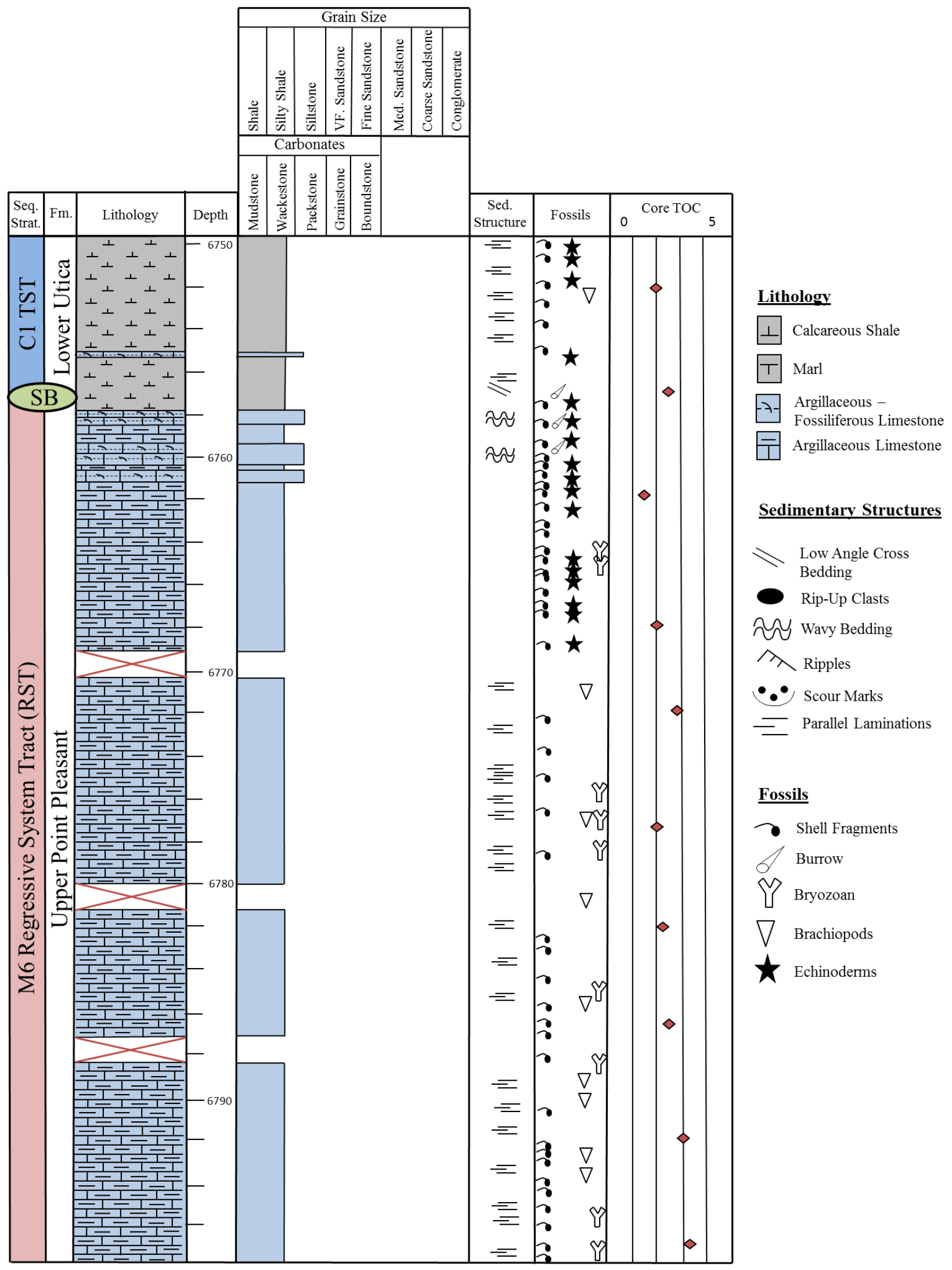




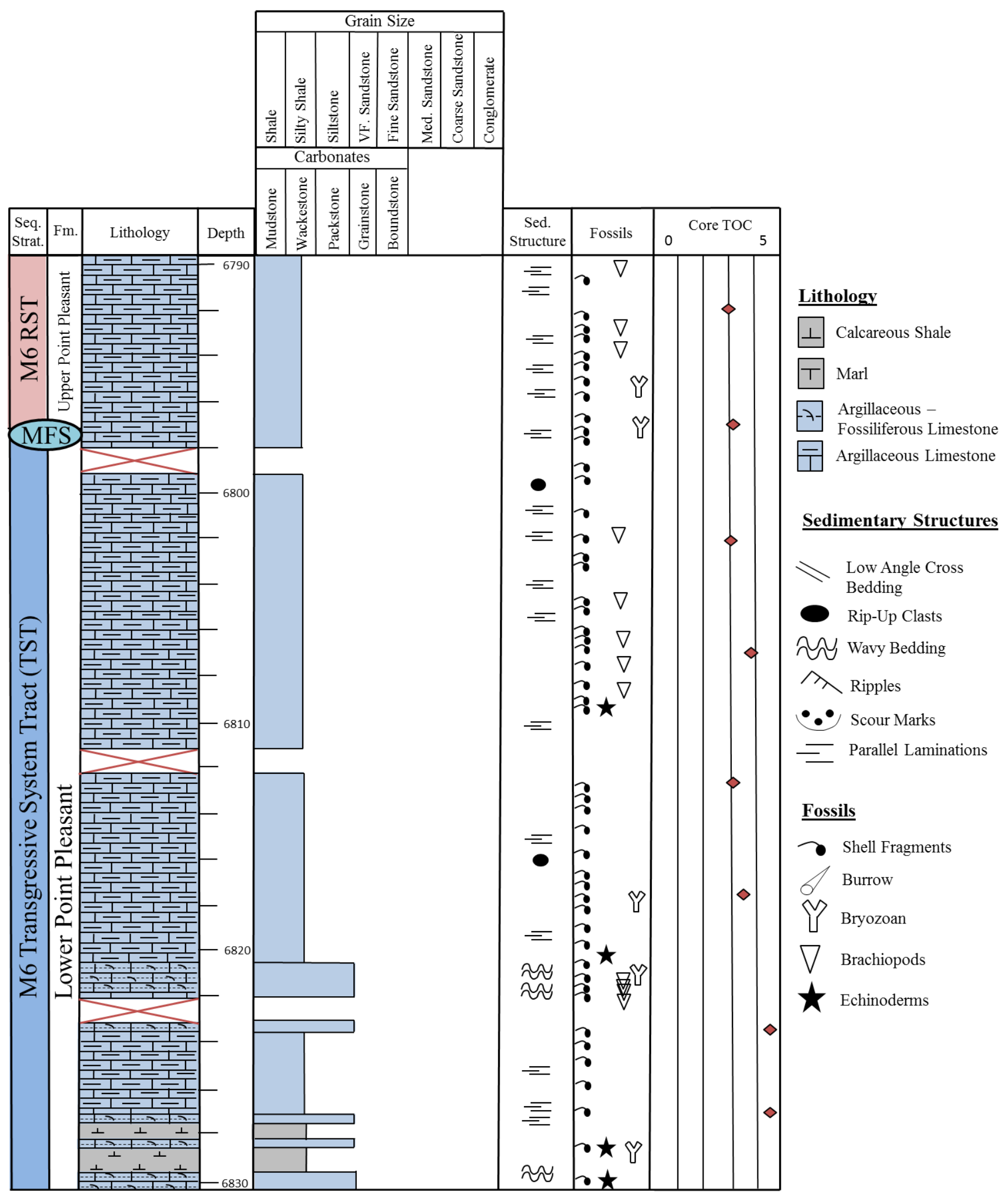




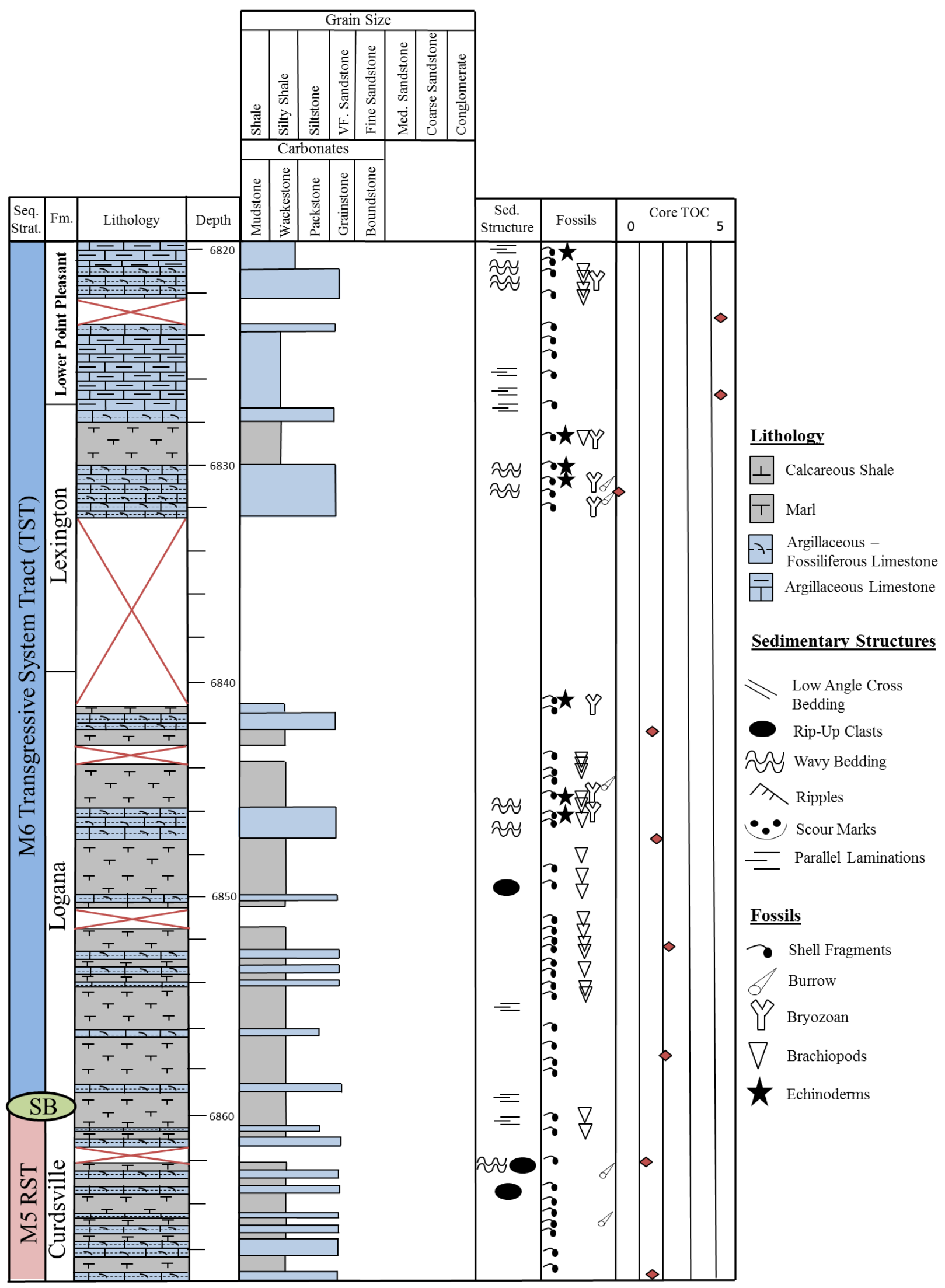




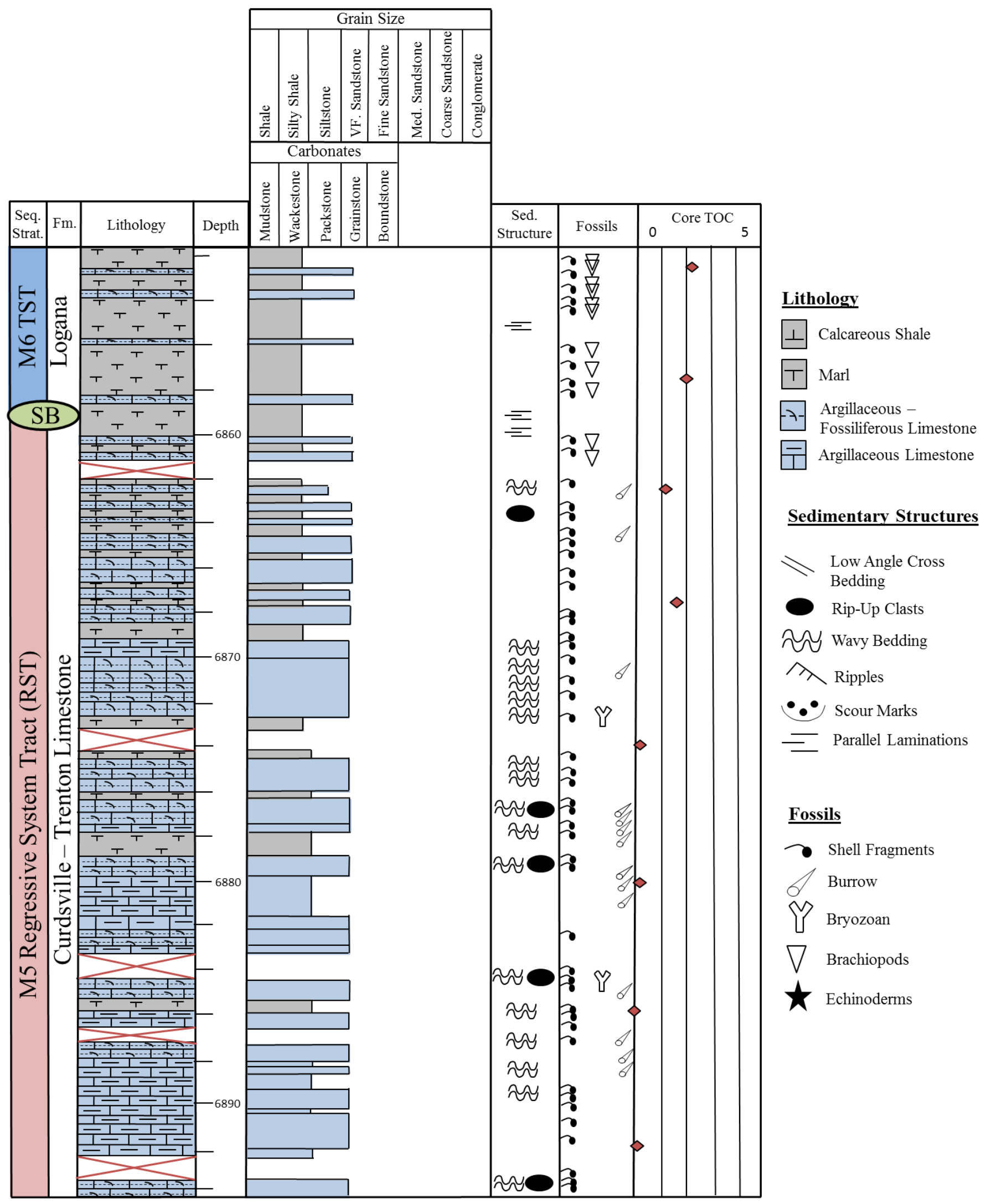

